\title{
XXVI Congresso Brasileiro de Cefaleia
}

\section{Temas Livres - Apresentação de pôsteres Cefaleia e Dor Orofacial}




\section{CEFALEIA}

\section{CE 01 \\ CEFALEIA SECUNDÁRIA À ANGIOPATIA CEREBRAL PÓS-PARTO: UMA DOENÇA BENIGNA?}

\author{
Abdal ERM; Abdal LHS; Carvalho AN;.; Rosemberg S; Pieri A
}

Objetivos: Descrever a apresentação clínica de uma puérpera com acidente vascular cerebral hemorrágico bilateral secundário à angiopatia cerebral pós-parto. Métodos: Revisão do prontuário e dos exames de neuroimagem da paciente. Resultados: Puérpera, no sétimo dia pós-operatório de parto cesareano atendida no pronto socorro com cefaleia há um dia. Após gestação e parto sem intercorrências, iniciou cefaleia insidiosa, contínua, de fraca a moderada intensidade com piora progressiva, não acompanhada de fotofobia, fonofobia, náusea e vômito. Apresentava antecedente de enxaqueca, mas a cefaleia atual tinha características diferentes das crises prévias. Na admissão estava em regular estado geral, PA: 130x80 mmHg, FC 60 bpm, Sat O2 $97 \%$ e glicemia casual $120 \mathrm{mg} / \mathrm{dl}$. Tinha sonolência (Glasgow 14), afasia leve, e ausência de déficit motor. A tomografia de crânio inicial evidenciou imagem compatível com hemorragia intraparenquimatosa parietal e occipital à esquerda. As hipóteses iniciais foram mau formação arteriovenosa ou trombose venosa cerebral. Frente a essas hipóteses, foi realizada uma ressonância nuclear magnética de encéfalo com angiografia arterial, pelo mesmo método. Esta evidenciou aumento da hemorragia à esquerda e um novo sangramento contralateral. A angiografia demonstrou estenose bilateral das artérias cerebrais médias sugestiva de vasoconstrição. A paciente apresentou piora do nível de consciência sendo submetida à drenagem bilateral dos hematomas. No quinto dia pós-operatório (PO) desta cirurgia a paciente foi extubada apresentando melhora clínica, porém com agitação e sonolência (Glasgow 14). No sexto PO apresentou cefaleia e devido à piora do nível de consciência foi intubada e uma nova tomografia de crânio evidenciou ressangramento. Evolviu com instabilidade hemodinâmica e no oitavo PO foi a óbito. Conclusão: A angiopatia pós-parto é um diagnóstico diferencial, potencialmente grave, de cefaleia no período puerperal

Referências: 1. Kubo S, Nakata H, Tatsumi T, Yoshimine T. Headache associated with postpartum cerebral angiopathy: monitoring with transcranial color-coded sonography. Headache. 2002;42:297-300.

2. Fugate JE, Ameriso SF, Ortiz G, et al. Variable Presentantions of Postpartum Angiopathy. Stroke 2012;43:670-676.

\section{CE 02 \\ CEFALEIA EM HEMODIÁLISE: RELATO DE POSSÍVEL FATOR DE ALÍVIO}

Borba Jr AM; Agra HNC; Spinelli A; Schuch NB; Santos N

Introdução: A fisiopatologia da cefaleia relacionada à hemodiálise (HD) é incerta. (1) Este estudo objetiva discutir uma hipótese da gênese da patologia. Relato de caso: Paciente masculino, 53 anos, em programa de HD por Nefropatia Diabética, três dias por semana. Com início das crises de cefaleia após a terceira hora do procedimento dialítico. Apresentavam alívio parcial com a ingestão de analgésicos, e cessavam cerca de quatro horas após o término da sessão. $\bigcirc$ paciente não apresentava outros sintomas clínicos, algumas vezes registrou-se aumento súbito de pressão arterial que ao retornar ao valor basal não modificava os sintomas. Ocorreu melhora sintomática após a troca do horário das sessões de diálise do segundo turno para o primeiro do dia. Discussão: $\bigcirc$ paciente em questão preenchia os critérios diagnósticos da cefaleia da diálise. A hipótese da melhora do paciente pode estar interligada à liberação de somatostatina $(\mathrm{GH})$ o que acarretaria um aumento dos níveis de glicose pela manhã. Tornando o paciente mais tolerante as mudanças de osmolaridade sérica provocadas pelo processo dialítico realizado neste horário em relação ao anterior. Conclusão: A fisiopatologia da cefaleia relacionada à HD ainda é desconhecida. Com essa hipótese, inicia-se o estudo das cefaleias na Clínica em questão, para avaliar o papel do horário da sessão na gênese das crises dos pacientes.

Referências: 1. Jesus ACF, Oliveira HÁ, Paixão MOR, Fraga TP, Barreto, FJN, Valença MM. Clinical description of hemodialysis headache in end-stage renal disease patients. Arq Neuropsiquiatr. 2009;67(4):978-81.

2. Antoniazzi AL, Bigal ME, Bordini CA, Speciali JG. Cefaleia relacionada à hemodiálise: análise dos possíveis fatores desencadeantes e do tratamento empregado. Arq Neuropsiquiatr. 2002;60(3-A):614-8.

\section{CE 03 \\ DESCOMPRESSÃO DE NERVO PERIFÉRICO: OPÇÃO DE TRATAMENTO PARA MIGRÂNEA CRÔNICA?}

\section{Pereira CV}

Introdução: Muitos pacientes com migrânea crônica, mesmo utilizando diversas medicações, não conseguem cessar as crises, apresentam efeitos colaterais, não obtendo boa qualidade de vida. Há mais de uma década, estudos demonstram eficácia da descompressão nervosa periférica no tratamento da migrânea crônica (nervos supraorbitário, supratroclear, zigomático-temporal e occipital). Relato de Caso: Paciente de 53 anos, sexo feminino, com história de enxaqueca há 18 anos (critérios de migrânea, definidos pelo ICHD II). História de diversos tratamentos com controle parcial e temporário das crises migranosas (topiramato, betabloqueador, ácido valproico, derivados da ergotamina, divalproato de sódio, sumatriptano, entre outros). Relatava localização álgica, primariamente, occipital. Submetida a bloqueio nervoso com remissão imediata da cefaleia. Concordou, de forma livre e consciente, em submeter-se ao procedimento cirúrgico. Em janeiro de 2011, foi realizada a descompressão do nervo occipital maior direito e esquerdo, retirando-se a parte medial do músculo semiespinhal. Paciente evolui, há mais de 18 meses, sem cefaleia. Impressão - A descompressão nervosa pode ser uma alternativa para o paciente não beneficiado pelo tratamento clínico medicamentoso.

\section{CE 04 \\ ADAPTAÇÃO TRANSCULTURAL E CONSISTÊNCIA INTERNA DO QUALITY OF LIFE HEADACHE - YOUTH PARA A POPULAÇÃO BRASILEIRA}

\section{Silva GA²; Bezerra e Silva DW'; Freitas DS²; Costa CNB'; Siqueira $\mathrm{GR}^{4}$; Silva GAM ${ }^{5}$; Lima $R C A^{5}$; Ximenes $\mathrm{RCC}^{3}$; Silva $L C^{6}$; Lucena $N^{7}$; Martins $H A L^{3}$; Vieira $L P B^{7}$; Valença $\mathrm{MM}^{3}$; Oliveira $\mathrm{DA}^{3}$}

'Mestranda pelo Programa de Pós-Graduação em Fisioterapia/UFPE ${ }^{2}$ Graduanda em Fisioterapia pela Universidade Federal de Pernambuco ${ }^{3}$ Doutor pelo Programa de Pós-Graduação em Neuropsiquiatria e Ciências do Comportamento/UFPE 
${ }^{4}$ Doutora pelo Programa de Pós-Graduação em Saúde da Criança e do Adolescente/UFPE

${ }^{5}$ Mestranda pelo Programa de Pós-Graduação em

Neuropsiquiatria e Ciências do Comportamento/UFPE

${ }^{6}$ Doutoranda Programa de Pós-Graduação em Neuropsiquiatria e Ciências do comportamento/UFPE

${ }^{7}$ Mestranda pelo Programa de Pós-Graduação em

Neuropsiquiatria e Ciências do Comportamento/UFPE

(Objetivos: Traduzir o questionário Quality of Life Headache Youth (QLH-Y) para o português do Brasil, adaptar transculturalmente e avaliar a consistência interna dos seus itens em uma amostra de adolescentes de ambos os gêneros, estudantes de escolas públicas estaduais. Métodos: $\bigcirc$ instrumento original foi traduzido do inglês para o português, gerando uma síntese consensual. A versão em português do instrumento foi retrotraduzida, e então desenvolvida uma versão pré-final para um teste de campo com 30 adolescentes com idade entre 10 e 19 anos. Após a adequação do instrumento, foi realizado um estudo piloto com 100 estudantes entre 10 e 19 anos. Foi avaliada a consistência interna através do alfa de Cronbach para cada domínio e cada subescala. Resultados: Os resultados encontrados na consistência interna da versão brasileira foram satisfatórios, com o valor do alfa de Cronbach de 0,906 (superior a 0,7) indicando um grau elevado de consistência interna. Conclusão: $\bigcirc$ questionário Quality of Life Headache - Youth foi devidamente traduzido e adaptado transculturalmente para a língua portuguesa brasileira. A versão em português do Quality of Life Headache Youth apresenta uma consistência interna excelente e uma boa compreensão dos seus itens pela adaptação transcultural.

\section{CE 05 \\ O PAPEL DOS MÚSCULOS CERVICAIS NA ESTABILIDADE CERVICAL E NA PATOGÊNESE DA MIGRÂNEA: REVISÃO DE LITERATURA}

Bezerra e Silva DW'; Lacerda CRB²; Albuquerque JE²;

Queiroz AKD²; Maia TFLD²; Almeida CCS²; Barros MMMB²;

Leite $\mathrm{LC}^{2}$; Lucena $\mathrm{NC}^{2}$; Martins $\mathrm{HAL}^{3}$;

Valença $\mathrm{MM}^{3}$; Oliveira $\mathrm{DA}^{3}$

'Mestranda pelo Programa de Pós-Graduação em Fisioterapia/UFPE

${ }^{2}$ Graduanda em Fisioterapia pela Universidade

Federal de Pernambuco

${ }^{3}$ Doutor pelo Programa de Pós-Graduação em Neuropsiquiatria e Ciências do Comportamento/UFPE

Objetivos: Elucidar o papel da musculatura cervical na patogênese da migrânea, a fim de fundamentar e direcionar o tratamento fisioterapêutico de pacientes com desordens musculares associadas a esta doença. Métodos: Foi feito um levantamento da literatura, no período de janeiro de 2012 a junho de 2012, nas bases de dados PubMed, Cochrane e Bireme. Os descritores para a pesquisa foram: "músculos cervicais," "migrânea," "coluna vertebral" e "sensibilização do sistema nervoso central." Os limitadores foram: pesquisa em humanos, artigos nos idiomas inglês, francês, espanhol e português. Artigos com animais, crianças e adolescentes foram excluídos. Resultados: Foram encontrados 75 artigos, dos quais 51 foram excluídos, segundo os critérios de elegibilidade estabelecidos. De acordo com os autores estudados, um dos processos envolvidos na patogênese da migrânea é caracterizado pela ativação do sistema trigeminovascular, via núcleo caudado para neurônios de terceira ordem no tálamo e destes para estruturas corticais de percepção da dor, desencadeando a dor sentida na migrânea. No núcleo trigeminocervical convergem as fibras sensitivas do nervo trigeminal e as fibras sensitivas das raízes nervosas cervicais superiores. Por consequência, aferências nociceptivas da musculatura cervical inervada pelas raízes nervosas cervicais superiores podem estimular o núcleo caudado e conduzir à sensibilização central e à ativação da cascata neuroinflamatória trigeminovascular, mediante a liberação de quimioreceptores periféricos como bradicinina, serotonina e substância P. Ademais, pacientes migranosos podem apresentar alterações musculoesqueléticas cervicais, como o controle motor deficitário, modificando a estabilidade, a mobilidade e a biomecânica desta região. Conclusão: Evidências sugerem o envolvimento de mecanismos periféricos, provenientes dos músculos cervicais, na sensibilização do sistema nervoso central e no surgimento dos sintomas de dor na migrânea. A partir de tais achados é possível direcionar o plano de tratamento de pacientes, através de exercícios terapêuticos específicos que promovam a diminuição da frequência, da intensidade e da duração das crises de migrânea.

\section{CE 06 \\ HEADACHE TYPE AND ASPECTS OF REPRODUCTIVE LIFE IN YOUNG WOMEN}

\section{Melhado EM; Galego AR; Galdezzani JP; Queiroz LP; Bigal ME}

Objectives: To contrast aspects related to women's reproductive cycle (age of first period, number of pregnancies, headaches during pregnancy) as a function of headache type. Methods: Sample consisted of 422 college students. A structured questionnaire were responded and allowed the classification of the headaches according to the Second Edition of the International Classification for Headache Disorders. Aspects of reproductive life were asked (use of contraceptive pills, first period, duration of period, headaches during pregnancy). We contrasted findings as a function of headache type. Results: Median age of menarche was 12.3 years. Women with migraine with aura (MA) were significantly more likely to have had their menarche at earlier ages than women without migraine ( $p=$ 0.03). Women with chronic daily headaches (CDH), in turn, were significantly more likely than women with episodic migraine or with no headaches to have long periods $(p<0.05)$. Use of hormonal contraceptive pills was strikingly similar as a function of having or not migraine headaches, having or not aura (73\% for all groups). Interestingly, during pregnancy, MA and $\mathrm{CDH}$ responded to a significantly higher proportion of the headaches, relative to outside of pregnancy $(p<0.01)$. Conclusions: The fact that women with MA are equally likely to receive hormonal contraceptives relative to others raise the question whether providers are assessing risk of cardiovascular outcomes in some of these women. MA and CDH were relatively more common during pregnancy that outside pregnancy needs to be explored, with a focus of whether these headaches are associated with complications during pregnancy. The finding that the menstrual cycle may vary as a function of headache frequency also raises the suspicion that hormonal fluctuations not only relate to the prevalence of migraine, but also to the frequency of headaches. 


\section{CE 07}

\section{HEADACHES AND MENSTRUATION IN COLLEGE WOMEN}

\author{
Galego AR; Melhado EM; Galdezzani JP; Bigal ME; Queiroz LP
}

Objective: Menstrual headaches often do not fulfill criteria for migraine. (1) Because menstrual migraine is common and debilitating, non-migraine headaches that occur in relationship to the menstrual cycle are often neglected or misdiagnosed. The aim was to classify headaches as a function of the menstrual cycle according to the Second Edition of the International Classification for Headache Disorders, ${ }^{(1)}$ in college students. Methods: Sample consisted of 422 college students. A structured questionnaire was given to students and allowed the classification of the headaches according to the Second Edition of the International Classification for Headache Disorders. Headaches were classified as per the ICHD-2 by a neurologist with expertise in the headache field. Results: Of a sample of 422 students, 334 (79.1\%) had headaches, and 140 (33.2\%) had headaches associated to the menstrual cycle. Of them, most were menstrually-related headaches (happened also outside of the menstruation - prevalence of $32.2 \%$ ), but pure menstrual headache happened in $1.0 \%$. Among the menstrual headaches, majority were migraine (27.5\%). Of the migraines $13.3 \%$ were without aura, $7.8 \%$ were migraine with aura and $6.4 \%$ were probable migraine. Menstrually-related tension type headache occurred in $3.1 \%$ of the sample; menstrually related idiopathic stabbing headache occurred in $0.5 \%$ and unclassified menstrual headaches happened in $0.7 \%$. Conclusions: Most female college students are affected by menstrual headaches. Although migraine without aura responds by the vast majority, other headaches such as tension-type headaches, idiopathic stabbing headaches, and migraine with aura also happen. Our findings suggest that the ICHD-2 criteria, (1) stating that menstrual migraine can only be classified in women without aura, is proper to classify pure menstrual migraine, but is too restrictive for menstrually-related migraine.

Reference: 1. Headache Classification Subcommittee of the International Headache Society. The International Classification of Headache Disorders. Cephalalgia. 2004;24(Suppl1):1-151.

\section{CE 08
RELAÇÃO ENTRE FIBROMIALGIA E CEFALEIA PRIMÁRIA}

\author{
Bordinio $\mathrm{EC}^{\prime}$; Inove $\mathrm{CSL}^{2}$; Esposito SB ${ }^{3}$ \\ 'Acadêmica do sexto ano, Faculdade de Ciências Médicas e da \\ Saúde - PUC SP \\ ${ }^{2}$ Acadêmica do sexto ano, Faculdade de Ciências Médicas e da \\ Saúde - PUC SP \\ ${ }^{3}$ Professor Doutor da Disciplina de Neurologia da Faculdade de \\ Ciências Médicas e da Saúde - PUC SP
}

Objetivos: Estudar as cefaleias primárias comuns em pacientes portadores de fibromialgia; correlacionar a intensidade usual da cefaleia e o impacto de fibromialgia e correlacionar a frequência da cefaleia e o impacto da fibromialgia. Métodos: Em um ambulatório de reumatologia de um hospital universitário, acompanhamos um grupo de 81 pacientes com fibromialgia (FM) e que apresentavam cefaleia concomitante, no período de agosto de 2010 a junho de 2011 . Para o diagnóstico de fibromialgia, foram utilizados os critérios do Colégio Americano de Reumatologia (ACR) e para identificar os diferentes tipos de cefaleia primária, os critérios da
Classificação International de Cefaleia da International Headache Society (ICHD-II). Os pacientes recebiam a Agenda de Dor onde preenchiam as características da cefaleia durante um mês. Esta agenda era devolvida no retorno do paciente. Na agenda constavam os seguintes tópicos: qualidade da dor, intensidade, frequência, uso de analgésicos e outros medicamentos, fenômenos associados, fatores de melhora e fatores de piora. Para conhecer o impacto de fibromialgia, no retorno do paciente aplicamos um questionário padronizado e validado, o Questionário de Impacto de Fibromialgia (QIF). Resultados: Dos 81 pacientes com fibromialgia, 73 eram mulheres e 8 homens, com idade média de 50 anos (27-77). Para homogeneização da amostra, foram estudadas apenas as pacientes do sexo feminino. Das 73 pacientes 55 apresentavam migrânea ou provável migrânea, 10 CTT ou provável CTT e 8 não puderam ser classificadas. Não foram encontradas correlações entre a intensidade de cefaleia e o impacto de fibromialgia (coeficiente de correlação de Pearson $r=0,173$ ); tampouco houve correlação entre a frequência de crises e impacto de fibromialgia. Ocorreu significância entre o tipo de cefaleia e o impacto da fibromialgia para os grupos migrânea e provável migrânea. Conclusão: A população estudada apresentou um elevado número de pacientes portadores de migrânea. Houve significância entre o tipo de cefaleia e o impacto da fibromialgia para os grupos migrânea e provável migrânea o que sugere uma situação de agravamento diante da associação de ambas as patologias.

\section{CE 09 \\ AVALIAÇÃO DO EQUILÍBRIO, AGILIDADE E PRESENÇA DE TONTURA EM PACIENTES COM MIGRÂNEA COM E SEM AURA}

\author{
Carvalho GF'; Gonçalves $\mathrm{MC}^{1}$; Florêncio $L^{1}$; Dach F²; \\ Ferreira KS²; Chaves TC'; Speciali JG²; Bevilaqua-Grossi D' \\ ${ }^{1}$ Fisioterapeuta; ${ }^{2}$ Neurologista
}

Objetivo: Avaliar a oscilação do centro de pressão (COP), a agilidade e o impacto da tontura em pacientes com migrânea com aura (MA) e sem aura (M). Métodos: As pacientes, todos do gênero feminino, foram triadas do ambulatório de cefaleia de um hospital terciário e diagnosticadas com migrânea com aura ou migrânea sem aura por neurologistas especialistas em cefaleia de acordo com a ICHD-II (2004). (1) Foram excluídas as pacientes obesos, com vestibulopatias, doenças sistêmicas ou outros tipos de cefaleia. Foram avaliadas 92 voluntárias, sendo 31 do grupo M, 31 do grupo MA e 30 do GC (Tabela 1). O COP foi mensurado através da estabilometria com uma plataforma de força (AMTI - OR6-71000) em apoio bipodal e unipodal, com olhos abertos e fechados. A agilidade foi avaliada pelo teste Timed Up and Go (TUG) e os sintomas de tontura pelo questionário Dizziness Handicap Inventory (DHI). Para análise entre os grupos, foi utilizado um modelo de regressão linear com efeitos mistos com $\alpha<0,05$. Resultados: Os resultados revelaram maior oscilação no grupo MA em relação ao grupo M e GC em apoio bipodal com olhos abertos e fechados $(p<0,02)$. Pacientes com MA apresentaram maior deslocamento do COP em relação ao grupo $M$ nas situações unipodal com olhos abertos $(p<0,02)$ (Figura 1). Não houve diferença no tempo de realização do TUG (seg.) entre os grupos MA (8,5 seg.) e M (8,2 seg.), porém ambos os grupos foram diferentes do GC $(6,5$ seg.) $(p<0,01)$. Sintomas de tontura foram verificados em $80 \%$ do grupo MA e $65 \%$ do grupo $M$, com impacto significante nas atividades de vida diária $(p<0,001)$. Conclusões: Nossos dados demonstraram que pacientes com migrânea (com e sem aura) apresentam 
alterações no equilíbrio dinâmico e na mobilidade, além da alta prevalência de tontura, com impacto em vários aspectos da vida diária. A aura parece influenciar de forma significativa a estabilidade postural destes pacientes.

Referência: 1. International Headache Society. The International Classification of Headache Disorders, 2nd Edition. Cephalagia, v. 24, suppl. 1, p. 1-160, 2004.
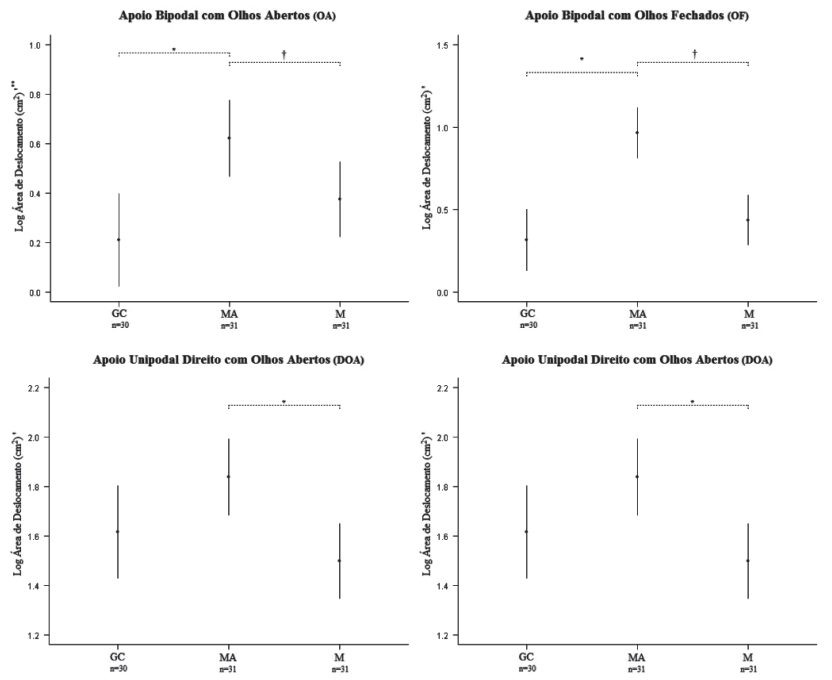

Figura 1. Log. da média e intervalo de confiança das áreas de oscilação corporal $\left(\mathrm{cm}^{2}\right)$ em apoio bipodal com olhos abertos (OA), olhos fechados (OF), Apoio unipodal direito (DOA) e esquerdo (EOA) com olhos abertos do Grupo Controle (GC), Grupo Migrânea sem Aura (M) e Grupo Migrânea com Aura (MA). ${ }^{* *}$ Transformação da variável em Logaritmo. ${ }^{*} p=0,001 ; \dagger p=0,02$.

\section{CE 10}

\section{QUALIDADE DE VIDA E INCAPACIDADE RELACIONADA À} SAÚDE DE CRIANÇAS COM MIGRÂNEA

\section{Ferracini GN; Dach F; Speciali JG}

A migrânea nas crianças, durante e entre as crises, leva a uma redução da participação em atividades escolar, tarefas de casa e lazer, além do comprometimento dos aspectos psicológicos, ocasionando um impacto negativo na qualidade de vida relacionada à saúde. Este estudo objetivou avaliar a incapacidade que esta condição causa na vida diária de crianças de 6 a 12 anos de idade, de ambos os gêneros e se influencia a qualidade de vida. A amostra foi composta por 50 crianças com migrânea sem aura e 50 crianças sem histórico de cefaleia. Para verificar a incapacidade aplicou-se o questionário Pediatric Migraine Disability Score e para qualidade de vida o Pediatric Quality of Life Inventory4.0 TM. Os meninos perderam em média 13 (DP 26,36) dias e as meninas em média 15 dias (DP 22,43) em atividade escolar, tarefas de casa e lazer. De acordo com o grau de incapacidade, 19 (38\%) crianças apresentaram o Grau I (ausência) de incapacidade, 17 (34\%) o Grau II (leve), sete (14\%) o Grau III (moderado) e sete (14\%) o Grau IV (grave) sem diferença entre os gêneros [IC95\% (-14,02 - 16,67); $p=0,86$ ] sobre atividade e rendimento escolar, tarefas de casa e lazer. A qualidade de vida, pela percepção dos pais, é pior nas crianças com migrânea [IC95\% $(-16,92--6,18) p<0,01]$, mas na percepção das crianças a qualidade de vida é semelhante nos dois grupos. Quando se analisa separadamente os vários domínios do questionário, pela percepção dos pais, há diferenças nos domínios físico [IC95\%
$(-15,24--1,88) p<0,01]$ e psicossocial [IC95\% (-17,96- - 6,74) $p<0,01]$. Enquanto que pela auto-avaliação das crianças, houve diferença nos domínios emocional [IC95\% (-16,95 - -5,70) $p<0,01]$ e escolar [IC95\% $(-15,90--5,74) p<0,01]$. Não foi encontrada correlação entre os dias perdidos devido à cefaleia e a qualidade de vida relacionada à saúde.

\section{CE 11 \\ CONFIABILIDADE DA PRECISÃO DOS MONOFILAMENTOS SEMMES-WEINSTEIN EM PACIENTES COM MIGRÂNEA}

Grunewald JNC(1); Gonçalves $M C^{(1)}$; Nagamine $H M^{(1)}$; Dach F(2); Florencio LL ${ }^{(1)}$; Carvalho GF(1); Speciali JG(2); Bevilaqua-Grossi $D^{(1)}$

(1)Departamento de Biomecânica Medicina e Reabilitação do Aparelho Locomotor da FMRP-USP

(2)Departamento de Neurociências e Ciências do Comportamento da FMRP-USP

Introdução: A sensibilização central, em pacientes com migrânea, pode ser avaliada com os monofilamentos Semmes-Weinstein 1,2. A versão nacional contém 6 monofilamentos (SORRI $\circledast$ ) de cores diferentes, graduados em gramas. Este é um aparelho acessível e de fácil aplicação. Objetivo: Verificar a confiabilidade da carga aplicada pelos monofilamentos Semmes- Weinstein (SORRI ${ }^{\circ}$ ) na região cefalica e extracefalica de pacientes migranosas. Métodos: Foram avaliadas 19 mulheres com migrânea, diagnosticadas segundo os Critérios da Classificação Internacional de Cefaleias, com média de intensidade de dor $5 \pm 1$ em uma escala de 0 a 10. As pacientes tinham em média, idade de $40 \pm 20$ anos e frequência de dias de dor $8 \pm 7$ no mês. Os monofilamentos foram acoplados à célula de carga do Von Frey digital, que transmite a força aplicada em gramas para o visor do aparelho, possibilitando a quantificação da real carga aplicada, já que a orientação do manual é aplicar uma força suficiente para deformar o fio. Foram realizadas 2 avaliações, com intervalo de 15 minutos, contendo três repetições em 5 pontos de maneira aleatória: região frontal e músculo masseter bilateralmente e região do antebraço direito, com o paciente na posição sentada e olhos fechados. A análise estatística utilizou as médias de cada avaliação para calcular o Coeficiente de concordância proposto por Lin, que varia de 0 a 1 , (0 a 0,30 baixa confiabilidade; de 0,31 a 0,60 moderada confiabilidade; 0,61 ou mais excelente confiabilidade). Resultados: Verificamos que a confiablidade da carga aplicada pelos monofilamentos de cor verde, violeta e laranja apresentam moderada confiabilidade e os monofilamentos azul, vermelho e rosa baixa confiabilidade (Tabela 1). Conclusão: Não é recomendável o uso exclusivo dos Monofilamentos Semmes-Weinstein (SOR$R(\circledR)$ para quantificação da sensibilidade de pacientes migranosas, uma vez que sua confiabilidade nas regiões cefálicas e extra cefálicas variou de moderada a baixa.

Tabela 1 - Confiabilidade dos monofilamentos Semmes-Weinstein em pacientes com migrânea pelo coeficiente de Lin

\begin{tabular}{lcclll}
\hline \multicolumn{2}{c}{ Monofilamento $(\mathrm{g})$} & Coeficiente Lin & \multicolumn{2}{l}{ IC (95\%) } \\
\hline Verde & $(0,05)$ & 0,33 & 0,12 & 0,51 \\
Azul & $(0,2)$ & 0,11 & 0,08 & 0,31 \\
Violeta & $(2,0)$ & 0,43 & 0,25 & 0,59 \\
Vermelho & $(4,0)$ & 0,28 & 0,08 & 0,46 \\
Laranja & $(10)$ & 0,48 & 0,29 & 0,64 \\
Rosa & $(300)$ & 0,23 & 0,07 & 0,44 \\
\hline
\end{tabular}


Referências: 1. Zappaterra $M$ et al. Basal cutaneous pain threshold in headache patients. J Headache Pain. $2011 ; 12: 303-310$.

2. Keizer D, Wiihe van M, Post WJ. Quantifying allodynia in patients suffering from unilateral neuropathic pain using Von Frey monofilaments. Clin J Pain. 2007;23:85-90.

\section{CE 12 \\ HIV E CEFALEIA: UM ESTUDO CASO-CONTROLE}

\author{
Rocha Filho PAS'; Santos RC'2; Bezerra MEM²; \\ Gonçalves LR ; Coutinho Junior JR ${ }^{4}$ \\ Neurologista; ${ }^{2}$ Acadêmica medicina; \\ ${ }^{3}$ Psicóloga; ${ }^{4}$ Médico residente Neurologia
}

Objetivos: Comparar prevalência, características e fatores associados à cefaleia nos pacientes HIV positivos com pacientes atendidos em unidades do programa de saúde da família da cidade do Recife. Métodos: Estudo caso-controle. Casos: pacientes HIV positivos; linfócitos T CD4 + > 500/ $\mathrm{mm}^{3}$, sem TARV atendidos consecutivamente no Ambulatório de Doenças Infecciosas do Hospital Oswaldo Cruz e do Hospital Correia Picanço. Controles: pacientes atendidos consecutivamente em postos de saúde. Instrumentos: Questionários sociodemográficos, epidemiologia do HIV e características das cefaleias; questionário Hospital Anxiety and depression Scale; questionário HIT-6 (Headache Impact Test). Análise de dados: Inicialmente todas as variáveis serão analisadas descritivamente. Para as variáveis quantitativas, cálculo de médias e desvios-padrão. Para as variáveis qualitativas serão calculadas frequências absolutas e relativas. Será utilizado o teste não paramétrico de Mann-Whitney avaliará a hipótese de igualdade entre dois grupos e para a comparação entre proporções será utilizado o teste qui-quadrado ou o teste exato de Fisher. Resultados: Foram entrevistados 235 pacientes, $80 \mathrm{HIV}+$ e 155 nos postos de saúde, $62 \%$ do sexo feminino; a idade média foi 38 anos (DP $=17) ; 90 \%$ dos pacientes HIV + e $67 \%$ dos pacientes HIV negativos tiveram cefaleia nos últimos 12 meses $(p<0,01$, Qui-quadrado). Os pacientes HIV+ tiveram significativamente menos dias e menor impacto da cefaleia. Não houve diferença significativa de intensidade da cefaleia nem da prevalência de migrânea ou de cefaleia tipo tensional entre os dois grupos, como também entre a intensidade dos sintomas depressivos ou ansiosos. Conclusão: Pacientes com HIV tiveram maior prevalência de cefaleia que pacientes atendidos em postos de saúde. Não houve diferença entre os tipos de cefaleia ou prevalência de sintomas depressivos/ansiosos entre os grupos.

\section{CE 13}

\section{O QUE MOTIVA O PACIENTE A PROCURAR} ASSISTÊNCIA MÉDICA POR CEFALEIA?

\begin{abstract}
Rocha Filho PAS'; Gonçalves LR²; Coutinho Junior JR ${ }^{3}$
'Neurologista; ${ }^{2}$ ssicóloga; ${ }^{3}$ Médico residente Neurologia.

Hospital Universitário Oswaldo Cruz, Universidade de
\end{abstract} Pernambuco - UFPE

Objetivos: Verificar expectativas do paciente quanto ao atendimento e o que influencia nessa expectativa. Métodos: Pacientes atendidos pela primeira vez no Ambulatório de Cefaleias do Hospital Universitário Oswaldo Cruz da Universidade de Pernambuco no período de 08/01/2007 a 15/05/2012 foram entrevistados utilizando-se questionário padronizado e o Hospital Anxiety and Depression Scale. A associação das variáveis foi verificada através do teste do $\chi^{2}$. Resultados: Entrevistaram-se 532 pacientes, idade média $=42,3$ anos $(D P=16,1), 82,5 \%$ do sexo feminino; $37,4 \%$ tinham escolaridade superior ao primeiro grau. Média de médicos consultados anteriormente por cefaleia $=2,5(\mathrm{DP}=3,5)$; $32 \%$ já haviam procurado mais de 2 médicos. Tempo médio com cefaleia $=14$ anos $(\mathrm{DP}=12,5) ; 60 \%$ tinham mais de 5 anos com cefaleia. Frequência média de cefaleia $=16$ dias por mês $(D P=11,2)$, $48,1 \%$ tinham cefaleia crônica diária, 23,4\% tinham cefaleia tipo tensional, $71,2 \%$ tinham migrânea Os motivos alegados para se ter a consulta foram: "Preocupação em ter doença grave" $(26,2 \%)$; "Fazer um exame complementar" (22,2\%), "Alívio da dor" (19,5\%); "Ter uma explicação" (18,9\%) e "Ter acompanhamento médico" (13,2\%). Não houve associação entre o motivo ser "Preocupação em ter doença grave/Fazer um exame complementar" e o gênero, a escolaridade, em ter passado em consulta por mais de 2 médicos, em ter diagnóstico de migrânea, de cefaleia tipo tensional, de ansiedade ou depressão, ter cefaleia há mais de 2 anos ou ter cefaleia crônica diária. Conclusões: Os motivos mais frequentemente alegados para se ter a consulta foram: "Preocupação em ter doença grave" (26,2\%); "Fazer um exame complementar" (22,2\%). Nenhuma das variáveis estudadas influiu nesses motivos.

\section{CE 14 \\ DECÚBITO COMO FATOR AGRAVANTE DA CEFALEIA NA CRISE MIGRANOSA}

\author{
Macci JP; Jabarra CP; Teles MCM; Ferreira GF; \\ Souza JA; Moreira Filho PF
}

Introdução: As crises de migrânea são frequentemente incapacitantes. A atividade física e os movimentos de abaixar a cabeça são fatores reconhecidos de aumento transitório da intensidade da dor durante as crises. Por esse motivo muitos pacientes buscam o repouso. Na prática clínica, verifica-se que uma parcela de pacientes se queixa de agravamento da cefaleia pelo decúbito, durante as crises de migrânea, preferindo permanecer na posição recostada ou sentada. Esse dado, até onde sabemos, não foi estudado. Objetivos: 1) Verificar, numa amostra de pacientes migranosos, a porcentagem daqueles que se queixam de agravamento da cefaleia, durante a crise, pelo decúbito. 2) Verificar se existem diferenças com relação à piora pelo decúbito entre os sexos. Metodologia: Estudo retrospectivo de análise de prontuários. Foram avaliados os dados da anamnese de 734 pacientes consecutivos, com queixa principal de cefaleia, atendidos numa clínica terciária, desde que se passou a utilizar o programa HIPATIA (tutorial e banco de dados em cefaleias). Utilizando-se de filtros de pesquisa, foram selecionados os pacientes que receberam o diagnóstico de migrânea em qualquer de suas modalidades (1.1 a 1.6 da Classificação da IHS 2004) num total de 563 (76,7\%). Todos os pacientes foram interrogados quanto a fatores de agravamento da cefaleia, no período da crise, entre eles, o decúbito. Os que afirmaram apresentar agravamento pelo decúbito foram contabilizados e divididos de acordo com o gênero. Resultados: Dos 563 pacientes (482 mulheres 85,6\%; 81 homens - 14,4\%) com diagnóstico de migrânea (1.1 a 1.6 da Classificação da IHS 2004), 20,7\% (n=1 17) queixaram-se de agravamento pelo decúbito. A queixa foi referida por $21,7 \%$ $(n=105)$ das mulheres e por $14,8 \%(n=12)$ dos homens. Essa diferença não se revelou estatisticamente significativa $(p<0,15)$. Conclusão: $\bigcirc$ agravamento da cefaleia pelo decúbito, durante a crise de migrânea, é freqüente em pacientes de ambos os gêneros. 


\section{CE 15 \\ DESENVOLVIMENTO DO RACIOCÍNIO CLÍNICO EM CEFALEIAS DE ESTUDANTES DE MEDICINA ATRAVÉS DE INTERVENÇÃO SOCIOEDUCATIVA}

\author{
Silva Junior AA; Brandão KV
}

Introdução: A dificuldade dos médicos da atenção primária em conduzir os casos de cefaleias primárias, podem ser decorrente do desafio diagnóstico destas condições que não tem marcador biológico, frente à baixa carga horária sobre o tema nos cursos de graduação. Objetivos: Avaliar o impacto de uma intervenção sócioeducativa sobre cefaleias no desenvolvimento do raciocínio clínico em estudantes de medicina. Métodos: Foi realizado atendimento voluntário a pacientes com cefaleia, no Centro de Especialidades Médicas do distrito norte de Belo Horizonte, coordenado pelo docente em neurologia da Faculdade de Ciências Médicas - Unifenas$\mathrm{BH}$. Dez alunos do sétimo período, selecionados aleatoriamente, participaram do atendimento supervisionado a pacientes com cefaleia, após passarem por processo de aprendizagem ativa (desenvolvimento de um script de raciocínio clínico através da discussão de casos). O grupo controle foi composto por 21 alunos, que passaram pelo método tradicional de ensino (aula expositiva sobre os critérios diagnósticos e bases terapêuticas das cefaleias). Após a intervenção todos fizeram um teste de avaliação de aprendizado. Resultados: Foram atendidos 21 pacientes (19 F) e migrânea sem aura foi o diagnóstico mais comum. O grupo treinado pelo método de ensino baseado em problema teve $78 \%$ de acerto nos testes, enquanto a taxa do grupo controle foi de $66 \%$. Conclusão: $\bigcirc$ atendimento social supervisionado parece uma alternativa viável, como processo ativo de educação médica no Brasil, como complemento à reduzida carga horária das escolas de medicina do país.

\section{CE 16 \\ CEFALEIA POR DISSECÇÃO BILATERAL DA ARTÉRIA VERTEBRAL}

\section{Cruz LS; Ribeiro LFS; Torres BR; Campos GM; Cruz PS; Corrêa IAB}

Objetivo: Analisar os aspectos da cefaleia relacionada à dissecção bilateral da artéria vertebral. Método: Revisão da literatura crítica nas bases de dados MEDLINE e SciELO nos últimos 10 anos. Resultados: A dissecção da artéria vertebral bilateralmente (DAVB) é uma condição pouco comum e extremamente relacionada a acidentes vasculares cerebrais em pacientes jovens. Sua fisiopatologia corresponde à ruptura da camada íntima ou da média com entrada de sangue entre os folhetos e posterior oclusão do lúmen arterial. Pode ser espontânea ou pós-trauma e gerar sinais neurológicos como cerebelares (ataxia), vertigem e distúrbios da visão, dependendo do local de obstrução e eficácia das anastomoses com sistema carotídeo. Aproximadamente $82 \%$ dos pacientes com DAVB apresentam dor precedendo o déficit neurológico, como cervicalgia e cefaleia, sendo esta mais prevalente e classicamente descrita como occipital, bem localizada e diferente de outras que o paciente eventualmente tenha, enquanto aquela é descrita como uni ou bilateral na porção posterior do pescoço. Esses sintomas podem indicar o momento da dissecção e servir como alerta. Fatores de risco clássicos como doenças vasculares, tabagismo e dislipidemia são controversos, uma vez que a formação de lesões ateromatosas não parece ser o principal fator que desencadeia a fragilização arterial e predisposição à dissecção. A enxaqueca, na ausência de fatores de risco clássicos, tem sido extremamente relacionada a essa afecção, pois especula-se que alterações mecânicos como vasodilatação e constrição durante episódios crônicos possam comprometer a lâmina elástica e predispor a doença. $O$ padrão ouro para diagnóstico é a angiografia digital, podendo ser substituída pela angioressonância. Conclusão: DAVB é rara, pouco suspeitada pelos médicos e pode não apresentar déficits focais. A cefaleia intensa na região occipital ou cervicalgia na região posterior do pescoço constituem sintomas de alerta que podem indicar o momento da dissecção.

Referências: 1. Adaletli I, Sirikci A, Ulus S, Yilmaz MH, Kervancioglu S, Kurugoglu S. Traumatic bilateral vertebral artery dissection at the dural entry point. Pediatr Surg Int 2006; 22: 468-70.

2. Campos $C R$, Evaristo EF, Yamamoto Fl et al.Dissecção espontânea cervical carotídea e vertebral. Arq Neuropsiquiatr 2004; 62(2-B): 492-8.

3. Nagurney JT, Feldman D, Cahill DP, Gatha NM, Koroshetz WJ. Unusual visual symptoms in a patient with bilateral vertebral artery dissection: a case report. J Emerg Med 2006; 31 (2): 169-71.

4. Taylor MW, Senkowski CK. Bilateral Vertebral Artery dissection after Blunt Cervical Trauma: case Report and Review of the Literature. J Trauma. 2002; 52: 1186-8.

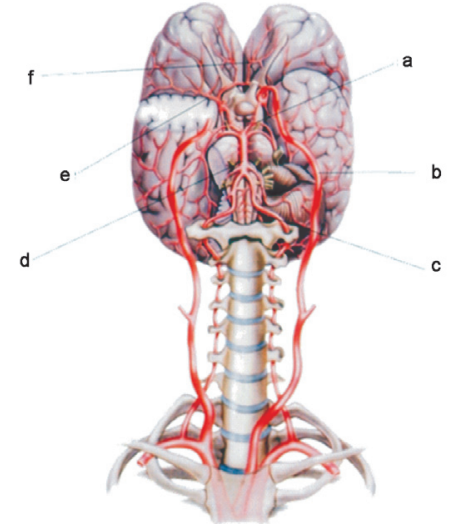

Anatomia da carótida interna e vasos intracerebrais: (a) artéria comunicante posterior; (b) artéria carótida interna; (c) artéria vertebral; (d) artéria basilar; (e) artéria cerebral média; (f) artéria cerebral anterior.

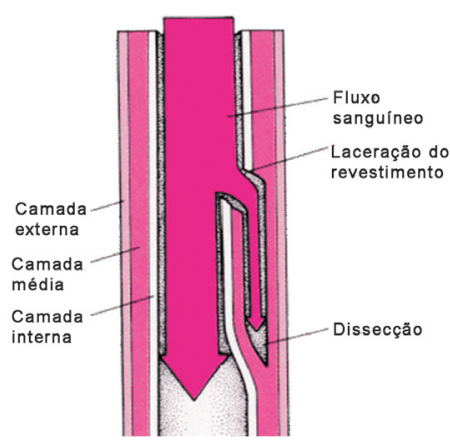

Esquema ilustrativo da dissecção bilateral.

\title{
CE 17
AVALIAÇÃO FISIOTERAPÊUTICA DA COLUNA CERVICAL EM UM AMBULATÓRIO TERCIÁRIO DE CEFALEIA
}

\author{
Florêncio LL'; Casimiro $\mathrm{ECB}^{3}$; $\mathrm{Braz} \mathrm{CA}^{3}$; Carvalho GF'; \\ Gonçalves $\mathrm{MC}^{1}$; Chaves TC'; Dach F2; \\ Speciali JG²; Bevilaqua-Grossi $D^{1}$ \\ ${ }^{1}$ Fisioterapeuta; ${ }^{2}$ Neurologista; ${ }^{3}$ Estudante
}

Objetivo: Verificar se há diferença na amplitude de movimento da coluna cervical dos indivíduos com diferentes tipos de cefaleia atendidos em um serviço terciário especializado em cefaleia e algias orofaciais, uma vez que, nessa população, a avaliação desse 
segmento tem sido recomendada. ${ }^{(1)}$ Métodos: Foram selecionados, no período de 1 ano e 6 meses, 90 sujeitos com média de idade de 42 anos (DP: 11,05$)$, sendo 77 do sexo feminino. Foram incluídos aqueles com idade entre 18 e 65 anos, somente com um diagnóstico de cefaleia e concordantes com o Termo de Consentimento Livre e Esclarecido. Foram excluídos os indivíduos submetidos a bloqueios periféricos durante a consulta, que apresentavam história de trauma na face ou na região cervical, com diagnóstico de doenças sistêmicas degenerativas e mulheres grávidas. A avaliação da amplitude de movimento cervical foi realizada através do Cervical Range of Motion (CROM) por um avaliador cego quanto ao diagnóstico da cefaleia. Os movimentos de flexão, extensão, inclinação lateral e rotação foram repetidos três vezes e mensurados em uma sequência aleatorizada por sorteio. A análise dos dados consistiu na comparação das médias das três medidas para cada movimento baseando-se no diagnóstico da cefaleia. Para isso, utilizou-se os testes de ANOVA two way e o post hoc Duncan test pelo programa SPSS 16.0. O intervalo de confiança adotado foi de $95 \%$ e o valor de $\alpha=0,05$. Resultados: Não houve diferença entre as médias dos grupos em todos os movimentos cervicais $(p>0,05)$ (Tabela 1). No entanto, as médias dos movimentos foram menores quando comparadas às médias do grupo controle, baseado nos dados da literatura cuja população apresenta parâmetros semeIhantes. ${ }^{(2)}$ Conclusão: Não há diferenças importantes nas amplitudes de movimento cervical entre os diferentes tipos de cefaleia avaliados. Mas a redução da amplitude, comparada ao controle, reforça a importância da avaliação cervical na prática clínica.

Tabela 1. Média e desvio padrão da amplitude de movimento cervical nos diferentes tipos de cefaleia avaliada através do Cervical Range of Motion (CROM)

\begin{tabular}{|c|c|c|c|c|c|c|c|c|c|c|c|c|}
\hline & \multicolumn{2}{|c|}{$\begin{array}{l}\text { MSA } \\
(n=44)\end{array}$} & \multicolumn{2}{|c|}{$\begin{array}{l}\text { MCA } \\
(n=11)\end{array}$} & \multicolumn{2}{|c|}{$\begin{array}{c}M C \\
(n=15)\end{array}$} & \multicolumn{2}{|c|}{$\begin{array}{l}\text { CTT } \\
(n=6)\end{array}$} & \multicolumn{2}{|c|}{$\begin{array}{l}\text { Outras } \\
(n=14)\end{array}$} & \multicolumn{2}{|c|}{$\begin{array}{c}\text { Controle * } \\
(n=15)\end{array}$} \\
\hline & Média & DP & Média & DP & Média & DP & Média & DP & Média & DP & Média & DP \\
\hline Flexão & 57 & 12,5 & 53 & 10,9 & 58 & 13,1 & 51 & 16,3 & 55 & 8,1 & 58 & 10,2 \\
\hline Extensão & 57 & 16,2 & 59 & 11,7 & 54 & 14,3 & 57 & 13,9 & 56 & 17 & 68 & 11,1 \\
\hline $\begin{array}{l}\text { Inclinação } \\
\text { direita }\end{array}$ & 40 & 9,3 & 39 & 8,8 & 41 & 8,6 & 42 & 8,8 & 43 & 8,7 & 46 & 6,2 \\
\hline $\begin{array}{l}\text { Inclinação } \\
\text { esquerda }\end{array}$ & 46 & 9,6 & 42 & 10,1 & 47 & 7,3 & 46 & 9,5 & 48 & 7,2 & 49 & 5,9 \\
\hline $\begin{array}{l}\text { Rotação } \\
\text { direita }\end{array}$ & 61 & 8,8 & 57 & 7,9 & 61 & 9,9 & 60 & 3,4 & 59 & 11,3 & 69 & 8,4 \\
\hline $\begin{array}{l}\text { Rotação } \\
\text { esquerda }\end{array}$ & 63 & 11,3 & 60 & 7,7 & 62 & 12,5 & 62 & 9,7 & 63 & 14,3 & 64 & 7,1 \\
\hline
\end{tabular}

MSA= migrânea sem aura; $M C A=$ migrânea com aura; $M C=$ migrânea crônica; $C T T=$ cefaleia do tipo tensional; $\mathrm{DP}=$ desvio padrão.

*Grupo controle foi retirado de Bevilaqua-Grossi et al ${ }^{2}$, dados avaliados na mesma população com média de idade semelhante.

Referência: 1. Jull G, Amiri M, Bullock-Saxton J, Darnell R, Lander C. cervical musculoskeletal impairment in frequent intermittent headache. Part 1: subjects with single headaches. Cephalalgia. 2007; 27:793-802.

2. Bevilaqua-Grossi D, Pegoretti KS, Goncalves MC, Speciali JG, Bordini CA, Bigal ME. Cervical mobility in women with migraine. Headache. 2009 May;49(5):726-31.

\section{CE 18 \\ MIGRANEA, DISFUNÇÃO TEMPOROMANDIBULAR E ALTERAÇÕES DA POSTURA CORPORAL}

\author{
Ferreira $\mathrm{MC}^{\prime}$; Florêncio $\mathrm{LL}^{\prime}$; Bevilaqua-Grossi D'; \\ Speciali JG²; Dach F²; Chaves TC \\ ${ }^{1}$ Fisioterapeuta; ${ }^{2}$ Neurologista
}

Objetivo: Avaliar a presença de alterações posturais corporais em mulheres com migrânea e verificar se a disfunção temporomandibular (DTM) contribui para agravar tais alterações. Métodos: Foram avaliados 03 grupos de 22 integrantes do sexo femi- nino com idades entre 18 e 50 anos, compostos de migranosos $\operatorname{com} \operatorname{DTM}(30,27 \pm 9,82$ anos), migranosos sem DTM (31,72 \pm 9,82 anos) e grupo controle $(24,41 \pm 6.95$ anos) de mulheres sem DTM e sem migrânea. A DTM foi avaliada por meio da aplicação do eixo I do Critério de Diagnóstico para Pesquisa em DTM (RDC) TMD)(1) e o diagnóstico de migrânea foi realizado por neurologistas, de acordo com os critérios da segunda edição da Classificação Internacional de Cefaleias. ${ }^{(2)}$ Os voluntários foram submetidos à avaliação da postura corporal através da fotogrametria. Os pontos a serem avaliados foram fixados, por examinador treinado e, posteriormente, as imagens foram analisadas através de traçados considerando esses pontos de referência nas vistas anterior, lateral, posterior e face (Figura 1). Dezenove ângulos foram considerados e para verificação de diferenças entre os valores médios dessas medidas angulares entre os três grupos foi empregada a ANOVA two-way $(p<0.05)$. Resultados: foi verificada redução do ângulo de protrusão de cabeça e lordose cervical nos pacientes com Migrânea com e sem DTM, bem como maior frequência de assimetrias nos nesse grupo de pacientes (ombros e face). Também foi observada redução do ângulo de cifose torácica e aumento do ângulo de lordose lombar nos pacientes com migrânea e DTM (Tabela 1). Conclusões: os resultados desse estudo demonstraram a presença de alterações da postura corporal em pacientes com migrânea. Além disso, nossos achados confirmam a hipótese inicial de que a associação entre migranea e DTM pode contribuir para o agravamento dessas alterações posturais, especialmente para as alterações das curvaturas vertebrais mais caudais (cifose torácica e lordose lombar).

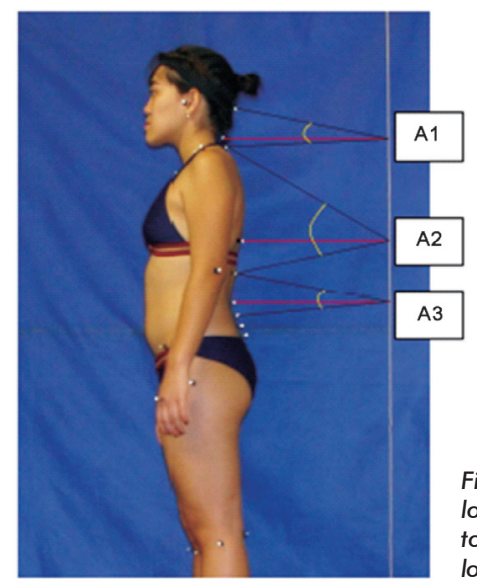

Figura 1 - Vista sagital. A1 - Ângulo de lordose cervical, A2 - Ângulo de cifose torácico e A3 - Ângulo de lordose lombar

Tabela 1 - Medidas angulares no plano sagital entre os grupos considerados nesse estudo

\begin{tabular}{|c|c|c|c|c|c|c|c|c|c|c|c|c|}
\hline \multirow{2}{*}{$\begin{array}{l}\text { Ângulos } \\
\text { (graus) } \\
\text { Grupos }\end{array}$} & \multicolumn{2}{|c|}{ APC } & \multicolumn{2}{|c|}{ ALC } & \multicolumn{2}{|c|}{ ACT } & \multicolumn{2}{|c|}{ ALL } & \multicolumn{2}{|c|}{ AEJ } & \multicolumn{2}{|c|}{ ATT } \\
\hline & Média & DP & Média & DP & Média & DP & Média & DP & Média & DP & Média & DP \\
\hline $\begin{array}{l}\text { Migrânea } \\
\text { + DTM }\end{array}$ & 67,83 & 2,53 & 14,63 & 0,97 & $40,13^{*}$ & 2,13 & $27,19^{*}$ & 2,36 & 181,53 & 4,57 & 100,31 & 1,10 \\
\hline Migrânea & 69,88 & 3,05 & 14,99 & 0,94 & $42,93^{*}$ & 3,88 & $25,48^{*}$ & 2,32 & 182,26 & 3,61 & 101,00 & 2,76 \\
\hline Controle & $73,03^{*}$ & 3,84 & $16,38^{*}$ & 1,55 & 47,27 & 4,11 & 22,68 & 1,51 & 182,02 & 5,06 & 99,47 & 4,38 \\
\hline $\begin{array}{l}\text { Nivel } \\
\text { p ANOVA) }\end{array}$ & $<0,0$ & & $<0,0$ & 009 & $<0$, & & $<0,0$ & & NS & & NS & \\
\hline
\end{tabular}
p ANOVA)

APC: ângulo de protrusão de cabeça; ALC: ângulo de lordose cervical; ACT: ângulo de cifose torácica; ALL: ângulo de lordose lombar; AEJ: ângulo de extensão lombar; ATT: ângulo tíbio társico; NS: Não significativo. * diferença significativa entre os grupos (ANOVA, $p<0.05$ )

Referências: 1. Dworkin SF, LeResche L. Research Diagnostic Criteria for temporomandibular disorders: rewiew, criteria, examinations and specifications, critique. Journal Temporomandibular disorders: Facial and Oral Pain. 1992; 6(4): 300-55.

2. Headache Classification Subcommittee of the International Headache Society. The International Classification of Headache Disorders, 2nd edition. Cephalalgia. 2004;24 (Suppl. 1):9-160. 


\section{CE 19 \\ PREJUÍZO FUNCIONAL DEVIDO À DISFUNÇÃO CERVICAL NAS CEFALEIAS}

Florêncio $L L^{(1)}$; Casimiro $E C B^{(3)}$; Carvalho $G F^{(1)}$; Gonçalves $M C^{(1)}$; Chaves TC(1); Dach $F^{(2)}$; Speciali JG ${ }^{(2)}$; Bevilaqua-Grossi $D^{(1)}$

(1) Fisioterapeuta; (2) Neurologista; ${ }^{(3)}$ Estudante

Objetivo: Avaliar a disfunção cervical em indivíduos com diferentes tipos de cefaleia atendidos em um serviço terciário especializado em cefaleia e algias craniofaciais. Materiais e métodos: Foram avaliados 88 sujeitos com média de idade de 42 anos (dp: 11, 1 1), sendo 76 do sexo feminino, durante o período de 1 ano. Os critérios de inclusão foram ter idade entre 18 e 65 anos, somente um diagnóstico de cefaleia e concordar com o Termo de Consentimento Livre e Esclarecido. Foram excluídos aqueles que apresentavam história de trauma na face ou na região cervical, diagnóstico de doenças sistêmicas degenerativas e mulheres grávidas. A avaliação da disfunção cervical foi realizada por um avaliador cego quanto ao diagnóstico e por meio da aplicação da versão brasileira do questionário Neck Disability Index (NDI), (1) cuja pontuação varia de 0-50 e classifica os indivíduos como: sem incapacidade (0-4), incapacidade leve (5-14), incapacidade moderada (15-24), incapacidade grave (25-34) e completa incapacidade (35 ou mais). ${ }^{(2)}$ A comparação do prejuízo funcional entre os grupos de cefaleia foi realizada por meio do teste chi-square utilizando o software SPSS 16.0, sendo adotado o intervalo de confiança de $95 \%$ e o valor de $\alpha=0,05$. Resultados: $\bigcirc$ subtipo de cefaleia parece não fazer diferença na classificação do prejuízo funcional, já que não houve diferença estatística entre elas $(p>0,05)$. No entanto, $83 \%(n=73)$ dos 88 indivíduos avaliados apresentaram algum nível de incapacidade funcional (Figura 1) relacionada à coluna cervical, sendo que 16\% ( $n=12)$ eram classificados nas formas mais graves. Conclusão: $\bigcirc$ relato de prejuízo funcional devido à dor no pescoço dentre os pacientes com cefaleia é bastante frequente, embora na amostra estudada o mesmo não esteve associado a algum subtipo específico de cefaleia. Tal constatação reforça a importância da avaliação musculoesquelética da coluna cervical nesses pacientes.

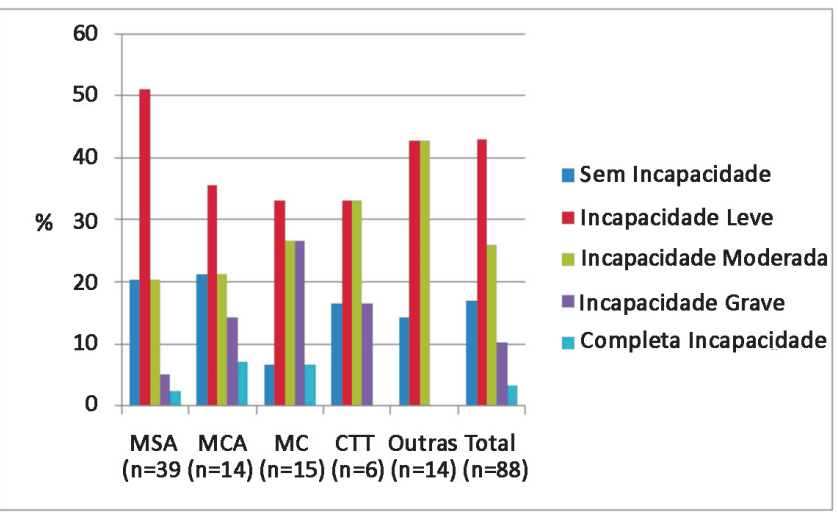

Figura 1. Gráfico sobre a frequência, em porcentagem, das classificações de disfunção cervical obtidas com o questionário Neck Disability Index (NDI) em pacientes com diferentes tipos de cefaleia. $M S A=$ migrânea sem aura; $M C A=$ migrânea com aura; $M C=$ migrânea crônica; CTT = cefaleia do tipo tensional.
Referências: 1. Cook C, Richardson JK, Braga L, Menezes A, Soler X, Kume P, Zaninelli M, Socolows F, Pietrobon R. Cross-cultural adaptation and validation of the Brazilian Portuguese Version of the Neck Disability Index and Neck Pain and Disability Scale. Spine. 2006;31 (14):1621-7.

2. Vernon H, Mior S. The Neck Disability Index: a study of reliability and validity. J Manipulative Physiol Ther. 1991;14:409-15.

\section{CE 20 \\ ASPECTOS CLÍNICOS DA EVOLUÇÃO DA SÍNDROME DE TOLOSA-HUNT: ESTUDO DE CASO}

\author{
Gonçalves AFB; Almeida Junior JA; Maciel DA; \\ Vieira LP; Araújo RKR
}

Objetivo: Analisar o processo de identificação da Síndrome de Tolosa-Hunt (STH), dando ênfase nos critérios diagnósticos da International Headache Society (IHS). Métodos: Pesquisa bibliográfica com levantamento de casos clínicos da STH e relato de caso do paciente em estudo. Resultados: Realizado relato de caso de um paciente, sexo masculino, 24 anos, com dor retroorbitária unilateral de início agudo e estrabismo convergente à esquerda, cefaleia hemicraniana esquerda persistente, em aperto, de grande intensidade, acompanhada de náusea, fotofobia e fonofobia associadas à hiperestesia malar ipsilateral à dor. Realizado radiografia, TC e RM de encéfalo, sem alterações nas imagens radiológicas sugestivas da STH. Na RM de órbitas, os achados sugerem sinusopatia crônica. Houve melhora da dor orbitaria, nas primeiras 48 horas, após corticoterapia. Preenchendo, desta forma, os critérios diagnósticos da ICHD II para STH após ampla investigação dos diagnósticos diferenciais. Questiona-se uma possível associação da STH e a Sinusopatia Crônica. Paciente persiste, até dias atuais, com hiperestesia na região malar. Conclusões: A STH é uma enfermidade rara, portanto a condução do seu diagnostico através dos critérios da ICHD I| são de grande valia. Entretanto não há ainda protocolo definido de tratamento, do seguimento a longo prazo e critérios para classificar como recaída ou fracasso do tratamento bem como associação com outras doenças. Portanto, novos estudos se fazem necessários para desvendar tais aspectos do universo da STH.

\section{CE 21 \\ AS CRISES DE CEFALEIA PODEM TER DURAÇÃO REALMENTE MENOR QUE 2 HORAS NA INFÂNCIA E NA ADOLESCÊNCIA? ANÁLISE CRÍTICA PROSPECTIVA DOS CRITÉRIOS DIAGNÓSTICOS DA ICHD II}

\author{
Lima MMF; Martin LC
}

Objetivo: Analisar criticamente os critérios da Classificação Internacional das Cefaleias (ICHD II)-2004 prospectivamente. Método: Analisamos prospectivamente 150 indivíduos a nível ambulatorial, não tratados, orientando o preenchimento do diário da dor durante a primeira consulta, após 30 dias retornavam. Observamos todos os critérios da classificação ICHDII com crises > 2horas (Grupo ICHD II) e os mesmos critérios, mas sendo que o critério duração das crises em crianças seria menor que 2 horas (Grupo ICHD II-P). Empregou-se o critério diagnóstico clínico intuitivo (DCl) como padrão "gold standard". A comparação entre CDI, ICHDII, ICHDII -P foi realizada através do teste de Mc Nemar. Resultados: Idade média 11 anos $\pm 2,26,34 \%$ sexo masculino/66\% sexo feminino; em relação aos sintomas: $65 \%$ náusea, $52 \%$ vômitos, fotofobia $96 \%$, fonofobia 97\%, tontura 
52\%, osmofobia 54\%, este último não acrescenta ao diagnóstico, pois todos que a apresentavam também tinham foto/fonofobia. Duração: ICHD II - 88 crises $>2$ horas e ICHD II-P - 62 crises $<2$ horas. Observamos que os critérios da ICHD II apresentam uma sensibilidade (S) de 58\% quando comparadas ao do CDI 100\% e o da ICHDII-P 94\% com Mc Nemar $p<0,001$. Conclusões: $\bigcirc$ uso dos critérios atuais da ICHD II, através da evidência de um estudo prospectivo demonstra um aumento importante (94\%) da sensibilidade comparada a $(S=58 \%$ ) da duração (>2horas). Podemos então aceitar a duração $<2$ horas para as cefaleias na infância e na adolescência.

\section{CE 22}

\section{EFEITO ADICIONAL DA FISIOTERAPIA AO TRATAMENTO MEDICAMENTOSO NA REDUÇÃO DA INTENSIDADE E FREQUÊNCIA DA MIGRÂNEA - VIABILIDADE DE UM ESTUDO CONTROLADO RANDOMIZADO EM UM SERVIÇO TERCIÁRIO DE ASSISTÊNCIA A SAÚDE}

\section{Gonçalves $\mathrm{MC}^{\prime}$; Dach F²; Nagamine HM'; Chaves $\mathrm{TC}^{1}$; Florêncio

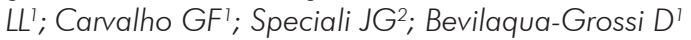 \\ ${ }^{1}$ Fisioterapeuta; ${ }^{2}$ Neurologista}

Objetivo: Demonstrar a viabilidade da condução de um estudo controlado randomizado (ECR), em um serviço terciário, utilizando técnicas de terapia manual em pacientes com migrânea em uso de tratamento medicamentoso, com o intuito de verificar o efeito adicional da fisioterapia e realizar uma análise preliminar da eficácia dessa intervenção. Métodos: $\bigcirc$ tamanho amostral foi calculado para detectar a diferença entre grupos de um ponto em uma escala de 0 a 3 para intensidade de dor e de 3 dias de dor em uma escala de 0 a 9 dias. $O$ tamanho amostral sugerido foi de 50 pacientes, 25 em cada grupo. Os dados de ambos os grupos serão analisadas por intenção de tratamento. Um examinador cego avalia a frequência, intensidade e duração da migrânea com o diário de dor e os demais parâmetros estão descritos na figura 1. Posteriormente, os pacientes são distribuídos aleatoriamente para os grupos de tratamento: G1 - medicação + fisioterapia e G2- medicação. Os grupos serão comparados para os desfechos primários intensidade, frequência e duração da dor. $\bigcirc$ diagnóstico e a prescrição do tratamento medicamentoso são realizados por neurologistas. $\bigcirc$ tratamento fisioterapêutico é realizado 2 vezes por semana durante 40 minutos, por 6 semanas consecutivas, e consiste em terapia manual e exercícios respiratório (Figura 1). Este trabalho foi registrado no

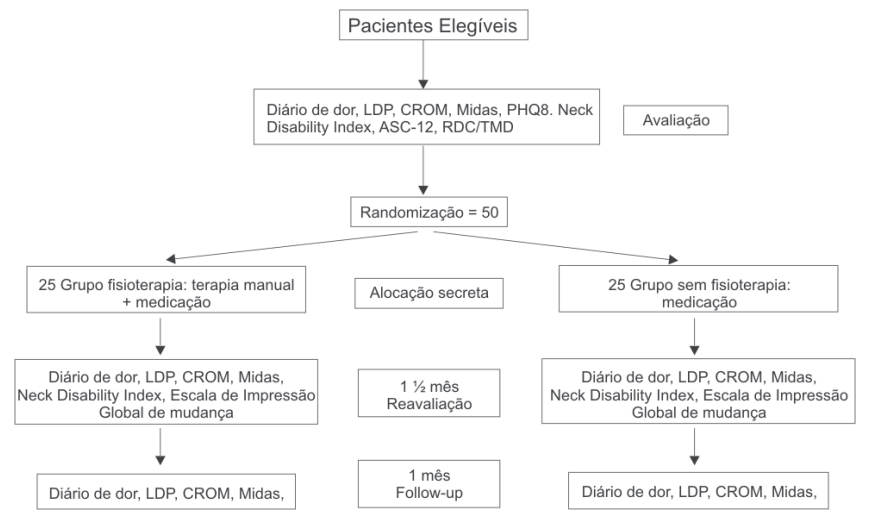

Figura 1 - Diagrama de fluxo completo
Registro de Ensaios Clínicos Brasileiros nRBR-6kvx74. Resultados: $\bigcirc$ estudo esta em plena condução apresentando apenas dificuldade de aderência no grupo G1. A análise dos dados foi realizada em apenas 11 mulheres com migrânea sem aura, média de idade $41 \pm 9,80$ e tempo de doença em anos de 16,89 $\pm 8,33$, já que o estudo ainda esta em curso, os resultados estão apresentados como um único grupo (Tabela 1) e revelam redução nos parâmetros avaliados. Conclusão: A viabilidade do ECR em pacientes com migrânea sem aura em um serviço terciário foi demonstrada.

Tabela 1 - Média e desvio padrão da frequência, duração e intensidade das crises de migrânea em 11 voluntárias pré e pós-tratamento

\begin{tabular}{lccc}
\hline & $\begin{array}{c}\text { Dias de dor } \\
\text { Mês }\end{array}$ & $\begin{array}{c}\text { Duração da dor } \\
\text { horas }\end{array}$ & $\begin{array}{c}\text { Intensidade } \\
\text { da dor 0-3 }\end{array}$ \\
\hline Pré-tratamento & $18,67 \pm 7,89$ & $33,33 \pm 17,23$ & 3,00 \\
Pós-tratamento & $13,33 \pm 7,23$ & $20,00 \pm 12,33$ & $1,78 \pm 0,79$ \\
\hline
\end{tabular}

\section{CE 23 \\ AVALIAÇÃO DA QUALIDADE DE VIDA EM CRIANÇAS MIGRANOSAS}

\author{
Martins ML; Valério RC; Almeida TJC; Laender VR; \\ Rezende DF; Jurno ME
}

Introdução: As cefaleias são uma condição com alta prevalência na população infanto-juvenil, sendo que a migrânea ocupa lugar de destaque entre as cefaleias, causando importante diminuição na qualidade de vida de seus portadores. Objetivo: Avaliar o impacto da migrânea na qualidade de vida de crianças utilizando como parâmetros a resposta ao Brasilian SF-36. Materiais e métodos: Trata-se de um estudo de corte transversal com análise comparativa de dois grupos voluntários, sendo um grupo composto por crianças migranosas e outro por crianças sem migrânea. A partir de então, foi aplicado em ambos os grupos o questionários da qualidade de vida Brasilian SF-36. Resultados: Este estudo foi composto por 66 crianças de 5 a 15 anos, das quais 30 (45,45\%) erammigranosas e $36(54,55 \%)$ sadias. A idade média das migranosas foi de 10,9 anos, o desvio padrão (DP) $\pm 3,0$ anos, e a idade média do grupo controle foi de 10,4 anos, com DP $\pm 3,1$. A partir da análise do Brasilian SF-36, oito aspectos foram avaliados, a saber: Capacidade Funcional, Aspectos Físicos, Dor, Estado Geral, Vitalidade, Aspectos Sociais, Aspectos Emocionais e Saúde Mental. Os resultados obtidos mostraram que migranosos são diferentes dos não migranosos em todos os aspectos mensurados e que apresentaram, sempre, desempenhos piores que os não migranosos quanto às oito dimensões medidas pelo Brasilian SF36. Conclusão: Os autores concluem que a qualidade de vida das crianças portadoras de migrânea foi afetada em todos os aspectos avaliados pelo Brasilian SF-36.

Referências: 1. Arruda MA, Albuquerque RCAP, Bigal ME. Migrânea na infância e adolescência: avanços que contribuem para a prática clínica. PediatriaModerna. 2010 Maio/Jun; 46(3):87-100.

2. Subcomitê de Classificação das Cefaleias. Classificação Internacional das Cefaleias. $2^{a}$ ed. São Paulo: Alaúde Editorial; 2004.

3. Jacobs H, Gladstein J. Pediatric Headache: A Clinical Review. Headache. 2012 Feb;52(2):333-9.

4. Langeveld JH et al. A quality of life instrument for adolescents with chronic headache. Cephalalgia. 1996; 16:183-96.

5. Ciconelli RM. Tradução para o português e validação do questionário genérico de avaliação de qualidade de vida SF-36 (Brasil SF-36). [Tese de Doutorado]. São Paulo: Escola Paulista de Medicina de São Paulo da Universidade Federal de São Paulo; 1999. 


\section{CE 24 \\ FREQUÊNCIA DE CEFALEIA E MIGRÂNEA EM CRIANÇAS E ADOLESCENTES EM UM AMBULATÓRIO DE ATENDIMENTO PEDIÁTRICO}

\author{
Veiga AMO; Abrahão ACT; Nogueira BCV; Borges FL; \\ Loschi MG; Cordeiro MF; Ferraz M; Veiga B; Jurno ME
}

Introdução: A cefaleia é um sintoma comum na prática hospitalar pediátrica. No entanto, muito pouco é conhecido sobre a prevalência e as causas das dores de cabeça fora do hospital. A migrânea é dita como a causa mais comum de cefaleia primária em crianças. Em crianças e adolescentes, destaca-se a importância do diagnóstico e tratamento precoces, prevenção das crises de migrânea, para orientação adequada de seus responsáveis e professores, objetivando a melhoria na qualidade de vida e no perfil psicológico de seus portadores. Objetivos: $\bigcirc$ objetivo do presente trabalho foi estabelecer a frequência de cefaleia e migrânea na criança e no adolescente na faixa etária de 5 a 15 anos, de acordo com os critérios estabelecidos pela Sociedade Internacional de Cefaleia no ambulatório de pediatria. Métodos: Foram entrevistadas 149 crianças, dos sexos feminino e masculino, na faixa etária de 5 a 15 anos, nos ambulatórios de pediatria geral. $\bigcirc$ diagnóstico foi realizado segundo os critérios da Sociedade Internacional de Cefaleia, e foram utilizados instrumentos de estatística elementar para os resultados. Resultados: Os resultados obtidos mostram que a frequência de cefaleia e migrânea em crianças e adolescentes na faixa etária de 5 a 15 anos nos ambulatórios de pediatria geral foi de $66,4 \%$ e 5,37\% respectivamente. Conclusão: De acordo com os dados coletados, a migrânea está fortemente relacionada com a frequência dos episódios por mês, duração habitual das crises de horas ou mais, dor pulsátil e presença de aura.

Referências: 1. Barea LM, Santin R. Epidemiologia. In: Arruda MA, Guidetti V. Cefaleias na Infância e Adolescência. $1^{a}$ Ed. Ribeirão Preto: Instituto Glia; 2007. p.18-30.

2. Gherpelli JLD. Cefaleias na infância e adolescência. Ped Moderna. 1996;32(3):419-427.

3. Arruda MA. Enxaqueca na infância e adolescência: atualização no diagnóstico e tratamento. Ped Moderna. 2009 mar-abr;45(2):37-50.

4. Arruda MA. Anamnese da criança com cefaleia. In: Arruda MA, Guidetti V. Cefaleias na Infância e Adolescência. $1^{a}$ Ed. Ribeirão Preto: Instituto Glia; 2007. p.31-48.

\section{CE 25}

\section{MIGRÂNEA DURANTE A GESTAÇÃO - PERFIL CLÍNICO}

Pereira ECA'; Rocha GHS'; Coelho J'; Alvarenga LC' Borges NR'; Rezende DF²; Jurno $\mathrm{ME}^{3}$

'Alunos da Faculdade de Medicina de Barbacena:

2Estatístico, Professor da Faculdade de Medicina de Barbacena

${ }^{3}$ Doutor, Neurologista, Coordenador da Residência de Clínica Médica do HRB/FHEMIG e Professor da

Faculdade de Medicina de Barbacena

Introdução: Um dos fatores que pode influenciar esse quadro de migrânea nas mulheres são as alterações hormonais observadas durante a gravidez. Estudos evidenciam que a maioria das mulheres grávidas, que apresentava cefaleia pré-gestacional, exibiu melhora ou desaparecimento da mesma durante a gestação, especialmente quando se refere à migrânea menstrual. Objetivo: Relacionar a incidência da migrânea com o período gestacional das pacientes que foram admitidas no âmbito ambulatorial em uma clínica de pré-natal e comparar a frequência da cefaleia, com o período prégravidez. Materiais e métodos: $\bigcirc$ trabalho constatou em um estudo de corte transversal realizado mediante a uma entrevista sobre cefaleia na gestação, entre gestantes que apresentaram cefaleia no período gestacional e que foi diagnosticada como migrânea através dos critérios da Classificação Internacional, no período de julho de 2011 a fevereiro de 2012. Foram recrutadas 200 pacientes neste período. Resultados: $O$ presente estudo foi realizado em um grupo de gestantes que se encontravam no terceiro trimestre de gestação e com queixa de cefaleia prévia ao período gestacional. $\bigcirc$ grupo foi composto por 200 pacientes, onde se observou que $82(41,0 \%)$ pacientes eram migranosas e as restantes 118 (59,0\%) pacientes não preenchiam os critérios para diagnóstico de migrânea. Os resultados obtidos neste trabalho relacionando as pacientes migranosas com os trimestres investigados, condizem com relatos da literatura, em que as crises de enxaqueca muitas vezes, têm a frequência aumentada no primeiro trimestre, mas se espera diminuir nos segundo e terceiro trimestres da gravidez. Conclusão: Os dados obtidos com a realização do nosso trabalho estão em concordância com estudos anteriormente apresentados, os quais foram demostrados uma diminuição gradual de dores de cabeça ao longo dos três trimestres de gestação.

Referências: 1. Subcomitê de Classificação das Cefaleias. Classificação Internacional das Cefaleias. $2^{a}$ ed. São Paulo: Alaúde Editorial; 2004.

2. Melhado EM. Cefaleia na gestação. [Tese].CAMPINAS: Faculdade de Ciências Médicas da Universidade Estadual de Campinas; 2005.

3. Melhado EM. Cefaleia na mulher. Rio de Janeiro: Atheneu, 2011

4. Melhado E, Maciel JJA, Guerreiro CAM. Headaches during pregnancy in women with a prior history of menstrual headaches. Arq Neuropsiquiatr 2005;63(4):934-40.

5. Kvisvik EV et al. Headache and migraine during pregnancy and puerperium: the MIGRA-study. J Headache Pain (201 1) 12:443-51.

6. Serva WAD et al. Course of migraine during pregnancy among migraine sufferers before pregnancy. Arq Neuropsiquiatr 2011;69(4):613-9.

\section{CE 26 \\ MIOPIA AGUDA E HIPERTENSÃO INTRA- OCULAR APÓS USO DE TOPIRAMATO}

Piazzi FG'; Tavares RF? ; Matos MR? ; Moura e Silva IS²; Moura e Silva Filho PP3; Jurno ME ${ }^{4}$

'Residentes de Clínica Médica do Hospital Regional de Barbacena/FHEMIG

${ }^{2}$ Aluna da Faculdade de Medicina de Barbacena

${ }^{3}$ Oftalmologista, Professor da Faculdade de Medicina de Barbacena

${ }^{4}$ Neurologista, Coordenador da Residência de Clínica Médica do HRB/FHEMIG e Professor da Faculdade de Medicina de Barbacena

Introdução: A enxaqueca acomete cerca de 6 a $7 \%$ dos homens e 18 a 20\% das mulheres principalmente entre 25 e 55 anos de idade, responsável por seu enorme impacto na atividade produtiva. O topiramato juntamente com o divalproato de sódio são os únicos dois anticonvulsivantes que tem aprovação do FDA para a prevenção da enxaqueca. É uma droga segura mas não isenta de efeitos colaterais. $\bigcirc$ principal deles é a nefrolitíase, e a nível ocular diplopia, nistagmo, conjuntivite e anomalias de acomodação. As alterações oftalmológicas não são comuns, o mais alarmante é o quadro de miopia aguda associada a glaucoma de ângulo fechado bilateral, que geralmente regride com a interrupção da droga. Caso clínico: Paciente do sexo feminino, 36 anos, portadora de hipotireoidismo, enxaqueca, miopia e astigmatismo bilaterais, apresentou quadro de diminuição súbita de acuidade visual após o uso de topiramato. A miopia inicial da paciente era de 1,75 graus em olho 
direito e 0,5 grau em olho esquerdo e evoluiu para 12 graus bilateral e hipertensão intraocular 24 horas após a ingestão do anticonvulsivante. Paciente recuperou sua acuidade visual e pressão intraocular cerca de 48 horas após interrupção da medicação. Objetivo: Alertar não só a classe médica mas também os pacientes para as possíveis alterações visuais causadas pelo uso do medicamento. Conclusão: Alertamos que, embora raras as alterações oftalmológicas aparecem e se não reconhecidas em tempo hábil podem causar efeitos danosos ao paciente.

\section{CE 27 \\ O MÉDICO E A MIGRÂNEA: CONHECIMENTO E PROCEDIMENTOS NO ACOLHIMENTO A PACIENTES EM UM SERVIÇO DE PRONTO-ATENDIMENTO}

\author{
Azevedo ACl; Petrin CS'; Rezende LA'; Michel LCS'; \\ Kfuri TV'; Moreira SRG'; Jurno ME ${ }^{3}$ \\ 'Alunas da Faculdade de Medicina de Barbacena \\ ${ }^{2}$ Doutor, Psicólogo, Professor da Faculdade de Medicina de \\ Barbacena \\ ${ }^{3}$ Doutor, Neurologista, Coordenador da Residência de \\ Clínica Médica do HRB/FHEMIG e Professor da Faculdade de \\ Medicina de Barbacena
}

Objetivo: Este trabalho visa analisar o conhecimento que um grupo de médicos em Unidades de Emergência, de uma cidade de médio porte localizada em Minas Gerais, têm a respeito da migrânea/enxaqueca e de como foram o acolhimento realizados por eles a pacientes em crise de cefaleia. Método: Este trabalho de caráter qualitativo utilizou instrumentos como Ficha de Identificação e Estratificação da Amostra e Roteiro de Entrevista SemiEstruturada, tendo como base os critérios de diagnóstico das cefaleias da Sociedade Internacional de Cefaleia e as Recomendações da Sociedade Brasileira de Cefaleia para o tratamento das crises de dor de cabeça, sendo realizadas entrevistas com os médicos participantes do estudo. Resultado: Nas unidades de emergência desta cidade é frequente o atendimento de pacientes com crise migranosa. De acordo com os entrevistados, a maioria dos pacientes superestima sua dor, porém, o mesmo não ocorre com os médicos, que dizem subestimar a dor de seu paciente. Segundo os entrevistados há uma relação de migrânea com distúrbios psicológicos e seus pacientes necessitam de um atendimento especial, inclusive de um ambiente adequado para atendimento. Nota-se também que não há um critério estabelecido para a escolha de medicamentos assim como para realização de exames complementares e internação. Conclusão: Diante do estudo realizado nota-se uma deficiência no acolhimento do paciente migranoso e no conhecimento dos médicos em relação a essa patologia.

\section{CE 28}

\section{RELATO DE CASO: SÍNDROME DE TOLOSA-HUNT}

\section{Teles MCM; Jabarra CP; Ferreira GF; Macci JP; Souza JA; Moreira Filho PF}

Objetivo: Relatar um caso da Síndrome de Tolosa-Hunt em que houve a remissão do quadro álgico desacompanhado da recuperação da paresia dentro das primeiras 72 horas após início do corticoide. Método: Relato de caso de JBS, 57 anos, masculino, morador de Niterói, natural do RJ, aposentado, casado, escolarida- de de 4 anos. Iniciou quadro de dor periocular em aperto, diplopia, ptose palpebral a esquerda e dor ao toque da face a esquerda. Sem outros sintomas associados. Melhora parcial da dor com analgésico comum. Três anos antes do quadro atual, apresentou diplopia, com duração de 3 meses e melhora com o uso de Vitamina B1 $300 \mathrm{mg} /$ dia. Ao exame apresentava ptose palpebral a esquerda, paralisia de músculo oblíquo superior e músculo reto medial a esquerda, reflexo fotomotor lentificado a esquerda. Angiotomografia e Ressonância Magnética de crânio sem alterações. Teste oral de tolerância a glicose normal. Resultado: Iniciado prednisona $60 \mathrm{mg} /$ dia após 25 dias do inicio do quadro, com resolução completa da dor em menos de 72 horas, com alguma melhora da ptose palpebral e paresia de músculos reto medial e obliquo superior a esquerda. Conclusão: Apesar dos critérios levar em conta uma melhora da paresia em 72 horas, o caso em questão e muitos outros trabalhos mostram que a resolução da paresia pode necessitar de um tempo muito maior ou até deixar sequelas. Sugerimos que este critério seja revisto. Na prática diária, observa-se que nem sempre os critérios diagnósticos são plenamente preenchidos, e que a exclusão de outras causas e bom senso nos faz diagnosticar condições raras, como a Síndrome de Tolosa-Hunt.

\section{CE 29 \\ TRADUÇÃO E ADAPTAÇÃO TRANSCULTURAL DO QUESTIONÁRIO PEDIATRIC MIGRAINE DISABILITY ASSESSMENT (PEDMIDAS) PARA O PORTUGUÊS (BRASIL)}

\author{
Freire NVS; Gonçalves LR; Coutinho Junior JR; \\ Hershey AD; Rocha Filho PAS
}

Objetivo: Traduzir e adaptar transculturalmente o questionário Pediatric Migraine Disability Assessment (PedMIDAS) da língua inglesa para o português/Brasil. Métodos: Estudo de validação. Foi realizado a tradução e adaptação transcultural do questionário PedMIDAS do inglês para o português/Brasil em cinco etapas: tradução inicial (3 tradutores brasileiros bilíngues), síntese da tradução (reunião com 5 profissionais), retrotradução à língua de origem (2 tradutores nativos de língua inglesa), revisão da tradução por um comitê de juízes e pré-teste da versão final, que foi aplicada em 40 crianças em idade escolar e adolescentes, atendidos no ambulatório de neurologia pediátrica do Hospital Universitário Oswaldo Cruz-HUOC. Resultados: Q1: Nos últimos 3 meses, quantos dias inteiros de aula você faltou por causa de dor de cabeça? (100\% sem dificuldades), Q2: Fora aqueles dias inteiros que você perdeu, nos últimos 3 meses, quantos dias você perdeu mais da metade das aulas por causa da dor de cabeça? $187,5 \%$ sem dificuldades), Q3: Fora os dias que você faltou a escola ou alguma aula, nos últimos 3 meses, quantos dias você não foi capaz de fazer nem metade do que você normalmente faz na escola por causa de dor de cabeça? (85\% sem dificuldades), Q4: Quantos dias você não conseguiu fazer atividades em casa por causa de dor de cabeça (por exemplo, obrigações de casa, lição de casa, etc.)? (100\% sem dificuldades), Q5: Quantos dias você não conseguiu participar de outras atividades por causa de dor de cabeça (por exemplo, brincar, sair para a rua, praticar esportes...)? (100\% sem dificuldades), Q6: Fora os dias que você não participou das atividades da pergunta anterior, quantos dias você participou mas não conseguiu fazer nem metade do que é capaz? ( $85 \%$ sem dificuldades). Conclusão: A versão brasileira do questionário PedMIDAS foi respondida sem dificuldades pela maioria das crianças e adolescentes. 


\section{CE 30}

\section{DIAGNÓSTICO DE CEFALEIA PRIMÁRIA POR ALUNOS INTERNOS DO CURSO DE MEDICINA NA CIDADE DE CAMPINA GRANDE - PARAÍBA}

\author{
Sampaio PGG; Oliveira TTS; Galdino GS
}

Objetivos: Avaliar a capacidade de realização do diagnóstico diferencial das cefaleias primárias mais frequentes, por acadêmicos internos de medicina, visando identificar o nível de conhecimento sobre cefaleias primárias na população estudada, além de investigar se há conhecimento, por parte desses alunos, da Classificação Internacional das Cefaleias. Método: Estudo descritivo, analítico, comparativo, aprovado pelo Comitê de Ética da FCM-CG e realizado no período de janeiro a junho de 2012. A amostra foi composta por 45 internos, o instrumento de coleta de dados foi um questionário autoaplicável, contendo duas histórias clínicas, ficcionais, contemplando os critérios diagnósticos explícitos, listados na Classificação Internacional das Cefaleias (ICHD II), referentes a quadros de migrânea sem aura (MAS) e cefaleia tipo tensional crônica (CTTC). Análise qualiquantitativa a partir dos critérios estabelecidos no questionário utilizado, através do programa Microsoft Excel. Resultados: Dos 45 alunos 37,7\% consideraram como as principais hipóteses diagnósticas para história 01 : MSA e CTT, com $64,4 \%$ encaminhando esse paciente para neurologista/cefaliatra. Com relação à história 02, 31, 1\% propuseram unicamente o diagnostico de CTT e $57,7 \%$ redirecionariam o paciente para o neurologista/cefaliatra. Conclusão: É possível sugerir que os internos entrevistados têm conhecimento básico acerca das cefaleias primárias de acordo com os diagnósticos propostos por eles nas duas histórias.

Palavras-chave: Internos; Cefaleia; Diagnóstico

Referências: 1. Moskowitz MA, Buzzi MG. Migraine general aspects. Handb Clin Neurol. 2010 97:253-66.

2. Krymchantowski A V.; Cefaleias do tipo tensional: atualização; J. brás. Med vol 80 ed.6 p.28-34,2001.

3. Ortiz F, Junior ER. Cefaleias Primárias: Aspectos Clínicos e Terapêuticos; São Paulo $20022^{a}$ Edição; Editora Zeppelini.

\section{CE 31 \\ ASSOCIAÇÃO DE HÁBITOS E COMPORTAMENTOS ALIMENTARES COM A PRESENÇA DE CEFALEIA}

Silva PMF; Soares CBRB; Soares VBRB; Melo MG; Vasconcelos FMN; Silva TAB; Nery MW; Lima RCA; Freire DDO; Costa CNB; Ximenes RCC; Valença MM; Oliveira DA

Objetivo: Avaliar a relação dos hábitos alimentares com queixa de cefaleia em adolescentes. Método: Foram avaliados 128 adolescentes (88 meninas), com idade entre 10 e 19 anos. Para avaliar os hábitos e costumes alimentares foi utilizado um diário alimentar composto por questões que avaliam as preferências e aversões alimentares segundo sete grupos alimentares: grupo 1 - cereais, pães, tubérculos e raízes; grupo 2 - hortaliças e leguminosas; grupo 3 - frutas; grupo 4 - carnes e ovos; grupo 5 - leite e produtos lácteos; grupo 6 - óleos e gorduras; grupo 7 - açúcares e doces; questões sobre as frequências semanais das refeições; questões para avaliar o grau de influência das pessoas do convívio do adolescente na escolha da sua alimentação, as fontes de informação do adolescente sobre alimentação, contexto em que o adolescente se alimenta em relação à companhia e local. Para rastrear a cefaleia primária foram utilizados os critérios estabelecidos pela Sociedade Internacional de Cefaleia (ICHD-II). Resultados: 90,6\% ( $n=116$ ) queixaram-se de cefaleia nos últimos seis meses. Não houve diferença estatística entre gênero e queixa de cefaleia [81 (92\%) meninas e $35(87,5 \%)$ meninos, $p=0,514]$. Dentre os grupos de alimentos que mais gosta houve associação entre os do grupo $5 \mathrm{com}$ queixa de cefaleia $(p=0,016)$. Não foram verificadas associações significativas entre ocorrência de cefaleia com a frequência de cada uma das refeições, influência de pessoas do convívio, companhia e local e segundo as informações sobre alimentação $(p>0,05)$. $75 \%(n=97)$ faziam uso de analgésico sem prescrição médica e $44,5 \%(n=57)$ afirmou absenteísmo escolar devido à cefaleia. Conclusão: $\mathrm{O}$ consumo de alimentos como leite e produtos lácteos desencadeou crises de cefaleia entre os adolescentes estudados. A investigação dos hábitos alimentares como fonte causadora de cefaleia é importante para tentar reduzir as crises e melhorar a qualidade de vida.

\section{CE 32}

FREQUÊNCIA DE CEFALEIA EM ADOLESCENTES COM SINTOMAS DE TRANSTORNOS ALIMENTARES

\section{Silva PMF; Santos MRP; Borges ÉA; Lima RCA; Silva GAM; \\ Vasconcelos FMN; Oliveira DA; Ximenes RCC; Souza SL}

Objetivo: Avaliar a frequência de cefaleia em adolescentes escolares da rede pública de ensino com sintomas de transtornos alimentares. Métodos: Foi realizado um estudo com 150 adolescentes com idade entre 10 e 17 anos. Para o rastreamento de comportamentos sugestivos de transtornos alimentares, foi utilizado o questionário Teste de Atitudes Alimentares (EAT) e para a avaliação da gravidade da bulimia nervosa a partir da avaliação de aspectos cognitivos e comportamentais, foi utilizado o Teste de Avaliação Bulímica de Edinburgh (BITE). Para classificar a cefaleia primária foram utilizados os critérios estabelecidos pela Sociedade Internacional de Cefaleia (ICHD-III). Resultados: A presença de sintomas sugestivos de transtornos alimentares foi de $42,7 \%$ dos pesquisados, desses $43,4 \%$ eram do sexo feminino e $41,2 \%$ do sexo masculino. Para esses adolescentes com sintomas positivos para o EAT, $96,9 \%$ apresentaram cefaleia. Mais da metade $(57,3 \%)$ dos adolescentes não apresentaram sintomas para o Teste de Avaliação Bulímica de Edimburgo (BITE), entre os que apresentaram sintomas, $41,4 \%$ eram do sexo feminino, 35,3\% tinham sintomas médios e $7,3 \%$ sintomas graves e $98,4 \%$ queixavam-se de cefaleia. Na avaliação da gravidade da bulimia nervosa, pelo BITE, apenas $8 \%$ foi considerado significativo e $3 \%$ de grande intensidade, neste estudo todos os adolescentes apresentaram também cefaleia. Apenas nove (6\%) adolescentes pesquisados declararam nunca terem sentido dor de cabeça. Conclusão: A frequência de cefaleia em adolescentes escolares da rede pública de ensino que apresentaram sintomas de transtornos alimentares é elevada e o gênero feminino é mais acomentido. Isto enfatiza a necessidade de intervenção sobre os fatores associados a sua ocorrência, proporcionando orientações apropriadas aos adolescentes.

\section{CE 33 \\ ALTERAÇÕES CORTICAIS DA MIGRÂNEA COM AURA}

Almeida KJ; Silva Neto RP; Arouca EMG; Galvão ACR; Torezano SW; Comerlatti LR; Fortini I 
Objetivo: Relatar achados neurorradiológicos em paciente com infarto migranoso. Relato do caso: Mulher de 23 anos, em uso de contraceptivo oral (ACO) apresentando cefaleia prévia numa frequência de três vezes por mês, temporal esquerda, forte intensidade, ora em pontadas ora em peso, com náuseas, vômitos, fotofobia, fonofobia e sem osmofobia. A dor era sempre precedida por diplopia e, algumas vezes, embaçamento visual bilateral. Tomava dipirona durante as crises (sem abuso). Apresentou, após acordar durante a madrugada, quadro súbito de dormência e perda de força (grau 0) no MSD e em hemiface esquerda. Observou dificuldade para falar e, concomitantemente, cefaleia temporal em pontadas, forte intensidade, sem náuseas ou vômitos, com fotofobia, fonofobia e vertigem. Antes da cefaleia, apresentou os mesmos sintomas visuais. Persistiu com cefaleia mesmo após usar Dorflex(C) e Dipirona. Não conseguia emitir palavras, compreendia comandos complexos, conseguia ler e entender sentenças, porém só escrevia palavras repetidas. Não conseguia nomear objetos ou repetir sentenças. Relatou que não conseguia encontrar as palavras. Voltou a dormir e ao acordar permaneceu com parestesias em MSD e face, iá conseguia realizar movimentos no MSD e falava sentenças simples como "sim" e "não". Continuava com cefaleia de fraca intensidade e procurou o hospital. À admissão, observou-se afasia não fluente com parafasias fonêmicas, discurso telegráfico, compreensão, nomeação, escrita e repetição preservadas. Hemiparesia direita completa desproporcionada de predomínio braquiofacial grau IV. Reflexos profundos globalmente simétricos e reflexo cutâneo plantar flexor bilateral. Hemi-hipoestesia direita completa. RNM encefálica evidenciou área de restrição difusional cortical acometendo terço inferior do giro pré-central esquerdo, com discreto realce pelo contraste. Angio-RNM normal e Doppler transcraniano com alterações hemodinâmicas associadas ao quadro migranoso. Recebeu alta com amitriptilina e suspensão de ACO. Conclusão: Migrânea com aura complexa (visual, sensitiva, motora e de linguagem) pode estar associada a achados neurorradiológicos raros quando evolui para infarto migranoso.

\section{CE 34 \\ ANÁLISE DO TEMPO DE PROFILAXIA DA MIGRÂNEA}

\section{Silva Neto RP; Almeida KJ; Valença MM}

Objetivo: Determinar o tempo mínimo para suspensão da profilaxia da migrânea em pacientes assintomáticos. Método: Através de estudo prospectivo, com comparação de grupos, empregando amostra de conveniência, 50 pacientes migranosos diagnosticados conforme os critérios da International Classification of Headache Disorders second editon foram tratados profilaticamente com atenolol, nortriptilina e flunarizina até o desaparecimento da cefaleia. Quando assintomáticos, foram divididos em dois grupos iguais: grupo A mantido profilaxia por mais 12 meses e grupo B, por mais 24 meses. Determinou-se a frequência de crises pré e pós-tratamento, num seguimento de três anos, utilizando-se diário da cefaleia. No seguimento, definiu-se como desfecho "tempo livre de dor" e "número de episódios de recidiva de cefaleia por ano". Resultados: Dos 50 pacientes tratados, 39 (78\%) eram mulheres, correspondendo à razão feminino/masculino de 3,5:1. A idade variou de 19 a 57 anos $(36,0 \pm 11,0)$. Dos 25 pacientes do grupo A, $20(80 \%)$ eram mulheres e $5(20 \%)$ homens e dos 25 do grupo B, 19 (76\%) eram mulheres e $6(24 \%)$ homens. A idade dos pacientes dos grupos A e B, foi igual, respectivamente, a 34,2 $\pm 10,4$ e 37,8 $\pm 11,4$ anos. Antes do tratamento, a frequência mensal das crises para os grupos $A$ e $B$ era, respectivamente, de 16,3 $\pm 12,8$ e 16,4 $\pm 11,8$ dias $(p=0,769)$. $\bigcirc$ tempo de desaparecimento da cefaleia foi, respectivamente, de 21,4 $\pm 11,2$ e 16,8 $\pm 9,9$ meses para os grupos $\mathrm{A} \mathrm{e} B\left(p=0,161, \chi^{2}\right)$. Os grupos não diferiram significativamente. Durante três anos sem tratamento, os grupos $A$ e $B$ mantiveram uma frequência anual de, respectivamente, 3,2 e 0,5 dias de cefaleia. Dos pacientes do grupo B, $76,0 \%$ (19/25) permaneceram assintomáticos durante o seguimento, versus $44,0 \%(11 / 25)$ do grupo $A$, com diferença significativa $\left(p=0,001, \chi^{2}\right)$. Conclusão: Considerando como desfecho o tempo livre de cefaleia após suspensão da profilaxia, melhores resultados foram obtidos com profilaxia da migrânea por 24 meses.

Palavras-chave: Migrânea; Profilaxia; Cura

\section{CE 35 \\ PREVALÊNCIA E IMPACTO DA MIGRÂNEA EM ALUNOS DE ODONTOLOGIA}

\author{
Barbosa FMCS'; Ferraz MGG'; Rocha EE²; \\ Matos RVL2; Fernandes RSM ${ }^{3}$
}

${ }^{1}$ Cirurgiã Dentista pela UFPE; ${ }^{2}$ Especialista em Disfunção Temporomandibular e Dor Orofacial pela FOR; ${ }^{3}$ Doutorado em Reabilitação Oral pela FORP-USP, Professora Adjunto da UFPE

A migrânea é uma cefaleia primária altamente prevalente e está entre as doenças mais incapacitantes. Seu diagnóstico deve seguir os critérios definidos pela Sociedade Internacional de Cefaleia. Esta pesquisa teve como objetivo identificar, dentre os estudantes do Curso de Odontologia da UFPE, os portadores de cefaleia e, entre esses, os migranosos. Através de questionários escritos, frequência mensal, a intensidade e a localização da dor foram analisadas e comparadas entre os grupos. $\bigcirc$ grau de impacto da migrânea nas atividades rotineiras dos alunos também foi avaliado, com o uso do Questionário de Avaliação da Incapacidade por Migrânea (MIDAS). Dos 256 questionários válidos, 45 alunos eram migranosos (G1) e 174, portadores de outros tipos de cefaleia (G2). Ao comparar os dois grupos, verificou-se que características como localização, frequência e intensidade da dor foram diferentes. O grau de impacto das crises de migrânea nas atividades profissionais, domésticas e sociais foram superiores nas mulheres. A partir das informações colhidas, os alunos portadores de cefaleia foram orientados a procurar centros especializados. Por abordar uma patologia de alta prevalência que provoca impacto substancial ao indivíduo e a sociedade, um estudo como este é importante ser realizado, pois possibilita o planejamento e a execução de melhores programas de saúde que visem o bem estar da população. No âmbito acadêmico, pesquisas como esta possibilitam que o tema, tão pouco abordado, seja esclarecido em sala de aula nos cursos de graduação e pós-graduação.

\section{CE 36 \\ SINTOMATOLOGIA DEPRESSIVA EM ADOLESCENTES COM CEFALEIA PRIMÁRIA}

Lima RCA; Freitas DS; Bezerra e Silva DW; Silva GA; Costa CNB; Siqueira GR; Silva GAM; Ximenes RCC; Silva LC; Martins HAL; Vieira LPB; Valença MM; Oliveira DA

Objetivo: Investigar a relação entre os sintomas depressivos e a cefaleia primária em adolescentes. Métodos: Foram avaliados 
117 estudantes (68 meninas) de escolas públicas estaduais, com idade variando entre 11 e 17 anos ( $14 \pm 1,7$ anos). Para classificar a cefaleia primária foram utilizados os critérios estabelecidos pela Sociedade Internacional de Cefaleia (ICHD-II). Para o rastreamento de sintomatologia depressiva foi utilizado o Inventário de Depressão Infantil (CDI). Resultados: Não houve diferença entre os gêneros em relação à média de idade $(13,9 \pm 1,8$ meninas e 14,2 \pm $1,6$ meninos; $p=0,342)$. Não houve associação estatística entre presença de sintomatologia depressiva e cefaleia no último mês [66/80 (82,5\%) adolescentes com cefaleia vs. 30/37 (81,1\%) sem cefaleia, $p>0,05 ; \chi^{2}$. Cefaleia no último mês foi observada em $80 / 117(68,4 \%)$ da amostra [53/68 (77,9\%) meninas e 27/49 $(55,1 \%)$ meninos; $\left.p=0,015, \chi^{2}\right]$. Sintomatologia depressiva foi observada em $96 / 117(82,1 \%)$ dos alunos [62/68 (91,2\%) meninas e $34 / 49(69,4 \%)$ meninos, $\left.p=0,003 ; \chi^{2}\right]$. As meninas apresentaram maiores médias de escore em todos os domínios do CDI com diferença estatística nos domínios: problemas interpessoais $(2,51 \pm$ $1,05$ meninas vs. $2,02 \pm 1,2$ meninos, $p=0021)$; humor deprimido $(4,37 \pm 1,3$ meninas vs. $3,61 \pm 1,8$ meninos, $p=0,013)$; inefetividade $(4,38 \pm 1,3$ meninas vs. $3,71 \pm 1,8$ meninos, $p=0,024)$ e autoestima negativa $(6,21 \pm 0,93$ meninas vs. 4,63 $\pm 2,4$ meninos; $p<0,05)$. Conclusão: Cefaleia primária e sintomas depressivos são frequentes entre os adolescentes estudados e as meninas são mais acometidas pelas duas condições.

\section{CE 37}

\section{ACHADOS AUDIOMÉTRICOS EM ADULTOS COM MIGRÂNEA: UM ESTUDO COMPARATIVO E CONTROLADO}

\author{
Agessi LM; Duarte JA; Kolontai A; Curi R; Ganança FF; \\ Carvalho DS; Villa TR
}

Objetivo: Comparar os achados audiométricos em indivíduos com migrânea e indivíduos sem cefaleia. Métodos: Foram avaliados 15 pacientes com migrânea sem aura, 12 pacientes com aura, diagnosticados de acordo com a International Headache Society (ICHD-II, 2004), e 15 indivíduos sem história de cefaleia. Idade entre 18 e 40 anos. Os critérios de exclusão: outras doenças neurológicas e otoneurológicas, exposição a ruído, antecedentes de trauma acústico, uso de drogas ototóxicas e otites de repetição. Uso atual de profiláticos para migrânea ou outros medicamentos com ação no sistema nervoso central. Avaliação: anamnese e audiometria tonal e vocal realizada por profissional fonoaudiólogo. A análise estatística foi realizada pelo teste ANOVA, com nível de significância de 5\% e intervalo de confiança de 95\%. Resultados: A idade média do grupo migrânea sem aura foi 29,5 anos $\pm 6,3$, migrânea com aura 28,7 anos $\pm 6,0$, controles sem cefaleia 29,1 anos $\pm 5,0$. Observamos que, apesar de todos os avaliados apresentarem limiares auditivos dentro da normalidade, houve diferença significante na orelha direita para o grupo migrânea sem aura e na orelha esquerda para o grupo migranea com aura, em comparação aos controles. Discussão: Estudos anteriores identificaram perda auditiva flutuante em frequências graves em pacientes com enxaqueca. A enxaqueca também já foi identificada como causa de perda súbita de audição em pacientes sem causa identificada que preenchiam critérios para migrânea. A literatura ainda é escassa sobre as alterações auditivas em pacientes com migrânea com ou sem aura. $\bigcirc$ presente estudo demonstrou uma diferença significativa dos limiares auditivos entre os grupos migrânea e controles sadios.
Tabela 1- Resultados do teste audiométrico do grupo migrânea com aura comparados ao grupo controle

\begin{tabular}{lccc}
\hline \multicolumn{1}{c}{$\begin{array}{c}\text { Audiometria limiares } \\
\text { auditivos }\end{array}$} & $\begin{array}{c}\text { Migrânea com } \\
\text { aura }\end{array}$ & Controle & p-valor \\
\hline $\begin{array}{l}\text { Média Orelha Direita } \\
\text { (Desvio Padrão) }\end{array}$ & $10,45( \pm 5,68)$ & $6,67( \pm 2,44)$ & 0,067 \\
$\begin{array}{l}\text { Média Orelha Esquerda } \\
\text { (Desvio Padrão) }\end{array}$ & $10,91( \pm 5,39)$ & $6,67( \pm 2,44)$ & 0,021 \\
\hline
\end{tabular}

Tabela 2 - Resultados do teste audiométrico do grupo migrânea sem aura comparados ao grupo controle

\begin{tabular}{lccc}
\multicolumn{1}{c}{$\begin{array}{c}\text { Audiometria limiares } \\
\text { auditivos }\end{array}$} & $\begin{array}{c}\text { Migrânea sem } \\
\text { aura }\end{array}$ & Controle & p-valor \\
\hline $\begin{array}{l}\text { Média Orelha Direita } \\
\text { (Desvio Padrão) }\end{array}$ & $10,67( \pm 4,17)$ & $6,67( \pm 2,44)$ & 0,031 \\
$\begin{array}{l}\text { Média Orelha Esquerda } \\
\text { (Desvio Padrão) }\end{array}$ & $9,67( \pm 3,52)$ & $6,67( \pm 2,44)$ & 0,091 \\
\hline
\end{tabular}

Referências: 1.Baloh RW. Neurootology of migraine. Headache. 1997; 37:615-21

2. Viirre ES, Baloh RW. Migraine as a cause of sudden hearing loss.

Headache. $1996 ; 36: 24-48$

3. Headache Classification Committee of the International Headache Society. The International Classification of Headache Disorders: 2nd edition. Cephalalgia 2004; 24 Suppl 1: 9-160.

4. Bolay H, Bayazit YA, Gunduz B, Ugur AK, Akçali D, Altunyay S, llica S, Babacan A. Subclinical dysfunction of cochlea and cochlear efferents in migraine: an otoacoustic emission study. Cephalalgia 2008;28:309-317

\section{CE 38 \\ AVALIAÇÃO DO PROCESSAMENTO AUDITIVO CENTRAL EM ADULTOS COM MIGRÂNEA E CONTROLES SEM CEFALEIA}

Agessi LM; Dias KZ; Carvalho DS; Pereira LD; Villa TR

Faculdade de Fonoaudiologia da Universidade Federal de São Paulo - UNIFESP

Setor de Investigação e Tratamento das Cefaleias - Departamento de Neurologia e Neurocirurgia - UNIFESP.

Objetivo: Comparar o desempenho em testes de processamento auditivo em indivíduos com migrânea com e sem aura e comparálos a um grupo controle sem cefaleia. Métodos: Foram avaliados 26 indivíduos com migrânea, com e sem aura, classificados de acordo com a International Headache Society (ICHD-II, 2004), e 15 controles. Grupo migrânea com aura: 10 mulheres e 1 homem, idade média de 29,3 anos $\pm 5,8$, média de 8,2 dias de cefaleia / mês $\pm 4,1$. Grupo migrânea sem aura: 14 mulheres e um homem, idade média de 29,5 anos $\pm 6,3$, média de 7,5 dias de cefaleia/ mês $\pm 2,3$. Grupo controle: 14 mulheres e um homem, com média de 29,1 anos. Os procedimentos realizados foram: anamnese, avaliação da função auditiva periférica, testes do Processamento auditivo central (PAC) como Gaps-in-noise, Padrão de duração, Dicótico de Dígitos e Localização. Os critérios de exclusão foram: doenças psiquiátricas, outras doenças neurológicas, perda auditiva, trauma craniano, uso de medicamentos ototóxicos, preventivos para migrânea ou que afetem o sistema nervoso central. Uso de álcool e drogas. A análise estatística foi realizada pelo teste ANOVA, com nível de significância de 5\% e intervalo de confiança de $95 \%$. Resultados: Todos os avaliados obtiveram limiares auditivos dentro da normalidade. Indivíduos com migrânea com e sem aura apresentaram pior desempenho em relação à resolução temporal e a ordenação temporal, quando comparados a controles sem cefaleia. Discussão: As funções do processamento auditivo envolvem estruturas anatômicas como tronco cerebral, córtex e neurotrans- 
missores. Aspectos neuroquímicos envolvidos na fisiopatologia da migrânea e das funções auditivas podem predispor indivíduos com migrânea déficits do processamento auditivo, com prejuízos nas habilidades de reconhecer, discriminar e compreender as informações auditivas, bem como a atenção e memória auditivas.

\begin{tabular}{|c|c|c|c|c|c|c|c|c|c|}
\hline & \multicolumn{4}{|c|}{ Migrânea com aura } & \multicolumn{4}{|c|}{ Controle } & \multirow[b]{2}{*}{ P-valor } \\
\hline & Média & D.P. & Min. & Máx. & Média & D.P. & Min. & Máx. & \\
\hline Gaps-in-noise O.D. & 5,45 & $\pm 1,13$ & 4 & 8 & 4,07 & $\pm 0,8$ & 3 & 5 & 0,06 \\
\hline Gaps-in-noise O.E. & 5,45 & $\pm 1,13$ & 4 & 8 & 4,07 & $\pm 0,8$ & 3 & 5 & 0,02 \\
\hline $\begin{array}{l}\text { Teste Padrão de } \\
\text { duração }\end{array}$ & $68,90 \%$ & $\pm 11,80 \%$ & $56 \%$ & $84 \%$ & $92,80 \%$ & \pm & $76 \%$ & $96,50 \%$ & $<0,001$ \\
\hline $\begin{array}{l}\text { Dicótico de } \\
\text { dígitos O.D. }\end{array}$ & $98,50 \%$ & $\pm 2,30 \%$ & $92,50 \%$ & $100 \%$ & $99,90 \%$ & $\pm 0,30 \%$ & $98,80 \%$ & $100 \%$ & 0,362 \\
\hline $\begin{array}{l}\text { Dicótico de } \\
\text { dígitos O.E. }\end{array}$ & $98,90 \%$ & $\pm 1,80 \%$ & $95 \%$ & $100 \%$ & $99,90 \%$ & $\pm 0,30 \%$ & $98,80 \%$ & $100 \%$ & 0,190 \\
\hline $\begin{array}{l}\text { Teste de } \\
\text { localização }\end{array}$ & 5 & 0 & 5 & 5 & 5 & 0 & 5 & 5 & 1,0 \\
\hline
\end{tabular}

Quadro 2. Desempenho nos testes de processamento auditivo do grupo migrânea sem aura comparado ao grupo controle

\begin{tabular}{lccccccccc}
\hline & \multicolumn{3}{c}{ Migrânea sem aura } & \multicolumn{2}{c}{ Controle } \\
& Média & D.P. & Min. & Máx. & Média & D.P. & Min. & Máx. & P-valor \\
\hline Gaps-in-noise O.D. & 5,87 & $\pm 2,1$ & 2 & 10 & 4,07 & $\pm 0,8$ & 3 & 5 & 0,005 \\
Gaps-in-noise O.E. & 5,6 & \pm 1 & 2 & 10 & 4,07 & $\pm 0,8$ & 3 & 5 & 0,008 \\
$\begin{array}{l}\text { Padrão de } \\
\text { duração }\end{array}$ & $77,90 \%$ & $\pm 14,60 \%$ & $46 \%$ & $100 \%$ & $92,80 \%$ & $\pm 6,70 \%$ & $76 \%$ & $96,50 \%$ & 0,003 \\
$\begin{array}{l}\text { Dicótico de } \\
\text { dígitos O.D. }\end{array}$ & $97,90 \%$ & $\pm 6,10 \%$ & $76,30 \%$ & $100 \%$ & $99,90 \%$ & $\pm 0,30 \%$ & $98,80 \%$ & $100 \%$ & $0,362$. \\
$\begin{array}{l}\text { Dicótico de } \\
\text { digitos O.E. }\end{array}$ & $98,80 \%$ & $\pm 2,60 \%$ & $90 \%$ & $100 \%$ & $99,90 \%$ & $\pm 0,30 \%$ & $98,80 \%$ & $100 \%$ & $0,190$. \\
$\begin{array}{l}\text { Teste de } \\
\text { localização }\end{array}$ & 5 & 0 & 5 & 5 & 5 & 0 & 5 & 5 & 1,0
\end{tabular}

Referências: 1. Headache Classification Committee of the International Headache Society. The International Classification of Headache Disorders: 2nd edition. Cephalalgia. 2004;24 Suppl 1:9-160.

2. Magis D, Joiris T, Di Clemente L, Allena M, Coppola G, Gerard P, Schoenen J. Interictal cognition in migraineurs: a study correlation psychometric and neurophysiological tests. Cephalalgia. 2007;27:714.

3. Demarquay G, Caclin A, Brudon F, Fischer C, Morlet D. Exacerbated attention orienting to auditory stimulation in migraine patients. Clinical neurophysiology. $2011 ; 122: 1755-63$.

4. Musiek F, Baran J Neuroanatomy, neurophysiology and central auditory assessment Part 1: Brainstem. Ear and Hearing. 1986;7:207-19.

\section{CE 39 \\ RACIOCÍNIO NÃO VERBAL, FUNÇÕES MOTORAS, E PRAXIA CONSTRUTIVA EM CRIANÇAS COM MIGRÂNEA UM ESTUDO CONTROLADO}

\author{
Moutran ARC; Pereira RA; Vaz L; Villa TR; Carvalho DS \\ Setor de Investigação e Tratamento das Cefaleias \\ Universidade Federal de São Paulo (Unifesp); Instituto de \\ Psicologia Aplicada (IPAF/Brasil)
}

Objetivo: Comparar o raciocínio não verbal, funções motoras e a praxia construtiva de crianças com migrânea e controles sem cefaleia. Método: Grupo migrânea: 10 crianças de ambos os sexos (6 meninas), diagnosticadas segundo os critérios da International Headache Society (ICHD-II, 2004), 6 com e 4 sem aura, idade entre 8 e 11 anos e 08 meses $(10,2 \pm 1,23)$, média de 8,6 dias de cefaleia /mês (DP $\pm 4,9$ ). Grupo controle: 10 crianças (5 meninas), mesma faixa etária (10,2 anos $\pm 0,91)$ sem história prévia de cefaleia. Testes utilizados: Matrizes progressivas coloridas de Raven (raciocínio não verbal), Bateria neuropsicológica Tübinger Luria-Christensen para crianças - TUKI (funções motoras) e o Teste de Figuras complexas de Rey (praxia construtiva e memória imediata visual). Critérios de exclusão: antecedentes mórbidos gestacionais, prematuridade, atraso no desenvolvimento psicomotor, deficiência intelectual, epilepsia, trauma craniano, doenças sistêmicas, meningite, síndromes genéticas, doenças psiquiátricas, uso de medicação profilática para cefaleia ou qualquer outra com efeito no sistema nervoso central. A análise estatística foi realizada por meio do teste t e Mann-Whitney sendo considerado significativo $p<0,05$. Resultados: $\bigcirc$ grupo migrânea apresentou escores significativamente menores que o grupo controle nas Matrizes Progressivas Coloridas de Raven escore bruto ( $p$ $<0,004)$ / percentil $(p<0,001)$; Figuras Complexas de Rey - Cópia $(p<0,016) /$ percentil $(p<0,003)$ e regulação do ato motor $(p<0,012)$. Conclusão: Crianças com migrânea quando comparadas aos controles apresentaram pior desempenho em testes de raciocínio não verbal, dificuldades na organização e integração perceptomotora, e na regulação do ato motor. Estes déficits podem gerar um impacto negativo no desempenho escolar e nas atividades cotidianas da criança.

\begin{tabular}{lrrrrr}
\hline & Grupo Migrânea & \multicolumn{3}{c}{ Grupo Controle } \\
\hline & Média & DP & Média & DP & $p$ \\
\hline Raven/Escore & 25 & $\pm 6,41$ & 32,1 & $\pm 1,26$ & $0,004^{*}$ \\
Raven Percentil & 51,4 & $\pm 25,34$ & 84 & $\pm 11,75$ & $0,001^{*}$ \\
Fig Rey Tempo (em & 278,5 & $\pm 46,67$ & $345,6 \pm 101,08$ & 0.072 \\
segundos) & & & & & \\
Fig Rey Cópia/Escore & 21,1 & $\pm 6,49$ & 27,7 & $\pm 4,48$ & $0,016^{*}$ \\
Fig Rey Percentil & 6,09 & $\pm 12,68$ & 38,41 & $\pm 27,04$ & $0,003^{*}$ \\
Fig Rey Memória & 11,05 & $\pm 5,33$ & 15,1 & $\pm 6,15$ & 0,133 \\
imediata/Escore & & & & & \\
Fig Rey Memória & 21,7 & $\pm 21,92$ & 43,58 & $\pm 27,85$ & 0,066 \\
imediata/Percentil & 10,6 & $\pm 1,34$ & 11,1 & $\pm 0,56$ & 0,499 \\
Função motora global & 28,1 & $\pm 2,02$ & 29,2 & $\pm 1,13$ & 0,162 \\
Função motora das mãos & 15,5 & $\pm 1,58$ & 16,3 & $\pm 0,82$ & 0,278 \\
Praxia Oral & 5,4 & $\pm 0,69$ & 6 & \pm 0 & $0,012^{*}$ \\
Regulação do ato motor & 37,6 & $\pm 1,89$ & 38,4 & $\pm 0,96$ & 0,427 \\
Sensaçães cutâneas & & & & & \\
sinestésicas & 9,7 & $\pm 0,67$ & 9,8 & $\pm 0,42$ & 0,913 \\
Estereognosia & & & &
\end{tabular}

Referências: 1. Headache Classification Subcommittee of the International Headache Society The international classification of headache disorders; 2 nd edition. Cephalalgia.2004; 24(suppl 1): 9-160.

2. Deegener G, Dietel B, Kassel H, Matthaei R, Nödl H. Neuropsychologische Diagnostik bei Kindern und Jugendlichen: Handbuch zur TÜKI - Tübinger Luria-Christensen neuropsychologische für kinder. Weinheim:Psychologie-Verlags-Union; 1992.

3. Angelini AL, Alves IRC, Custódio EM, Duarte WF, Duarte JLM. Manual Matrizes Progressivas Coloridas de Raven: escala especial. Centro Editor de Testes e Pesquisas em Psicologia, São Paulo, 1999.

4. Oliveira, MS. Figuras Complexas de Rey: teste de cópia e de reprodução de memória de figuras geométricas. Casa do Psicólogo, São Paulo, 2010.

\section{CE 40 \\ SÍNDROME DE MARFAN ASSOCIADA À MIGRÂNEA COM MÚLTIPLOS FENÔMENOS DE AURA: RELATO DE CASO}

Santos BFO; Villa TR; Carvalho DS

Setor de Investigação e Tratamento das Cefaleias, Departamento de Neurologia e Neurocirurgia, Universidade Federal de São Paulo (Unifesp)

Introdução: Migrânea com aura cursa com cefaleia e fenômenos neurológicos focais (visuais, sensitivos, sensoriais, motores) transitórios com duração de até 60 minutos e completamente reversíveis. A Síndrome de Marfan (SM) é uma patologia autossômica dominante com acometimento cardiovascular, ocular e esquelético. 
Trabalhos da literatura mostram maior ocorrência de migrânea com aura em pacientes com SM. Não foram encontrados, na literatura consultada, registros de casos de SM associada à migrânea e múltiplas auras. Relato de Caso: Paciente masculino, 20 anos, apresentando há 8 anos, crises de cefaleia temporal unilateral, principalmente à esquerda, de forte intensidade e de caráter pulsátil, associadas à fonofobia, fotofobia, náuseas e vômitos, durando de 6 a 12 horas. As crises são precedidas de fosfenos cintilantes e embaçamento visual e após 10 minutos no dimidio esquerdo percebe parestesia de membro superior e hemiface, seguida de hemiplegia e afasia motora. As auras tem duração entre 30 a 40 min, com resolução completa. Periodicidade trimestral no início, mas atualmente apresentando crises semanais. Antecedente familiar: mãe com migrânea sem aura. Paciente acompanhado em serviço de referência com diagnóstico de SM. Ressonância e angiorressonância magnética encefálica normais. Sem acometimento cardiovascular. Refere que nos últimos seis meses fez uso de flunarizina $30 \mathrm{mg} /$ dia, verapamil $80 \mathrm{mg} /$ dia e gabapentina $400 \mathrm{mg} /$ dia, sem melhora. Em primeira consulta em nosso serviço apresentava exame clínico e neurológico normais. Foram suspensos o verapamil e gabapentina, mantido flunarizina 10 mg e adicionado divalproato de sódio 500 mg/dia, ainda não retornou para avaliar a resposta ao novo esquema terapêutico. Discussão: Caso de paciente com Sindrome de Marfan associada à migrânea com aura se manifestando com múltiplas auras (visual, sensitiva e motora), aumento da frequência de crises e temporariamente com refratariedade a politerapia profilática convencional. Aparentemente, os mecanismos vasculares da migrânea e da Síndrome de Marfan são sinérgicos para maior gravidade neste paciente.

Referências: 1. Headache Classification Committee of the International Headache Society. The International Classification of Headache Disorders: 2nd edition. Cephalalgia. 2004;24 Suppl 1:9-160.

2. Koppen H, Vis JC, Gooiker DJ, Knudsen S, Bouma BJ, Tiissen JG, de Mol BA, Mulder BJ, Russell MB, Ferrari MD. Aortic root pathology in Marfan syndrome increases the risk of migraine with aura. Cephalalgia. 2012;32(6):467-72.

3. Russell MB, Ducros A. Sporadic and familial hemiplegic migraine: pathophysiological mechanisms, clinical characteristics, diagnosis, and management. Lancet Neurol. $2011 ; 10(5): 457-70$

\section{CE 41 \\ VISUAL ATTENTION IN CHILDREN WITH MIGRAINE: THE IMPORTANCE OF PROPHYLAXIS}

Villa TR; Moutran ARC; Gabbai AA; Carvalho DS

Division of Investigation and Treatment of Headaches (DITH),

Department of Neurology and Neurosurgery - UNIFESP

Background: To compare the visual attention of children newly diagnosed with migraine, children undergoing migraine prophylaxis, and a healthy control group. Method: Eighty-two children, aged 812 years, were enrolled and divided into three groups: Migraine group: diagnosed with migraine with $(n=5)$ or without aura $(n=25)$ according to the International Headache Society criteria (ICDH-II, 2004), 15 boys, with $5.8 \pm 3.2$ days of headache/month, without previous or current use of migraine prophylaxis. Migraine prophylaxis group: diagnosed with migraine with $(n=6)$ or without aura $(n=16)$, 10 boys, with $6.3 \pm 2.0$ days of headache/ month prior to treatment. Prophylactic treatment started 3-6 months before evaluation. Eight of them were taking sodium valproate (500-1000 mg/day), six propranolol (40-80 mg/day), five amitriptyline (25-50 mg/day), and three flunarizine (5-10 mg/day). Control group: children without headache, 16 boys. All were subjected to a visual attention assessment with the Trail Making Test parts A and B, Letter-Cancellation Test, and the Visual Attention Test 3rd edition. The untreated migraine group was evaluated after two days without headache, and the migraine prophylaxis group after two months without any migraine symptoms. Exclusion criteria: systemic illness, abnormalities on neurological examination, intelligence quotient (IQ) less than 80, psychiatric disturbances, learning disabilities, history of epilepsy, head trauma, use of other drugs acting on the central nervous system. Results: Children with untreated migraine performed significantly worse in all visual attention tests than did the control children or children undergoing migraine prophylaxis, especially with regard to selective and alternate attention. The migraine prophylaxis group performed as well as the control group. Conclusion:The deregulation of the neurochemical mechanisms underlying the physiopathology of migraine might induce visual attention deficits, but an effective prophylactic treatment might reverse migraine symptoms.

Table 1 - Results of visual attention assessment in migraine and migraine prophylaxis groups

\begin{tabular}{lccl}
\hline Attention visual tests & $\begin{array}{c}\text { Migraine } \\
\text { group }\end{array}$ & $\begin{array}{c}\text { Migraine } \\
\text { prophylaxis group }\end{array}$ & \\
\hline Trail making test A & $23.0 \pm 12.6$ & $7.1 \pm 8$ & \\
Trail making test B & $66.6 \pm 36.6$ & $43 \pm 19.6$ & $(\mathrm{p}=0.004)$ \\
Letter cancellation test & $148.4 \pm 55.1$ & $121.5 \pm 39.7$ & \\
Cancellation omission errors & $3.3 \pm 3.7$ & $2.5 \pm 2.9$ & \\
Reaction time task1 & $0.5 \pm 0.1$ & $0.5 \pm 0.05$ & \\
Reaction time task2 & $0.6 \pm 0.1$ & $0.6 \pm 0.1$ & \\
Reaction time task3 & $0.5 \pm 0.1$ & $0.5 \pm 0.09$ & \\
Omission errors task1 & $2.2 \pm 2.8$ & $0.9 \pm 0.7$ & $(p=0.019)$ \\
Omission errors task2 & $2.8 \pm 2.7$ & $2.3 \pm 1.8$ & \\
Omission errors task3 & $0.2 \pm 0.4$ & $0.05 \pm 0.2$ & \\
Action errors task1 & $2.4 \pm 1.7$ & $2.0 \pm 1.8$ & \\
Action errors task2 & $5.5 \pm 3.5$ & $3.6 \pm 2.9$ & \\
Action errors task3 & $2.4 \pm 5.7$ & $0.4 \pm 0.8$ & \\
*0 0.05 & & &
\end{tabular}
" $\mathrm{p} \leq 0.05$

Table 2 - Results of visual attention assessment in migraine prophylaxis and controls groups.

\begin{tabular}{lccl}
\hline Attention visual tests & $\begin{array}{c}\text { Migraine } \\
\text { prophylaxis group }\end{array}$ & Control group & \\
\hline Trail making test A & $17.1 \pm 8$ & $17.5 \pm 4.5$ & \\
Trail making test B & $43 \pm 19.6$ & $41.7 \pm 13.8$ & \\
Letter cancellation test & $121.5 \pm 39.7$ & $129.4 \pm 32.5$ & \\
Cancellation omission errors & $2.5 \pm 2.9$ & $2.9 \pm 3.3$ & \\
Reaction time task1 & $0.5 \pm 0.05$ & $0.6 \pm 0.1 \quad \quad(p=0,038)$ \\
Reaction time task2 & $0.6 \pm 0.1$ & $0.6 \pm 0.1$ & \\
Reaction time task3 & $0.6 \pm 0.1$ & $0.5 \pm 0.2$ & \\
Omission errors task1 & $0.9 \pm 0.7$ & $1.0 \pm 1.3$ & \\
Omission errors task2 & $2.3 \pm 2.0$ & $0.9 \pm 0.7$ & \\
Omission errors task3 & $0.05 \pm 0.2$ & $0.1 \pm 0.3$ & \\
Action errors task1 & $2.0 \pm 1.8$ & $1.6 \pm 1.3$ & \\
Action errors task2 & $3.6 \pm 2.9$ & $3.4 \pm 2.7$ & \\
Action errors task3 & $0.4 \pm 0.8$ & $0.6 \pm 1.0$ & \\
\hline
\end{tabular}

${ }^{*} \mathrm{p} \leq 0.05$

References: 1. Headache Classification Committee of the International Headache Society. The International Classification of Headache Disorders: 2nd edition. Cephalalgia. 2004;24 Suppl 1:9-160.

2. Villa TR, Correa Moutran AR, Sobirai Diaz LA, et al. Visual attention in children with migraine: a controlled comparative study. Cephalalgia. 2009;29(6):631-4.

3. Damen L, Bruiin J, Verhagen AP, Berger MY, Passchier J, and Koes BW. Prophylactic treatment of migraine in children. Part 2. A systematic review of pharmacological trials. Cephalalgia. 2006;26(5):497-505. 
DOR

\section{DOR 01}

\section{ACUPUNTURA COMO TERAPÊUTICA PARA ALODÍNEA}

\author{
Campana $A \mathrm{CR}^{1}$; Witzel $\mathrm{AL}^{2}$; Sato JE ${ }^{3}$; Pirró $A P R^{3}$; Nunes $\mathrm{A}^{4}$;
} Falleiros $\mathrm{V}^{3}$; Ferraz $\mathrm{BF}^{3}$

'Cirurgiã-Dentista Habilitada em Acupuntura, Aluna de Mestrado do Curso de Patologia e Estomatologia Básica e Aplicada da FOUSP.

2Especialista em DTM e DOF e Especialista em Estomatologia,

Professora Doutora da Faculdade de Odontologia da USP

${ }^{3}$ Médico Acupunturista; ${ }^{4}$ Cirurgião Dentista

Estudos têm demonstrado que a acupuntura é capaz de promover a regeneração de fibras nervosas (Inove 2011 1) e a liberação de substâncias como os opióides endógenos e oxitocina essenciais para a indução da analgesia (Andersson 1995). Objetivo: Esse trabalho tem como objetivo o relato de caso do tratamento com acupuntura de uma paciente que apresentava alodínea. Método: Paciente com queixa de alodínea mecânica localizada no lábio superior com uma extensão de $1 \mathrm{~cm}$ para lado direito a partir da linha mediana e um $\mathrm{cm}$ para lado esquerdo e em altura comprometendo desde a linha branca do lábio superior até a transição para mucosa intraoral. O toque causava sensação de choque forte graduado na escala visual numérica como 9 . $\bigcirc$ tratamento efetuado foi a acupuntura local e sistêmica, num total de 8 sessões de 20 minutos de duração. Resultado: Após 8 sessões de acupuntura a paciente relatou que na escala visual numérica o choque reduziu para 10 e ficou localizado em apenas um ponto do tubérculo central do lábio superior. Conclusão: Nesse caso, o tratamento com acupuntura pode ter acelerado a regeneração do tecido nervoso e se mostrou eficaz no controle da queixa apresentada pela paciente. A terapêutica deve ser reproduzida em um número maior de pacientes para confirmação do resultado.

Referências: Andersson S. and Lundeberg T. Acupuncture from empiricism to science: functional background to acupuncture effects in pain and disease. Med. Hypotheses, 45 (3): $271-281,1995$.

Inove M, Katsumi Y, Itoi M, Hojo T, Nakajima M, Ohashi S, Oi Y, Kitakoji H. Direct current electrical stimulation of acupuncture needles for peripheral nerve regeneration: an exploratory case series. Acupunct Med. 2011 Jun;29(2):88-93. Epub 2011 Feb 28.

\section{DOR 02 \\ HEADACHE COMPLAINTS INCREASE THE RISK FOR TEMPOROMANDIBULAR DISORDER AMONG BRAZILIAN ADOLESCENTS: A POPULATION-BASED STUDY}

Franco AL. DDS. MScl ; Fernandes G. DDS. MSc' ; Gonçalves DAG. DDS. MSc. PhD²; Bonafé FSS. DDS'; Camparis CM. DDS. MSc. PhD²; Ohrbach R. DDS. PhD³

'Post Graduate student; ${ }^{2}$ Professor - Discipline of Occlusion, Temporomandibular Disorders and Orofacial Pain, Department of Dental Materials and Prosthodontics, Faculdade de Odontologia de Araraquara, UNESP- Univ. Estadual Paulista

${ }^{3}$ Associate Professor - Department of Oral Diagnostic Sciences, University at Buffalo, NY

Objective: To verify if headache complaints (HAc) are associated to temporomandibular disorders (TMD) in Brazilian adolescents. Methods: This was a cross-sectional study conducted in a representative population sample from Araraquara, São Paulo,
Brazil. Overall, 24 public schools were visited and 3117 adolescents (12-14 years age) were invited to participate of the study. TMD was assessed and classified according to the Research Diagnostic Criteria for Temporomandibular Disorder (RDC/TMD) Axis I. HAc was investigated based on the question 18 of RDC/TMD Axis II history questionnaire. Chronic TMD pain was considered as pain that has persisted beyond the normal tissue healing time (3 months), as proposed by the International Association for the Study of Pain (IASP). Results: The sample consisted of 1307 individuals (response rate of $41.93 \%), 56.8 \%(n=742)$ women. Overall, 397 (30.4\%) adolescents were diagnosed with TMD and 595 (45.5\%) presented HAc. Comparing to boys, girls showed higher risks for presenting both, TMD and HAc (Relative Risk (RR) = 1.39; 95\% Confidence Interval $(\mathrm{Cl})=1.15-1.67)$, especially those with menarche (1.38; 1.16-1.66). Individuals reporting HAc presented higher risks for TMD (1.88; 1.62 - 2.17). Regarding the presence of pain, HAc increased the risks for painful TMD diagnoses (1.51; 1.40-1.62), higher for combined (muscle and joint) painful TMD (1.24; 1.18-1.31). Also, HAc slightly increased the risk for acute TMD pain (1.09; 1.05-1.14), but HAc elevated the risk in higher magnitude for chronic TMD pain $(1.41 ; 1.32-1.51)$. Conclusion: $\mathrm{HAc}$ increased the risk for TMD in adolescents, especially in girls with menarche. The risk was particular higher for painful and chronic TMD.

Keywords: Facial pain; Temporomandibular joint dysfunction syndrome; Headache; Epidemiology; Adolescents.

References: 1. LeResche L, Mancl LA, Drangsholt MT, Huang G, Von Korff M Preditors of onset of facial pain and temporomandibular disorders in early adolescence. Pain. 2007;129(3)-269-278.

2. Nilsson IM, Drangsholt M, List T. Impact of temporomandibular disorder pain in adolescents: differences by age and gender. J Orofac Pain. 2009;23(2): 1 15-22.

3. Dunn KM, Jordan KP, Mand L, Drangsholt MT, LeResche L. Trajectories of pain in adolescents: a prospective cohort study. Pain. $2011 ; 152: 66-73$.

\section{DOR 03 \\ CORRELAÇÃO ENTRE OSTEOARTROSE E DISCO DESLOCADO DA ARTICULAÇÃO TEMPOROMANDIBULAR: ESTUDO CLÍNICO E IMAGINOLÓGICO}

\section{Bolzan MC'; Witzel $\mathrm{AL}^{2}$; Costa JES ${ }^{3}$; De Luca CEP4; Hara $E^{5}$; Yamashita $\mathrm{H}^{6}$; Lederman $\mathrm{H}^{6}$}

'Professor do Curso de Disfunção Temporomandibular da FUNDECTO USP, Especialista em DTM e DOF

${ }^{2}$ Professora Doutora da Disciplina de Estomatologia Clínica da Universidade de São Paulo, Especialista em DTM e DOF e Especialista em Estomatologia

${ }^{3}$ Aluna de Mestrado do Curso de Diagnóstico Bucal da FOUSP ${ }^{4}$ Aluno de Doutorado do Curso de Diagnóstico Bucal da FOUSP, Especialista em Ortodontia

${ }^{5}$ Aluno de pós-graduação da Universidade de Okayama, Japão ${ }^{6}$ Médico Radiogista da Universidade Federal de São Paulo

Objetivo: Avaliar a correlação entre disco deslocado e osteoartrose na articulação temporomandibular (ATM). Métodos: Foram avaliados 51 pacientes com diagnóstico de disfunção temporomandibular, através da aplicação do RDC, que verificou: ruídos articulares, dores à palpação nos músculos da mastigação e ATM, redução na movimentação da mandíbula. Aos pacientes foi solicitada Ressonância Magnética, a qual foi interpretada para a detecção da presença de disco deslocado, osteoartrose e desvio na forma. Estes achados foram comparados entre si e com dados clínicos; apertamento dental, bruxismo, abertura da boca menor que 40 
$\mathrm{mm}$, diferença da abertura ativa e passiva maior que $5 \mathrm{~mm}$, dor à apalpação no masseter profundo, dor à palpação na cápsula e história de trauma. Resultados: Existe uma forte associação positiva entre osteoartrose (OA) e disco deslocado para ambos os lados da ATM. E no estudo da significância da associação foi detectada uma probabilidade maior da artrose acontecer antes do disco deslocado do que o contrário. $O$ único item clínico que uma associação positiva com a OA foi o bruxismo (ATM D) o outro item que apresentou correlação com o DD foi a redução da abertura da boca menor de $40 \mathrm{~mm}$. Conclusão: a osteoartrose tem alta correlação com o disco deslocado e pode ser a causa do deslocamento, o bruxismo pode levar a osteoartrose e a redução da abertura pode um sinal clínico de disco deslocado.

\section{DOR 04 \\ ABORDAGEM MULTIPROFISSIONAL EM UM CENTRO SECUNDÁRIO DE DOR OROFACIAL}

\author{
Júnior AS; Brandão KV; Camargos HCM; Tomaz LPFN
}

Introdução: Pacientes com disfunções têmporo-mandibulares (DTM) e com cefaleias primárias ainda que adequadamente tratados, muitas vezes não apresentam melhora. Neste sentido parece que a abordagem multiprofissional, com escuta ampliada, pode colaborar para melhor compreensão dos casos a fim de otimizar futuras estratégias terapêuticas. Métodos: Inicialmente é aplicada uma entrevista semiestruturada que investiga semiologicamente o quadro doloroso, bem como a presença de hábitos parafuncionais em pacientes de um centro Odontológico de assistência secundária (AmbDof-CETRO). Posteriormente é realizada a palpação muscular pericraniana e cervical e avaliação neurológica. A última fase é realizada por acadêmicos de medicina, que aplicam de forma supervisionada, por um psicólogo e uma assistente social, o PRACTICE, que é uma ferramenta composta por 07 domínios, que exploram a dinâmica familiar no enfrentamento do problema em foco. As informações são codificadas pela ICPC-2, que permite a classificação das queixas da maneira enunciada, utilizando um sistema biaxial compreendendo sistemas orgânicos, psicológicos e sociais no primeiro eixo e as características do relato no segundo. Resultados: Foram atendidos 78 pacientes, sendo 59 (75,6\%) do sexo feminino. A disfunção têmporo-mandibular (DTM) foi a causa mais frequente de dor orofacial, principalmente a dor miofascial $(70,5 \%)$ e a capsulite/sinovite $(42,3 \%)$ da articulação têmporomandibular. Por outro lado, as cefaleias primárias também estiveram presentes em boa parte dos casos, cefaleia do tipo tensional em $46,1 \%$ e a migrânea em $25,6 \%$ das pessoas avaliadas. Destes, 17 passaram pela avaliação biopsicossocial e conforme a codificação pela ICPC-2 encontrou-se principalmente problemas do Eixo P (psicológicos) e Z (sociais). Conclusão: As DTM e cefaleias primárias estiveram presentes, de maneira comórbida, na maior parte dos casos. O PRACTICE e o ICPC-2 mostraram que eventos traumáticos psíquicos e físicos, estresse no trabalho e fragilidade sociofamiliar são aspectos inegavelmente importantes na abordagem dos pacientes, sendo, portanto, abordagem multiprofissional algo essencial nos quadros de dor orofacial.

Referência: 1. http://www.iasp-pain.org/Content/NavigationMenu/General ResourceLinks/PainDefinitions/default.html

\section{DOR 05}

\section{USO DA TOXINA BOTULÍNICA NA DTM E DOR OROFACIAL}

\author{
Rocha EE'; Matos RVL'; Fernandes RSM² \\ 'Especialista em Disfunção Temporomandibular e \\ Dor Orofacial pela FOR. \\ ${ }^{2}$ Doutorado em Reabilitação Oral pela FORP-USP, \\ Professora Adjunto da UFPE
}

A articulação temporomandibular (ATM), pelas suas peliculiaridades, é sede frequente de manifestações que cada vez solicitam mais atenção. A disfunção de qualquer um de seus elementos pode desorganizar todo o sistema estomatognático e desencadear os mais diversos quadros patológicos. As desordens temporomandibulares (DTM) constituem um grupo heterogêneo de condições, que envolvem a ATM e tecidos contíguos (músculos da mastigação e estruturas associadas). Pacientes com DTM podem apresentar, como principal sintoma, dor miofascial associada com função mandibular alterada. Pode apresentar sintomas como dor na cabeça, otalgia, zumbido ou mesmo dor de dente. Um tratamento definitivo para a DTM está sendo procurado, mas há dificuldades, já que não se tem o conhecimento exato de sua fisiopatologia. Alguns métodos terapêuticos são utilizados para eliminar a dor em pacientes com disfunção da ATM. Relaxantes musculares, placas oclusais, ajustes oclusais, fisioterapia, são alguns dos métodos de tratamento. Muitas vezes eles não surtem o efeito desejado. Diante deste contexto iniciou-se o uso da toxina botulínica com o intuito de ampliar as possibilidades terapêuticas na DTM, principalmente nos casos resistentes aos tratamentos convencionais. Neste estudo foi feito uma revisão sistemática sobre o emprego da toxina botulínica tipo $A$ nas DTM. O uso desta terapia é fundamentado na teoria de que a contração excessiva de um músculo é responsável pela origem da dor e da disfunção. Poucos estudos foram encontrados, a maioria com metodologia deficiente e número de pacientes reduzidos. Os estudos reportam uma diminuição da atividade e da força muscular promovendo o relaxamento e consequentemente a melhora do quadro álgico. Apesar dos estudos mostrarem resultados promissores, ela não é a primeira escolha de tratamento por não ser uma terapia definitiva e por ter seu custo elevado e necessitando de mais estudos; ela deve ser considerada, nas dores crônicas e hipertrofia muscular.

\section{DOR 06 \\ SLEEP BRUXISM, PAINFUL TEMPOROMANDIBULAR DISORDERS, AND SELF REPORTED HEADACHE IN A SAMPLE POPULATION OF ADOLESCENTS}
Fernandes G. DDS, MSc ${ }^{* 1}$; Franco AL. DDS, $\mathrm{MSc}^{7}$; Bonafé FSS. DDS'; Gonçalves DAG. DDS, PhD²; Camparis CM. DDS, $\mathrm{PhD}^{3}$

'Graduated Student; (2 Assistant Professor;

${ }^{3}$ Associated Professor, Araraquara Dental School, UNESP

Univ. Estadual Paulista, Department of Dental Materials and Prosthodontics, Araraquara, São Paulo, Brazil

Objective: To investigate the association among sleep bruxism (SB), painful temporomandibular disorders (TMD), and self reported headache in a representative population sample of adolescents aged $11-16$ years matriculated in public schools. Methods: The Research Diagnostic Criteria for Temporomandibular Disorders ${ }^{1}$, Portuguese 
version, ${ }^{2}$ were used to classify TMD. SB was diagnosed by clinical criteria proposed by American Academy of Sleep Medicine ${ }^{3}$ and the self reported headache, referring to the last six months, was obtained during the initial interview with the adolescents. Results: The sample consisted of 1122 adolescents (508 boys and 614 girl), with average of 12.7 years. Was found association among $S B$, painful TMD and self reported headache $(p<0.0001)$. The SB increased the risk for painful TMD (Odds Ratio $=2.5 ; 95 \%$ confidence interval=1.91-3.39). Similarly, painful TMD and SB increased the risk for self reported headache. The magnitude of association was higher for painful TMD $(5.1 ; 3.76-6.83)$, followed by SB $(1.7 ; 1.30-2.21)$. When the sample was stratified by the presence of SB and painful TMD, the presence of SB only did not increase the risk for self reported headache. The association between TMD and SB had significantly increased the risk for self reported headache (7.8; 4.81-12.62), followed by painful TMD only (4.2; 2.89-6.01). Conclusion:The association among SB and painful TMD greatly increased the risk for headaches in adolescents.

References: 1. Dworkin SF, LeResche L. Research Diagnostic criteria for temporomandibular disorders: review, criteria, examinations and specifications, critique. J Craniomand Disord. 1992:6:301-55.

2. Pereira Júnior FJ, Favilla EE, Dworkin S, et al. Critérios de diagnóstico para pesquisa das disfunções temporomandibulares (RDC/TMD). Tradução oficial para a língua portuguesa. J Bras Clin Odontol Integr. 2004; 8:384-95.

3. American Academy of Sleep Medicine. Sleep Related Movement Disorders. In: Sateia $\mathrm{MJ}$, ed. International classification of sleep disorders: diagnostic and coding manual. 2nd ed. Westchester, Illinois: American Academy of Sleep Medicine; 2005: 189-91.

\section{DOR 07 \\ SEVERIDADE DA DISFUNÇÃO TEMPOROMANDIBULAR EM RELAÇÃO AO GÊNERO: ESTUDO CLÍNICO E IMAGINOLÓGICO}

\section{Costa JES'; De Luca CEP²; Nunes TB?3 ; Di Matteo RC ${ }^{4}$; Campana $A C R^{5}$; Nunes $A B^{1}$; Witzel $A L^{6}$}

'Aluna(o) de Mestrado do Curso de Diagnóstico Bucal da FOUSP

${ }^{2}$ Aluno de Doutorado do Curso de Diagnóstico Bucal da FOUSP, Especialista em Ortodontia

${ }^{3}$ Aluna de Mestrado do Curso de Patologia e Estomatologia Básica e Aplicada da FOUSP

${ }^{4}$ Aluna de Doutorado do Curso de Diagnóstico Bucal da FOUSP, Especialista em Ortodontia e em Implantodontia.

${ }^{5}$ Ana Cristina Rodrigues Campana, Aluna de Mestrado do Curso de Patologia e Estomatologia Básica e Aplicada da FOUSP, Habilitada em Acupuntura

6Professora Doutora da Disciplina de Estomatologia Clínica da Universidade de São Paulo, Especialista em DTM e DOF e Especialista em Estomatologia

Objetivo: Avaliação das características clínicas e imaginológicas da Disfunção temporomandibular em relação ao gênero. Métodos: As variáveis clínicas observadas em 87 pacientes foram: idade, queixa principal, dor à palpação e presença de hábitos parafuncionais. A posição do disco articular (DA) observado por ressonância magnética (RM) foi dividida em: disco deslocado unilateral (DDU), bilateral sem redução (DDB), bilateral com redução unilateral (DDBU) e bilateral com redução bilateral (DDBB). A associação entre as variáveis clínicas e imagenológicas foi verificada por análise de variância e teste de Bonferroni para as numéricas, e pelos testes qui-quadrado ou exato de Fisher para o restante $(p<0,05)$. Resultados: Do total de pacientes examinados $80,5 \%$
(70/87) pertencem ao gênero feminino e 19,5\% (17/87) pertencem ao masculino. Estatisticamente a média da idade das mulheres foi menor que a média da idade dos homens $(p=0,0027)$. Os grupos DBSR, DRU, e DRB são formados proporcionalmente por mais mulheres do que os grupos DN e DU $(p=0,001)$. A dor a palpação foi maior para as mulheres, tanto para os músculos quanto para a articulação $(p=0,001)$. $\bigcirc$ hábito parafuncional esteve presente igualmente nos dois gêneros. Conclusão: A severidade da disfunção temporomandibular se apresentou maior entre as mulheres dentro do grupo de pacientes.

\section{DOR 08 \\ DOR MIOFASCIAL - SUA IMPORTÂNCIA NO DIAGNÓSTICO E CONTROLE EM INDIVÍDUOS COM CEFALEIAS}

von-Zuben JA

A Dor Miofascial (DMF) classifica-se entre as Dores Musculares Crônicas, onde encontramos os chamados "pontos gatilhos" capazes de referir dores na região orofacial a partir de um ou mais músculos envolvidos. ADMF, pode acometer um ou mais músculos posturais e funcionais do segmento cérvico-cranial-facial, e acompanha sintomas de dores de cabeça, limitação de movimentos, má postura, alteração de padrão de sono, irritabilidade pelo componente crônico envolvido, via SNC. Postula-se que seria decorrente de sensibilização do neurônio motor, resultando em disparos ectópicos de dores referidas. Muitas das dores de cabeça podem ser mantidas e ou originadas de pontos gatilhos. Uma vez diagnostica, através da palpação clinica, deve-se de imediato iniciar seu controle. Incluindo orientações de postura, esforços musculares, apertamento dental diurno, alterações nos padrões de sono, e hábitos parafuncionais. Pode-se controlar a DMF através de manobras de bloqueio anestésico periférico sem vaso-constritor, ice-spray de congelamento do ponto na superfície do músculo, alongamentos e massoterapia por deslizamento miofascial. Alguns autores sugerem uso de relaxantes musculares, anti-inflamatórios não esteroidais e outras drogas para compor uma estratégia geral no controle destes pontos gatilhos ativos. Por conta disto, a possibilidade de controlar e ou minimizar sintomas importantes dos indivíduos que sofrem de dores de cabeça, e devolvendo qualidade de vida a estes individuos.

Bibliografia: 1. Okeson JP. Dor orofacial - guia para avaliação, diagnóstico e tratamento. $1^{a}$ ed. São Paulo: Quitenssence Editora; 1998.

2. Okeson JP. Tratamento das desordens temporomandibulares e oclusão. São Paulo: Artes Médicas; 2000.

3. Siqueira JTT. Disfunção temporomandibular: classificação e abordagem clínica. In: Siqueira JTT, Teixeira MJ. Dor orofacial: diagnóstico, terapêutica e qualidade de vida. $1^{a}$ ed. Curitiba: Editora Maio; 2001.

4. Simmons D. Travell \& Simon's myofascial pain and dysfunction: the trigger point manual. Baltimore: Williams and Wilkins, 1999.

\section{DOR 09 \\ MANAGEMENT OF TMD SIGNS AND SYMPTOMS DURING THE USE OF OA FOR THE TREATMENT OF OSA - 2 YEARS FOLLOW-UP}

\author{
Giannasi $L C^{(1)}$; von-Zuben JA(2); Oliveira LVF(1)
}

Objective: The main propousal that is to show a straight relationship between TMD and Mandibular repositioning appliance (MRA); using just one clinical subject that refers TMJ pain and limited jaw opening. Methods: This study reports on the case of 
an occlusal splint (OS) used to relief the temporomandibular joint (TMJ)/masticatory muscles pain and close lock caused due to the mandibular repositioning appliance (MRA) for the treatment of obstructive sleep apnea (OSA). The treatment with OS lasted 105 days, and the patient could continue the OSA treatment. The TMJ became stable, without pain or locking, and the AHI reduced from 16.0 to 0.6 after six months, and both, OSA and TMD signs and symptoms remained controlled after 2 years. Conclusion: We conclude that it is possible to contour these intercurrent, which not happen frequently, allowing the patient to finish the OSA treatment.

\begin{tabular}{|c|c|c|c|}
\hline PSG parameters & Baseline & 6 months & 2 years \\
\hline $\mathrm{AHI}$ & 16.0 & 0.4 & 1.0 \\
\hline $\mathrm{SaO}_{2}$ nadir (\%) & 87.0 & 90.5 & 90.0 \\
\hline NREM1 $(\%)$ & 10.0 & 6.0 & 5.5 \\
\hline NREM2 (\%) & 69.1 & 55.0 & 57.0 \\
\hline NREM3 (\%) & 12.5 & 18.5 & 17.2 \\
\hline REM (\%) & 18.4 & 20.5 & 20.3 \\
\hline Sleep Efficiency (\%) & 81.3 & 89.1 & 90.0 \\
\hline
\end{tabular}

Definition of abbreviations: $\mathrm{AHI}$ : apnea/hypopnea index; $\mathrm{SaO}_{2}$ nadir: minimal oxyhemoglobin desaturation; NREM1: sleep stage 1; NREM2: sleep stage 2; NREM3: sleep stage 3; OA: oral appliance; PSG: polysomnogram; REM: rapid eye movement sleep stage

References: 1. Giannasi LC, Magini M, Costa MS, Oliveira CS, Oliveira JC, Bussadori SK, Oliveira LVF. Systematic assessment of the impact of oral appliance therapy on the temporomandibular joint during treatment of obstructive sleep apnea: long-term evaluation. Sleep Breath 2009; 13:375-381.

2. Almeida FR, Bitencourt LR, Almeida CI, Tsuiki S, Lowe AA, Tufik S. Effects on mandibular posture on obstructive sleep apnea severity and the temporomandibular joint in patients fitted with an oral appliance. Sleep 2002; 25:507-13

3. Almeida RF, Lowe AA, Sung JO, Tsuik S, Otsuka R. Long-term sequellae of oral appliance therapy in obstructive sleep apnea patients: Part 1. Cephalometric analysis. Am J Orthod Dentofacial Orthop 2006; 129: 195-204

4. Giannasi LC, Hirata RP, Politti F, Nacif SR, Leitão-Filho FS, Oliveira LVF. A novel protocol for occlusal splint adjustment to treat TMD in sleep bruxism. Fisioter. Mov 2012; 25:175-181.

\section{DOR 10 \\ ANÁLISE ELETROMIOGRÁFICA DO MÚSCULO MASSETER EM ISOMETRIA}

\section{Fonseca BF; Carvalho Júnior NR; Pinto MVM; Santos-Filho SD}

Objetivos: Analisar e medir bilateralmente a ação do músculo masseter em situação de isometria, nas três classes oclusais (classe I, classe II e classe III de Angle) através de análise eletromiográfica em um grupo de 31 universitários. Métodos: Estudo do tipo descritivo, com nível de significância de 95\% ( $<<0.05)$, realizado em uma amostra inicial composta por 100 universitários, que tiveram suas chaves oclusais submetidas a exame clínico oral. Posteriormente, foram selecionados, aleatoriamente, 31 universitários apresentando idade entre 18 e 27 anos; sendo 14 com classe I, 06 com classe II e 11 com classe III. Por último, todos os 31 universitários foram submetidos à análise eletromiográfica. Em relação ao gênero, foram 18 do sexo feminino e 13 do sexo masculino. $O$ registro da atividade elétrica foi feito bilateralmente no músculo masseter, sendo utilizados dois pares de eletrodos bipolares, um de cada lado. A situação analisada, em cada universitário, acompanhou a seguinte orientação: posição de apertamento dentário (isometria). Os universitários foram instruídos a apertarem bem os dentes, durante 30 segundos, sendo capturados os sinais eletromiográficos, do lado direito e esquerdo. Os dados obtidos da atividade eletromiográfica dos músculos masseteres foram submetidos à análise estatística, utilizando o teste de Mann-Whitney. Resultados: $\bigcirc$ músculo masseter, de ambos os lados, em contração isométrica, ou seja, máxima intercuspidação na classe III, entre as três classes estudadas, apresentou maior atividade do que no grupo das demais classes oclusais. Conclusão: $\bigcirc$ estudo demonstra que no apertamento máximo a musculatura que foi analisada recebe influência das classes oclusais.

\section{DOR 11 ASSOCIAÇÃO ENTRE DEPRESSÃO E DISFUNÇÃO TEMPOROMANDIBULAR}

\section{Carvalho Júnior NR; Fonseca BF; Pinto MVM; Santos Filho SD}

Objetivos: Verificar a presença e o grau de associação entre a ocorrência de depressão e disfunção temporomandibular (DTM). Métodos: Oitenta e cinco universitários - 56 mulheres e 29 homens - do Curso de Farmácia foram selecionados aleatoriamente, por meio de amostra estratificada proporcional. Os universitários foram divididos em grupos (período do curso) e subdivididos por extrato (turma); depois foi empregada a amostra aleatória simples, utilizando tabela de números aleatórios, em cada extrato. Após a seleção, um questionário para triagem de DTM (Research Diagnostic Criteria for Temporomandibular Disorders RDC-TMD), foi empregado sem a colaboração do examinador, de modo que não se criasse uma possibilidade de interferência nos resultados do exame a ser realizado. Posteriormente, foi realizado o exame clínico do RDC-TMD, específico para diagnóstico de DTM; durante essa etapa, foi solicitado, de alguns universitários, uma radiografia panorâmica das arcadas superior e inferior, em posição de boca aberta, para auxiliar no diagnóstico de um eventual quadro infeccioso crônico ou subagudo de origem dental, bem como para afastar a hipótese da presença de cistos ou neoplasias. Os universitários que apresentassem alguns desses achados positivos seriam excluídos do projeto de pesquisa. Os universitários foram divididos em dois grupos: Sem DTM (controle) e Com DTM. A presença e o grau de associação entre a ocorrência de depressão e DTM foram testadas através do teste Quiquadrado $\left(\chi^{2}\right)$ e do coeficiente de Yule $(Y)$. Resultados: Encontram-se discriminados na Tabela 1. Conclusão: Apesar da conhecida associação entre fatores psicológicos e DTM, não houve associação significativa $(p>0,05)$, no presente estudo, entre depressão e DTM.

\begin{tabular}{lccc}
\multicolumn{4}{l}{ Tabela 1 - Associação entre depressão e DTM } \\
\hline & Total & Sem DTM & Com DTM \\
\hline Sem depressão & 43 & 24 & 19 \\
Com depressão & 41 & 16 & 25 \\
p-valor & & & $>0,05^{\text {ns }}$ \\
p-valor ${ }^{\star}$ & & & - \\
\hline Total ${ }^{\ddagger}$ & 84 & 40 & 44
\end{tabular}

DTM: Disfunção Temporomandibular

* Teste Qui-quadrado; Grau de Liberdade - gl=1; ns=Não significativa

† Coeficiente de Yule

¥Não foi possível classificar um dos participantes quanto à presença ou não da depressão 


\section{DOR 12 \\ ASSOCIAÇÃO ENTRE DEPRESSÃO E DOR MIOFASCIAL DOS MÚSCULOS MASTIGATÓRIOS}

\author{
Carvalho Júnior NR; Fonseca BF; Pinto MVM; Santos Filho SD
}

Objetivos: Verificar a presença e o grau de associação entre a ocorrência de depressão e dor miofascial dos músculos mastigatórios (DMF). Métodos: Oitenta e cinco universitários 56 mulheres e 29 homens - do Curso de Farmácia foram selecionados aleatoriamente, por meio de amostra estratificada proporcional. Os universitários foram divididos em grupos (período do curso) e subdivididos por extrato (turma); depois foi empregada a amostra aleatória simples, utilizando tabela de números aleatórios, em cada extrato. Após a seleção, um questionário para triagem de disfunção temporomandibular - DTM (Research Diagnostic Criteria for Temporomandibular Disorders - RDC-TMD), foi empregado sem a colaboração do examinador, de modo que não se criasse uma possibilidade de interferência nos resultados do exame a ser realizado. Posteriormente, foi realizado o exame clínico do RDC-TMD, específico para diagnóstico de DTM; durante essa etapa, foi solicitado, de alguns universitários, uma radiografia panorâmica das arcadas superior e inferior, em posição de boca aberta, para auxiliar no diagnóstico de um eventual quadro infeccioso crônico ou subagudo de origem dental, bem como para afastar a hipótese da presença de cistos ou neoplasias. Os universitários que apresentassem alguns desses achados positivos seriam excluídos do projeto de pesquisa. Os universitários foram divididos em dois grupos: Sem DTM (controle) e Com DMF. A presença e o grau de associação entre a ocorrência de depressão e DMF foram testadas através do teste Qui-quadrado $\left(\chi^{2}\right)$ e do coeficiente de Yule $(Y)$. Resultados: Encontram-se discriminados na Tabela 1.

Tabela 1. Associação entre depressão e DMF

\begin{tabular}{lccc}
\hline & Total & Sem DTM & Com DTM \\
\hline Sem depressão & 37 & 24 & 13 \\
Com depressão & 36 & 16 & 20 \\
p-valor & & & $>0,05^{\text {ns }}$ \\
p-valor $†$ & & & - \\
\hline Total & 73 & 40 & 33
\end{tabular}

DTM: Disfunção Temporomandibular

DMF: Dor Miofascial dos Músculos Mastigatórios

* Teste Qui-quadrado; Grau de Liberdade - gl=1; ns=Não significativa

†Coeficiente de Yule

Conclusões: Apesar da conhecida associação entre fatores psicológicos e DMF, não houve associação significativa ( $p>0,05)$, no presente estudo, entre depressão e DMF. Embora não estatisticamente significativa, o estudo mostra uma grande associação entre depressão e o grupo "Com DMF" $\left(\chi^{2}=3,44\right)$.

\section{DOR 13 \\ HÁBITOS PARAFUNCIONAIS E DISFUNÇÃO TEMPOROMANDIBULAR}

Carvalho Júnior NR; Fonseca BF; Pinto MVM; Santos Filho SD

Objetivos: Verificar a presença e o grau de associação entre a ocorrência de hábitos parafuncionais e disfunção temporomandibular (DTM). Métodos: Oitenta e cinco universitários - 56 mulheres e 29 homens - do Curso de Farmácia foram selecionados aleatoriamente, por meio de amostra estratificada proporcional. Os universitários foram divididos em grupos (período do curso) e subdivididos por extrato (turma); depois foi empregada a amostra aleatória simples, utilizando tabela de números aleatórios, em cada extrato. Após a seleção, um questionário para triagem de DTM (Research Diagnostic Criteria for Temporomandibular Disorders - RDC-TMD), foi empregado sem a colaboração do examinador, de modo que não se criasse uma possibilidade de interferência nos resultados do exame a ser realizado. Posteriormente, foi realizado o exame clínico do RDC-TMD, específico para diagnóstico de DTM; durante essa etapa, foi solicitado, de alguns universitários, uma radiografia panorâmica das arcadas superior e inferior, em posição de boca aberta, para auxiliar no diagnóstico de um eventual quadro infeccioso crônico ou subagudo de origem dental, bem como para afastar a hipótese da presença de cistos ou neoplasias. Os universitários que apresentassem alguns desses achados positivos seriam excluídos do projeto de pesquisa. Os universitários foram divididos em dois grupos: Sem DTM (controle) e Com DTM. A presença e o grau de associação entre a ocorrência de hábitos parafuncionais e DTM foram testadas através do teste Qui-quadrado $\left(\chi^{2}\right)$ e do coeficiente de Yule (Y). Resultados: Encontram-se discriminados na Tabela 1.

Tabela 1 - Associação entre hábitos parafuncionais e DTM

\begin{tabular}{lccc}
\hline & Total & Sem DTM & Com DTM \\
\hline Sem hábitos parafuncionais & 48 & 29 & 19 \\
Com hábitos parafuncionais & 37 & 11 & 26 \\
p-valor* & & & $<0,005$ \\
p-valor ${ }^{\star} \square$ & & 40 & Y $=0,56$ \\
\hline Total & 85 & 45 \\
\hline
\end{tabular}

DTM: Disfunção Temporomandibular

* Teste Qui-quadrado; Grau de Liberdade - $\mathrm{gl}=1$

†Coeficiente de Yule

Conclusões: Houve associação significativa entre hábitos parafuncionais e DTM ( $p<0,005)$, com grau de associação moderado e positivo $(Y=0,56)$.

\section{DOR 14 \\ HÁBITOS PARAFUNCIONAIS E DOR MIOFASCIAL DOS MÚSCULOS MASTIGATÓRIOS}

\author{
Carvalho Júnior NR; Fonseca BF; Pinto MVM; \\ Santos Filho SD
}

Objetivos: Verificar a presença e o grau de associação entre a ocorrência de hábitos parafuncionais e dor miofascial dos músculos mastigatórios (DMF). Métodos: Oitenta e cinco universitários - 56 mulheres e 29 homens - do Curso de Farmácia foram selecionados aleatoriamente, por meio de amostra estratificada proporcional. Os universitários foram divididos em grupos (período do curso) e subdivididos por extrato (turma); depois foi empregada a amostra aleatória simples, utilizando tabela de números aleatórios, em cada extrato. Após a seleção, um questionário para triagem de Disfunção Temporomandibular - DTM (Research Diagnostic Criteria for Temporomandibular Disorders - RDC-TMD), foi empregado sem a colaboração do examinador, de modo que não se criasse uma possibilidade de interferência nos resultados do exame a ser realizado. Posteriormente, foi realizado o exame clínico do RDC-TMD, específico para diagnóstico de DTM; durante essa eta- 
pa, foi solicitado, de alguns universitários, uma radiografia panorâmica das arcadas superior e inferior, em posição de boca aberta, para auxiliar no diagnóstico de um eventual quadro infeccioso crônico ou subagudo de origem dental, bem como para afastar a hipótese da presença de cistos ou neoplasias. Os universitários que apresentassem alguns desses achados positivos seriam excluídos do projeto de pesquisa. Os universitários foram divididos em dois grupos: Sem DTM (controle) e Com DMF. A presença e o grau de associação entre a ocorrência de hábitos parafuncionais e DMF foram testadas através do teste Qui-quadrado $\left(\chi^{2}\right)$ e do coeficiente de Yule $(Y)$. Resultados: Encontram-se discriminados na Tabela 1.

Tabela 1 - Associação entre hábitos parafuncionais e DMF

\begin{tabular}{lccc}
\hline & Total & Sem DTM & Com DTM \\
\hline Sem hábitos parafuncionais & 40 & 29 & 11 \\
Com hábitos parafuncionais & 34 & 11 & 23 \\
p-valor* & & & $<0,001$ \\
p-valor ${ }^{\dagger}$ & & 40 & Y $=0,69$ \\
\hline Total & 74 & 44
\end{tabular}

DTM: Disfunção Temporomandibular

DMF: Dor Miofascial dos Músculos Mastigatórios

* Teste Qui-quadrado; Grau de Liberdade - gl=1

†Coeficiente de Yule

Conclusões: Houve associação significativa entre hábitos parafuncionais e DMF ( $p<0,001)$, com grau de associação moderado e positivo $(Y=0,69)$.

\section{DOR 15 \\ PREVALÊNCIA DA DISFUNÇÃO TEMPOROMANDIBULAR}

\section{Carvalho Júnior NR; Fonseca BF; Pinto MVM; Santos Filho SD}

Objetivos: Determinar a prevalência da disfunção temporomandibular (DTM) e sua proporção por gênero. Métodos: Oitenta e cinco universitários - 56 mulheres e 29 homens - do Curso de Farmácia foram selecionados aleatoriamente, por meio de amostra estratificada proporcional. Os universitários foram divididos em grupos (período do curso) e subdivididos por extrato (turma); depois foi empregada a amostra aleatória simples, utilizando tabela de números aleatórios, em cada extrato. Após a seleção, um questionário para triagem de DTM (Research Diagnostic Criteria for Temporomandibular Disorders - RDC-TMD), foi empregado sem a colaboração do examinador, de modo que não se criasse uma possibilidade de interferência nos resultados do exame a ser realizado. Posteriormente, foi realizado o exame clínico do RDC-TMD, específico para diagnóstico de DTM; durante essa etapa, foi solicitado, de alguns universitários, uma radiografia panorâmica das arcadas superior e inferior, em posição de boca aberta, para auxiliar no diagnóstico de um eventual quadro infeccioso crônico ou subagudo de origem dental, bem como para afastar a hipótese da presença de cistos ou neoplasias. Os universitários que apresentassem alguns desses achados positivos seriam excluídos do projeto de pesquisa. Os universitários foram divididos em dois grupos: Sem DTM (controle) e Com DTM. A prevalência da DTM foi calculada em frequência percentual e sua proporção por gênero através do teste Qui-quadrado $\left(\chi^{2}\right)$. Resultados: Encontram-se discriminados nas Tabelas 1 e 2.
Tabela 1 - Prevalência da DTM na amostra

\begin{tabular}{lccc}
\hline & Amostra & Sem DTM & Com DTM \\
\hline Frequência & 85 & 40 & 45 \\
Proporção* & $100 \%$ & $47 \%$ & $53 \%$ \\
\hline DTM: Disfunção Temporomandibular & &
\end{tabular}

DTM: Disfunção Temporomandibular

* Percentual na amostra total

\begin{tabular}{|c|c|c|c|}
\hline & Amostra & Sem DTM & Com DTM \\
\hline Mulheres & 56 & 22 & 34 \\
\hline Homens & 29 & 18 & 11 \\
\hline p-valor ${ }^{*} \square$ & & & $<0,05$ \\
\hline Total & 85 & 40 & 45 \\
\hline
\end{tabular}

DTM: Disfunção Temporomandibular

* Teste Qui-quadrado; Grau de Liberdade - gl=1

Conclusões: Os resultados indicam uma prevalência de 53\% para DTM e uma maior predisposição do gênero feminino para desenvolver DTM $(p<0,05)$. No grupo "Sem DTM" a proporção entre mulheres e homens foi de 1,22:1 e no grupo "Com DTM" essa proporção subiu para, aproximadamente, 3:1.

\section{DOR 16 \\ PREVALÊNCIA DA DOR MIOFASCIAL DOS MÚSCULOS MASTIGATÓRIOS}

\author{
Carvalho Júnior NR; Fonseca BF; Pinto MVM; \\ Santos Filho SD
}

Objetivos: Determinar a prevalência da dor miofascial dos músculos mastigatórios (DMF) e sua proporção por gênero. Métodos: Oitenta e cinco universitários - 56 mulheres e 29 homens - do Curso de Farmácia foram selecionados aleatoriamente, por meio de amostra estratificada proporcional. Os universitários foram divididos em grupos (período do curso) e subdivididos por extrato (turma); depois foi empregada a amostra aleatória simples, utilizando tabela de números aleatórios, em cada extrato. Após a seleção, um questionário para triagem de Disfunção Temporomandibular - DTM (Research Diagnostic Criteria for Temporomandibular Disorders - RDC-TMD), foi empregado sem a colaboração do examinador, de modo que não se criasse uma possibilidade de interferência nos resultados do exame a ser realizado. Posteriormente, foi realizado o exame clínico do RDC-TMD, específico para diagnóstico de DTM; durante essa etapa, foi solicitado, de alguns universitários, uma radiografia panorâmica das arcadas superior e inferior, em posição de boca aberta, para auxiliar no diagnóstico de um eventual quadro infeccioso crônico ou subagudo de origem dental, bem como para afastar a hipótese da presença de cistos ou neoplasias. Os universitários que apresentassem alguns desses achados positivos seriam excluídos do projeto de pesquisa. Os universitários foram divididos em três grupos: Sem DTM (controle), Com DTM e Com DMF. A prevalência da DMF foi calculada em frequência percentual e sua proporção por gênero através do teste Qui-quadrado $\left(\chi^{2}\right)$. Resultados: Encontram-se discriminados nas Tabelas 1 e 2 . Conclusões: Os resultados indicam uma prevalência de $40 \%$ de DMF na amostra total e de 75,56\% na amostra de universitários com DTM. Indicam também uma maior predisposição do gênero feminino para desenvolver DMF ( $p<0,05)$; no grupo "Sem DTM" a proporção entre mulheres e homens foi de 1,22:1 e no grupo "Com DMF" essa proporção subiu para, aproximadamente, 4:1. 
Tabela 1 - Prevalência da DMF na amostra

\begin{tabular}{llcll}
\hline & Total & Sem DTM & Com DTM & Com DMF \\
\hline Frequência & 85 & 40 & 45 & 34 \\
Proporção* $^{*}$ & $100 \%$ & $47 \%$ & $53 \%$ & $40 \%^{*}$ \\
Proporção $^{\dagger}$ & & & $100 \%^{\dagger}$ & $75,56 \%{ }^{\dagger}$
\end{tabular}

DTM: Disfunção Temporomandibular

DMF: Dor Miofascial dos Músculos Mastigatórios

* Percentual na amostra total

† Percentual levando-se em conta apenas o número de universitários com DTM

Tabela 2 - Proporção da DMF por gênero

\begin{tabular}{lcccc}
\hline & Amostra & Sem DTM & Com DTM & Com DMF \\
\hline Mulheres & 56 & 22 & 34 & 27 \\
Homens & 29 & 18 & 11 & 7 \\
p-valor & & & & $<0,05^{\star}$ \\
\hline Total & 85 & 40 & 45 & 34 \\
\hline
\end{tabular}

DTM: Disfunção Temporomandibular

DMF: Dor Miofascial dos Músculos Mastigatórios

* Teste Qui-quadrado; Grau de Liberdade - gl=1

\section{DOR 17 \\ ASSOCIAÇÃO ENTRE CEFALEIA SECUNDÁRIA RELACIONADA ÀS DISFUNÇÕES TEMPOROMANDIBULARES E ALTERAÇÕES POSTURAIS DA CABEÇA}

Lima RCA; Silva PMF; Soares VBRB; Soares CBRB; Vasconcelos FMN; Silva TAB; Nery MW; Costa CNB; Silva DWB; Valença MM; Ximenes RCC; Oliveira DA; Couto GBL

Objetivo: Avaliar a associação entre cefaleia secundária, disfunções temporomandibulares e alterações posturais da cabeça. Método: Foi realizado um estudo do tipo corte transversal, com 100 alunos (50 meninas) com idade de 10 a 19 anos, estudantes da rede pública estadual de ensino. Para avaliação das alterações posturais foi utilizado o Sistema Fisiometer de Avaliação, Software Biométrico de Avaliação Postural, Posturograma 3.0. Foi realizado o registro fotográfico, com o paciente na postura de pé (frontal, de costas e perfil direito), através uma máquina Câmera Digital Sony W330 - 14.1 megapixels - zoom 4x, posicionada a uma altura de um metro, a uma distância de dois metros do paciente. Os adolescentes foram submentidos a um exame clínico odontológico. Para identificação dos sintomas de desordens tempomandibulares foi utilizado o RDC/TMD "Research Diagnostic Criteria for Temporomandibular Disorders". Para classificar a cefaleia primária foram utilizados os critérios estabelecidos pela Sociedade Internacional de Cefaleia (ICHD-II). Resultados: $80 \%$ dos adolescentes apresentaram alteração na cabeça. $46 \%$ deles foram classificados com DTM e os tipos de DTM mais frequentes com diagnóstico foram: RDC/TMD - Eixo I - grupo III - ATM direita (27\%), RDC/TMD - Eixo I - grupo III - ATM direita (26\%), RDC/TMD - Eixo I - grupo II - ATM direita (12\%) e RDC/TMD - Eixo I - grupo II - ATM esquerda $(10,0 \%)$. Dos que tinham alteração as maiores frequências corresponderam aos que tinham osteoartrose direita e osteoartrose esquerda com $25 \%$ e $24 \%$ respectivamente. Cefaleia foi mais frequente nas meninas (54\%), a faixa etária mais acometida foi entre 15 e 19 anos $(51,2 \%)$ e entre os adolescentes com alteração postural da cabeça (50\%). Conclusão: Neste estudo não ficou comprovada à associação entre cefaleia secundária, sintomas de DTM e alteração postural da cabeça.

\section{DOR 18 \\ FREQUÊNCIA DA CEFALEIA EM ADOLESCENTES COM BRUXISMO EXCÊNTRICO}

Borges ÉA; Lima RCA; Santos MRP; Silva PMF; Vasconcelos FMN; Oliveira DA; Ximenes RCC; Siqueira N

Objetivo: Investigar e determinar se há relação significativa entre o bruxismo e a cefaleia nos adolescentes (10 a 19 anos - OMS). Metodologia: A amostra foi composta por 136 adolescentes com idade entre 10 e 17 anos. Para classificar a cefaleia primária foram utilizados os critérios estabelecidos pela Sociedade Internacional de Cefaleia (ICHD-II). Para detecção do bruxismo excêntrico foi realizada uma anamnese e exames clínicos intraoral (inspeção) e extraoral (palpação). Resultados: $\bigcirc$ sexo feminino foi predominante na amostra (66,2\%). 94,9\% dos adolescentes referiram ter cefaleia nos últimos seis meses e a presença de bruxismo foi de $23,5 \%$. O percentual de cefaleia foi 1,0\% mais elevado entre os pesquisados da faixa de 10 a 12 anos e foi $5,4 \%$ mais elevado no sexo feminino do que no masculino $(96,7 \%$ vs. $91,3 \%)$. Verificou-se associação significativa entre bruxismo e a variável sexo ( $p<0,05$, razão de prevalência do sexo feminino em relação ao masculino foi igual a 2,21, entretanto com intervalo que inclui o valor 1,00 ) sendo a prevalência de bruxismo mais elevada no sexo feminino do que no sexo masculino (28,9\% vs. $13,0 \%$ ). Não se comprovou associação significativa entre bruxismo e a variável faixa etária $(p>0,05)$. $\bigcirc$ estudo da associação entre bruxismo e cefaleia revelou que o percentual de cefaleia é de 100\% para os bruxômanos e de 93,3\% para os adolescentes que não apresentam bruxismo. Conclusões: A frequência de cefaleia nos adolescentes é alta e a frequência de bruxismo é quatro vezes menor que a da cefaleia. $\bigcirc$ bruxismo excêntrico é significativamente mais frequente no sexo feminino, porém não se comprova associação significativa entre sexo e cefaleia na faixa etária estudada.

\section{DOR 19 \\ DIAGNÓSTICO E TRATAMENTO DA DISFUNÇÃO TEMPOROMANDIBULAR: RELATO DE CASO}

\section{Di Matteo RC; Nunes TB; De Luca CEP}

Objetivo: Relatar o tratamento de uma paciente portadora de disfunção temporomandibular. Métodos: Paciente do gênero feminino, 44 anos, procurou o Centro de Diagnóstico Oral da Faculdade de Odontologia da Universidade de São Paulo (CDOFOUSP) com queixa de muita dor no rosto e mordida torta. Durante a anamnese a paciente relatou que há dois anos levou uma cabeçada no queixo e notou inchaço do lado direito do rosto. Desde então passou por vários dentistas, mas as terapêuticas propostas como cirurgia ortognática e exodontias múltiplas a assustaram. Exame clínico de palpação muscular e articular e exame de imagem de ressonância magnética da ATM revelaram quadro de disco deslocado bilateral sem redução, mialgia e artralgia. Resultados: A paciente foi tratada com placa estabilizadora oclusal, a mandíbula foi reposicionada e a dor desapareceu. Conclusão: Diagnóstico e tratamento corretos das DTMs são fundamentais para evitar iatrogenias e devolver qualidade de vida ao paciente. 


\section{DOR 20 \\ ANALGESIA DO LASER DE BAIXA POTÊNCIA NA ARTRALGIA DA ATM}

\author{
Carli ML; Guerra MB; Nunes TB; De Luca CEP
}

Objetivo: Avaliar uma possível ação analgésica do Laser de Baixa Potênica (LBP) em casos de artralgia da articulação temporomandibular (ATM) associado ou não à terapêutica medicamentosa com Piroxicam. Métodos: Foram randomizados e alocados em 3 grupos de tratamento 32 pacientes com diagnóstico de artralgia (grupo III) de acordo com o RDC/TMD. O primeiro grupo foi composto por 11 pacientes e recebeu LBP e Piroxicam placebo. $O$ segundo grupo foi composto por 10 pacientes e recebeu LBP placebo e Piroxicam. E o terceiro grupo foi composto por 11 pacientes e recebeu LBP e Piroxicam. $\bigcirc$ protocolo utilizado para o laser foi densidade de energia de $100 \mathrm{~J} / \mathrm{cm}^{2}$, potência de $100 \mathrm{~mW}$, tempo de 28 segundos, e 2,8J de energia por ponto. Foram irradiados ATM, músculo masseter e músculo temporal bilaterais em 2 sessões por semana durante 2 semanas. Piroxicam foi administrado na dose de $20 \mathrm{mg} 1$ vez ao dia durante 10 dias. Para avaliação do efeito analgésico, foi utilizada a Escala Visual Analógica (EVA) de dor antes e após cada sessão de laserterapia e após 30 dias do término do tratamento. Resultados: As três terapêuticas foram efetivas para reduzir a dor relatada pelo paciente, com diferenças significantes entre a dor relatada anterior ao tratamento e após o término do tratamento, com $p=0,0038$ para o grupo $A, p=0,0039$ para o grupo $B$, e $p=0,0059$ para o grupo $C$. Entretanto, não houve diferenças entre os grupos. Após 30 dias, houve um aumento significativo da dor $(p=0,0232)$ para os pacientes do grupo A. Conclusões: LBP e Piroxicam são eficazes na redução da dor em pacientes com artralgia da ATM, não havendo diferenças entre eles. LBP não apresentou efeito residual após 30 dias do término do tratamento.

\section{DOR 21 \\ FIBER-TYPE COMPOSITION, FIBER DIAMETER AND CAPILLARY DENSITY OF THE HUMAN JAW MUSCLES}

\section{Guimarães TB; Cabrini MBF; Wakamatsu A; Guimarães AS; Marieo SKN}

Objective: To analyze the muscle fiber type distribution concerning fast and slow myosin expression, and the amount of hybrid fibers in temporalis and masseter muscles in autopsy samples from $1 \mathrm{st}$ to 9th decades of age. Methods: We studied the differences of the fiber types in masseter and temporalis muscles along the first to ninth decades in both genders. Seventy-four (74) samples were analyzed by immunohistochemistry., within an 8--18 hours post mortem interval, of both genders, and from subjects in the first to ninth decade of life. It included at least two samples per decade per gender. For statistical analysis, the samples were grouped into three subgroups: young ( 0 to 25 years of age), adult ( 26 to 59 years of age) and old ( 60 and above years of age). Comparisons between two groups was used the t student test or the Mann-Whitney, and for three groups used the ANOVA or the Kruskal-Wallis test. The significance level was set at $p<0.05$. Results: Slow and fast muscle fiber distribution was similar in both muscles in both genders. Hybrid fiber was observed in all decades, and its frequency decreased significantly $(p<0.001)$ with aging in masseter. Neonatal myosin expression was observed in all decades; its expression was more frequent in masseter $(p=0.01)$, and males in temporalis $(p=0.025)$.

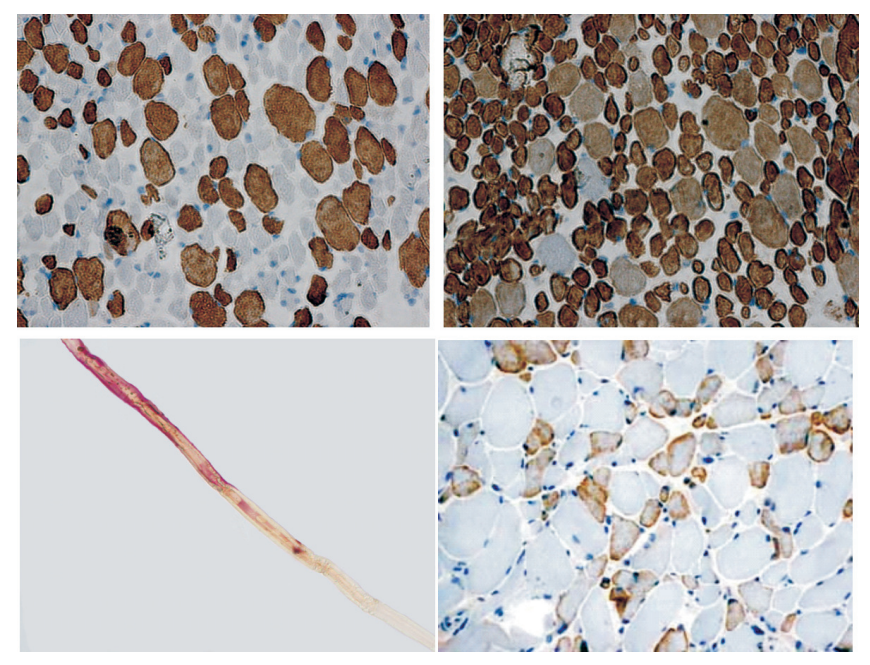

Figure 1 - Imunohistochemical preparations on sequential sections of masseter muscle of 3rd decade male with the antibodies against MyHC slow (A) and fast (B), showing the double staining. C: single muscle fiber manually teased from the masseter muscle of 4th decade male prepared with antibody agaist MyHC slow demonstrating the presence of a portion of the fiber stained and other without reactio, proving the presence of hybrid fiber. D: Temporalis muscle from 2nd decade male prepared with antibody againt MyHCneonatal showing the presence of neonatal fibers stained (in brown)

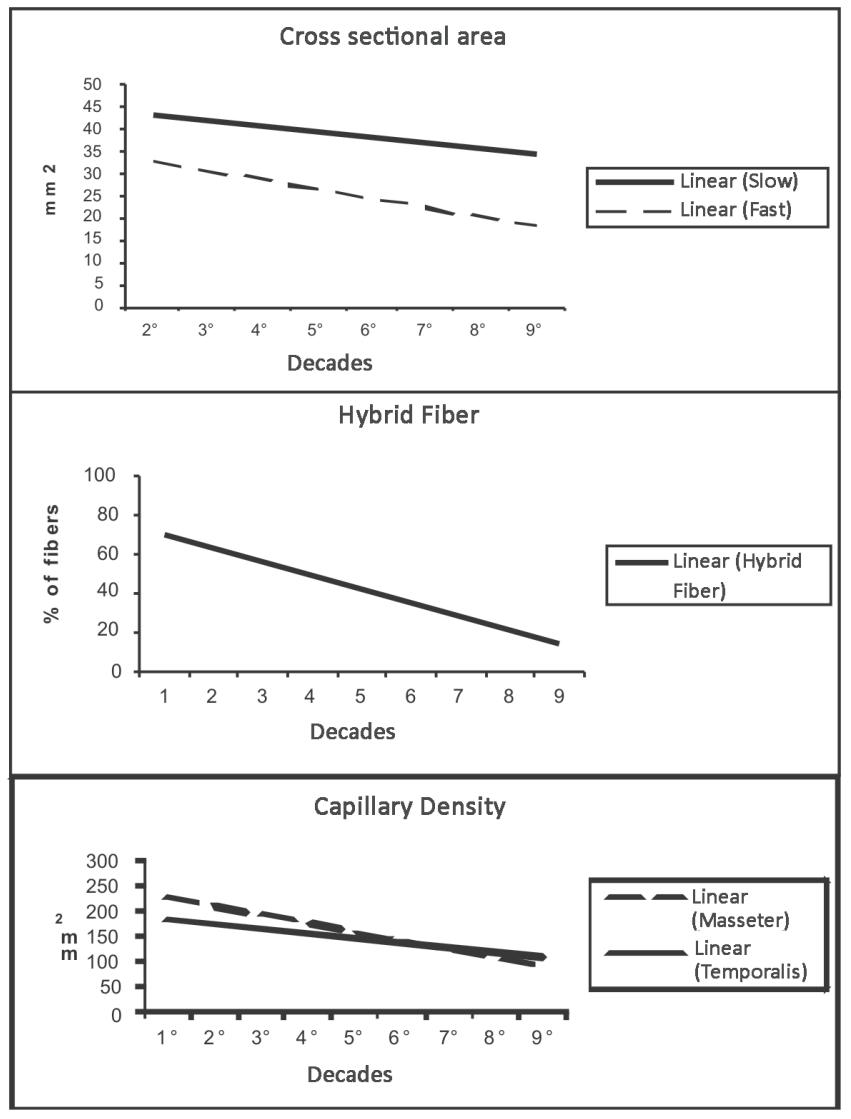

Figure 2. Graphics of cross section area (A), hybrid fiber (B), capillary density (C) showing the linear and tendency of the alterations along the nine decades of age 
Decrease of the cross-sectional area of fast and slow fibers and decrease in capillary density were detected with aging. Conclusions: The jaw muscles are essential components in the stomatognatic system. Their complex architecture allows them to execute several motor tasks. One of the structural peculiarities is the presence of hybrid and neonatal fibers in all decades.

References: 1.Korfage JA, Koolstra JH, Langenbach GE, van Eijden TM. Fiber-type composition of the human jaw muscles--(part 1) origin and functional significance of fiber-type diversity. J Dent Res. 2005 Sep;84(9):774-83.

2. Korfage JAM, Koolstra JH, Langenbach GEJ, Van Eijden TMGJ (2005). Fiber-type composition of the human jaw muscles-(Part 2) Role of hybrid fibers and factors responsible for inter-individual variation. J Dent Res 84:784-793.

3. Osterlund C, Liu JX, Thornell LE, Eriksson PO. Muscle spindle composition and distribution in human young masseter and biceps brachii muscles reveal early growth and maturation. Anat Rec (Hoboken). 2011 Apr;294(4):683-93

\title{
DOR 22 \\ PREVALÊNCIA DE DISFUNÇÃO TEMPOROMANDIBULAR EM PACIENTES COM HEMOFILIA
}

\author{
Guimarães TB; Guimarães SMB; Cabrini MBF
}

Objetivo: Verificar a prevalência de disfunção temporomandibular em pacientes hemofílicos. Métodos: Foram avaliados 39 pacientes hemofílicos do gênero masculino (18-51 anos) com idade mediana de 26 anos e 79 controles do gênero masculino (18-51 anos) com idade mediana de 27 anos. Os indivíduos foram submetidos ao questionário da Academia Europeia das Desordens Craniomandibulares para avaliação da presença de sintomas de disfunção temporomandibular (DTM). Os que responderam afirmativamente a pelo menos uma pergunta foram submetidos ao eixo I e ll do RDC (critério diagnostico para pesquisa em disfunção temporomandibular). A análise estatística foi realizada com o teste Quiquadrado. Resultados: Sinais ou sintomas de hemartrose na ATM não foram verificados na amostra estudada. Conclusão: A articulação temporomandibular é muito solicitada com cargas elevadas durante a mastigação e apertamentos, no entanto, hemartrose na ATM em pacientes com coagulonopatias parece ser raro. ${ }^{(1)}$ A presença de disfunção temporomandibular (DTM) tem sido pouco avaliada em pacientes com hemofilia. ${ }^{(2)}$ Uma das complicações mais comuns da hemofilia é a artropatia crônica que resulta de repetidos sangramentos na articulação, podendo levar a limitação de movimento. A limitação de movimento mandibular pode ser uma das características dos pacientes que apresentam DTM, que abrange um largo espectro de problemas clínicos da articulação e dos músculos na área orofacial, estas disfunções são caracterizadas principalmente por dor, ruídos nas ATMs e função mandibular irregular ou limitada. Os sinais e sintomas associados à ATM não apresentaram significância estatística na comparação do grupo controle com os pacientes hemofílicos.

Referências: 1. Soucie JM et al. Joint range-of-motion limitations among young males with hemophilia: prevalence and risk factors. Blood. 2004;103(7):2467-73.

2. Nishioka GJ et al. Hemophilic arthropathy of the temporomandibular joint: review of the literature, a case report, and discussion Oral Surg Oral Med Oral Pathol. 1988;65(2): 145-50.

3. Alpkiliç Baskirt E et al. Oral and general health-related quality of life among young patients with haemophilia. Haemophilia. 2009;15(1):193-8. 


\section{ÍNDICE REMISSIVO}

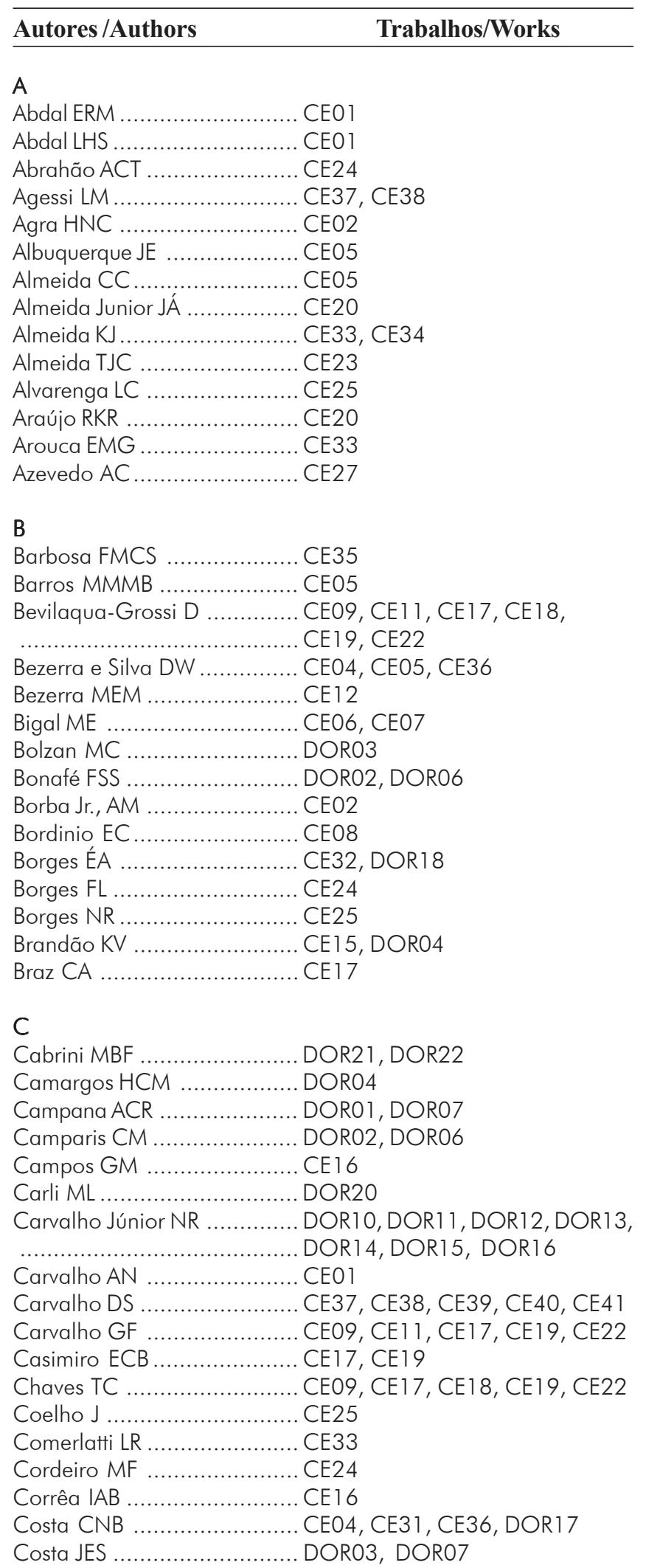

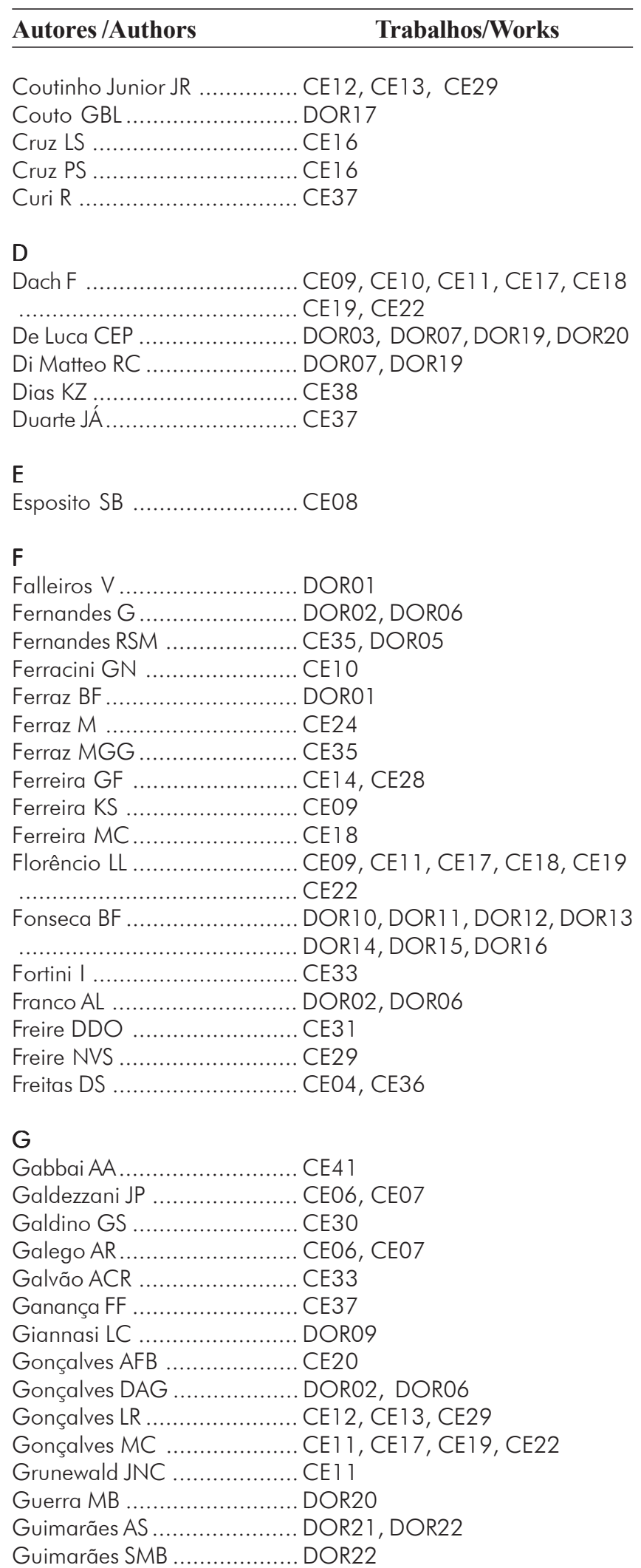




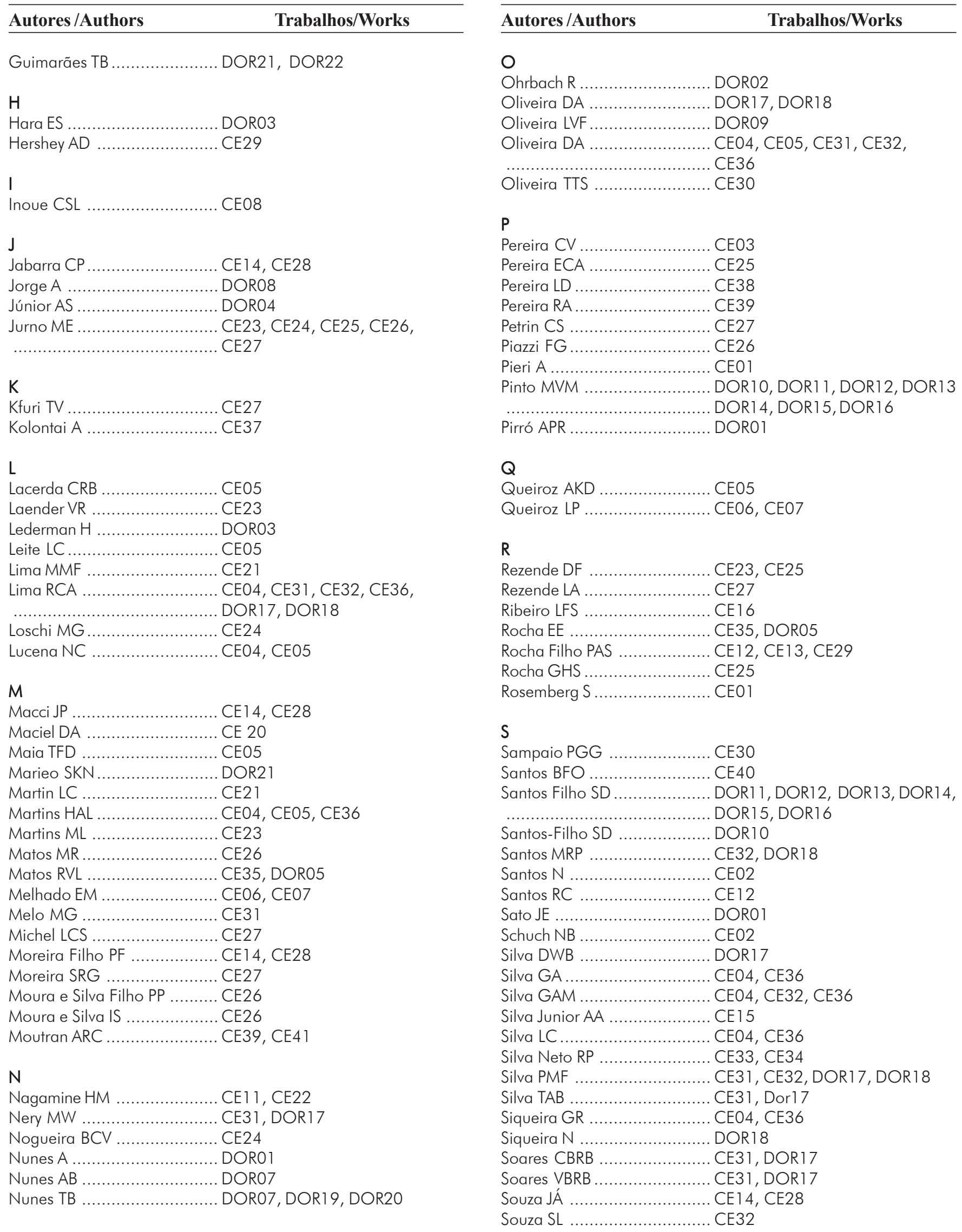




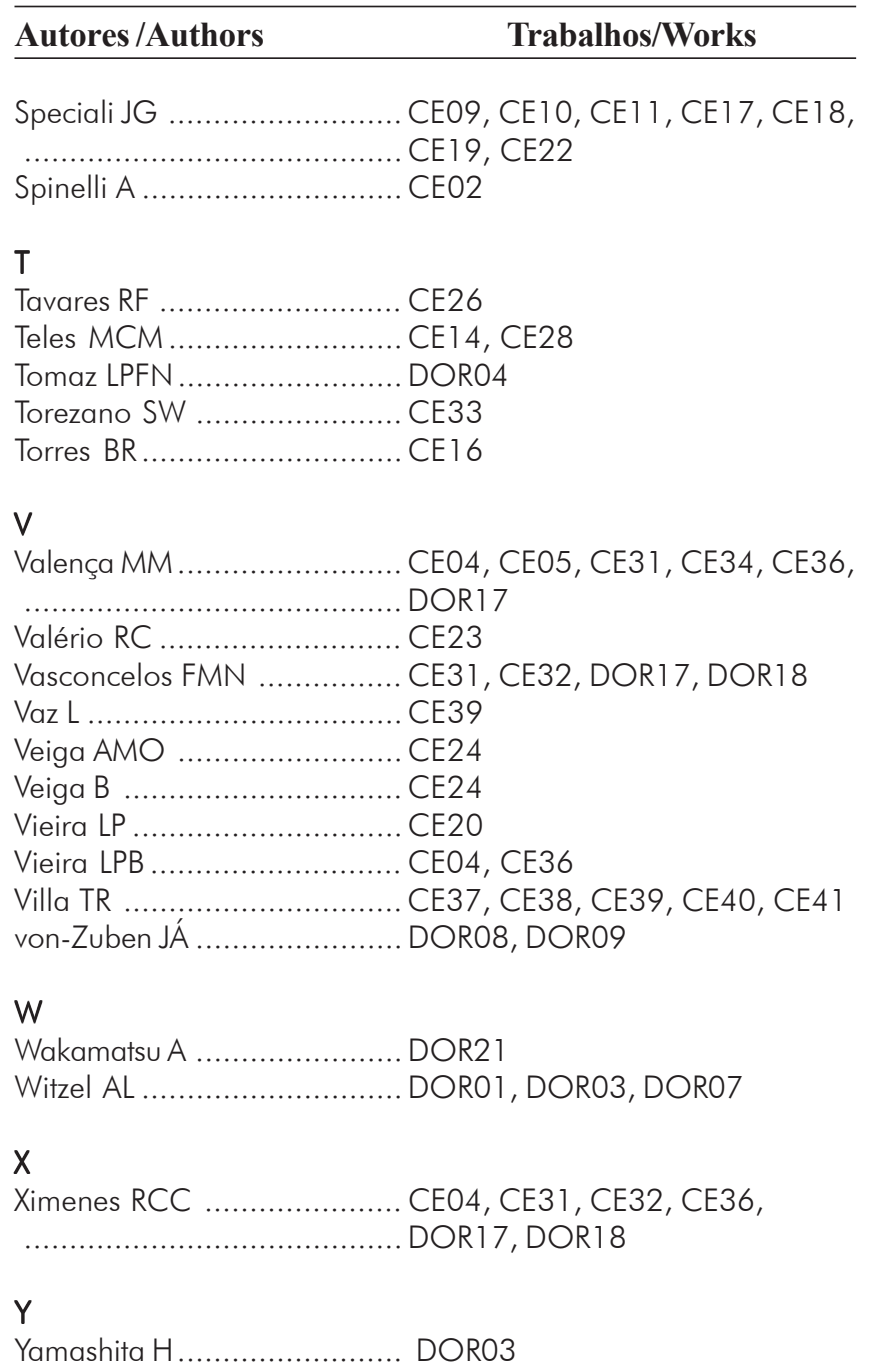

